\title{
WestVirginiaUniversity
}

THE RESEARCH REPOSITORY @ WVU

Graduate Theses, Dissertations, and Problem Reports

2004

\section{Failure mechanisms in impact erosion of ductile materials}

\author{
Ramesh Padavala \\ West Virginia University
}

Follow this and additional works at: https://researchrepository.wvu.edu/etd

\section{Recommended Citation}

Padavala, Ramesh, "Failure mechanisms in impact erosion of ductile materials" (2004). Graduate Theses, Dissertations, and Problem Reports. 1505.

https://researchrepository.wvu.edu/etd/1505

This Thesis is protected by copyright and/or related rights. It has been brought to you by the The Research Repository @ WVU with permission from the rights-holder(s). You are free to use this Thesis in any way that is permitted by the copyright and related rights legislation that applies to your use. For other uses you must obtain permission from the rights-holder(s) directly, unless additional rights are indicated by a Creative Commons license in the record and/ or on the work itself. This Thesis has been accepted for inclusion in WVU Graduate Theses, Dissertations, and Problem Reports collection by an authorized administrator of The Research Repository @ WVU. For more information, please contact researchrepository@mail.wvu.edu. 


\title{
FAILURE MECHANISMS IN IMPACT EROSION OF DUCTILE MATERIALS
}

\section{Ramesh Padavala}

\author{
Thesis Submitted to the \\ College of Engineering and Mineral Resources \\ at West Virginia University \\ in Partial Fulfillment of the Requirements \\ for the Degree of
}

\author{
Master of Science \\ in \\ Mechanical Engineering
}

Kenneth H. Means, Ph.D., Chair

Victor H. Mucino, Ph.D.

Charles F. Stanley, Ph.D.

Department of Mechanical and Aerospace Engineering

\section{Morgantown, West Virginia}

2004

Keywords: Ductile Erosion, Single Particle Impact, Ductile Materials 


\section{ABSTRACT \\ FAILURE MECHANISMS IN IMPACT EROSION OF DUCTILE MATERIALS}

\section{Ramesh Padavala}

Solid particle erosion in ductile materials is a common problem in many industrial applications. It is defined as material loss resulting from the mechanical contact between the particle and the metal surface. Many experimental studies were reported in the past to determine the loss of the material due to these ductile impacts. Conducting experiments for numerous materials at different conditions is difficult and costly. A finite element model to predict the ductile erosion loss at various conditions for different materials is more expedient.

In this thesis a finite element model was developed to predict the erosion loss for AL 6061-T0 at various boundary conditions when impacted by a single solid glass particle. The Aluminum model was developed in LS-INGRID and dynamic analysis performed using LS-DYNA3D to predict the erosion loss. Using suitable failure criteria the amount of material lost was predicted. For this purpose, a program written using AWK language was used to find the number of failed elements. The results of this model were compared with the experimental results of Sheldon and a close correlation was observed. Several parameters such as velocity of erodent, size of erodent, angle of attack and shape of the particle were varied and their effect on erosion loss (volume loss) was studied. The results were presented in the form of graphs that illustrate the dependencies between the volume loss and other parameters, which affect the erosion. The variation in erosion loss between the FEM model and the Sheldon experimental work as well as the erosion dependence on impact angle was explained. Finally the mechanism of material removal in impact erosion of ductile materials by a single particle was discussed. 


\section{ACKNOWLEDGEMENTS}

I would like to express my sincere gratitude to Dr. Kenneth Means for having provided me an opportunity to work under him. I thank him for his valuable guidance and suggestions through out my research work.

I am also grateful to Dr. Victor H. Mucino and Dr. Charles F. Stanley for their suggestions and help.

I would like to thank my parents for their love and affection. I would also like to thank my roommates and friends for their help and encouragement.

I am very grateful to Institute for the History of Technology and Industrial Archaeology at West Virginia University for providing the financial support. 


\section{TABLE OF CONTENTS}

TITLE PAGE

ABSTRACT

ACKNOWLEDGMENTS iii

TABLE OF CONTENTS iv

LIST OF FIGURES vi

LIST OF TABLES ix

CHAPTER 1. INTRODUCTION 1

CHAPTER 2. LITERATURE REVIEW 4

2.1 Erosion Models $\quad 4$

2.1.1 Ductile Material erosion 4

2.1.2 Brittle Material Erosion 9

2.2 Factors influence the Ductile Material Erosion 11

2.3 Single Particle Erosion 15

2.4 Multiple Particle Erosion 16

2.5 Energy loss during Single Particle Impact 17

2.6 Assumptions 21

CHAPTER 3. FINITE ELEMENT SIMULATION 22

3.1 Introduction $\quad 22$

3.2 Finite Element Model 22

3.3 Mesh Generation 23

3.4 Material Models $\quad 24$

3.5 Initial and Boundary Conditions 26

$\begin{array}{ll}\text { 3.6 Model Solution } & 28\end{array}$

3.7 Post Processing 29

3.8 Failure Criteria and Material Loss Estimation 31

3.9 Strain Hardening Effect on Erosion 34 
4.1 Introduction

4.2 Parametric Ranges

4.3 Model Validation

CHAPTER 5. CONCLUSIONS AND RECOMMENDATIONS

5.1 Conclusions

5.2 Recommendations for the Future Work

REFERENCES

APPENDIX A

APPENDIX B 


\section{LIST OF FIGURES}

Figure

Page

2.1 Erosion Behavior of Ductile and Brittle Materials

2.2 Energy Balance for a Single Particle Impact

2.3 Plastic Strain Associated with Single Particle Impact

3.1 Three Stages of Finite Element Analysis

3.2 Schematic Diagram for Target Metal and the Erodent

3.3 AL 6061-T0 Model Mesh Generation

3.4 Symmetric Plane of a Model

3.5 Contact Surfaces between Target metal and the Erodent

3.6 Profile of Effective Plastic Strain

3.7 Profile of Effective Stress

3.8 Energy Balance for a Model

4.1 Different shapes of the particle

4.2 Fringes of Plastic Strain for AL 6061-T0 plate impacted by $3 \mathrm{~mm}$ particle at $20 \mathrm{deg}$ with a velocity of $80 \mathrm{~m} / \mathrm{s}$

4.3 Fringes of plastic strain for AL 6061-T0 plate impacted by $3 \mathrm{~mm}$ particle at $20 \mathrm{deg}$ with a velocity of $80 \mathrm{~m} / \mathrm{s}$

4.4 Fringes of plastic strain for AL 6061-T0 plate impacted by $3 \mathrm{~mm}$ particle at $20 \mathrm{deg}$ with a velocity of $80 \mathrm{~m} / \mathrm{s}$

4.5 Fringes of plastic strain for AL 6061-T0 plate impacted by $3 \mathrm{~mm}$ particle at $20 \mathrm{deg}$ with a velocity of $80 \mathrm{~m} / \mathrm{s}$

4.6 Fringes of plastic strain for AL 6061-T0 plate impacted by $3 \mathrm{~mm}$ particle at $20 \mathrm{deg}$ with a velocity of $80 \mathrm{~m} / \mathrm{s}$

4.7 Fringes of von mises stresses for AL 6061-T0 plate impacted by 3mm particle at $20 \mathrm{deg}$ with a velocity of $80 \mathrm{~m} / \mathrm{s}$

4.8 Fringes of von mises stresses for AL 6061-T0 plate impacted by 3mm particle at $20 \mathrm{deg}$ with a velocity of $80 \mathrm{~m} / \mathrm{s}$

4.9 Fringes of von mises stresses for AL 6061-T0 plate impacted by 3mm particle at $20 \mathrm{deg}$ with a velocity of $80 \mathrm{~m} / \mathrm{s}$ 
4.10 Fringes of von mises stresses for AL 6061-T0 plate impacted by $3 \mathrm{~mm}$ particle at $20 \mathrm{deg}$ with a velocity of $80 \mathrm{~m} / \mathrm{s}$

4.11 Fringes of plastic strain for AL 6061-T0 plate impacted by $3 \mathrm{~mm}$ particle at $90 \mathrm{deg}$ with a velocity of $80 \mathrm{~m} / \mathrm{s}$

4.12 Fringes of plastic strain for AL 6061-T0 plate impacted by $3 \mathrm{~mm}$ particle at $90 \mathrm{deg}$ with a velocity of $80 \mathrm{~m} / \mathrm{s}$

4.13 Fringes of plastic strain for AL 6061-T0 plate impacted by $3 \mathrm{~mm}$ particle at $90 \mathrm{deg}$ with a velocity of $80 \mathrm{~m} / \mathrm{s}$

4.14 Fringes of plastic strain for AL 6061-T0 plate impacted by $3 \mathrm{~mm}$ particle at $90 \mathrm{deg}$ with a velocity of $80 \mathrm{~m} / \mathrm{s}$

4.15 Fringes of plastic strain for AL 6061-T0 plate impacted by $3 \mathrm{~mm}$ particle at $90 \mathrm{deg}$ with a velocity of $80 \mathrm{~m} / \mathrm{s}$

4.16 Fringes of plastic strain for AL 6061-T0 plate impacted by $3 \mathrm{~mm}$ particle at $90 \mathrm{deg}$ with a velocity of $80 \mathrm{~m} / \mathrm{s}$

4.17 Plot Showing Various Energies Versus Time for normal impact 54

4.18 Erodent Velocity Vs Volume loss $\quad 55$

4.19 Erodent Diameter Vs Volume Loss 56

4.20 Profile of effective plastic strain AL 6061-T0 plate impacted by $3 \mathrm{~mm}$ particle at $20 \mathrm{deg}$ with a velocity of $80 \mathrm{~m} / \mathrm{s}$

4.21 Profile of effective plastic strain AL 6061-T0 plate impacted by $3 \mathrm{~mm}$ particle at $90 \mathrm{deg}$ with a velocity of $80 \mathrm{~m} / \mathrm{s}$

4.22 Impact Angle Vs Volume Loss

4.23 AL 6061-T0 Model with Octahedral Shape Erodent

4.24 Fringes of plastic strain for AL 6061-T0 plate impacted by Octahedral Particle at $20 \mathrm{deg}$ with a velocity of $80 \mathrm{~m} / \mathrm{s}$

4.25 Fringes of plastic strain for AL 6061-T0 plate impacted by Octahedral particle at $20 \mathrm{deg}$ with a velocity of $80 \mathrm{~m} / \mathrm{s}$

4.26 Fringes of plastic strain for AL 6061-T0 plate impacted by Octahedral particle at $20 \mathrm{deg}$ with a velocity of $80 \mathrm{~m} / \mathrm{s}$

4.27 Profile of effective plastic strain AL 6061-T0 plate impacted by Octahedral particle at $20 \mathrm{deg}$ with a velocity of $80 \mathrm{~m} / \mathrm{s}$ 
D.1 Eight-node solid hexahedron element

D. 2 single degree of freedom damped system

D. 3 Forces acting on mass $m$ 


\section{LIST OF TABLES}

$\begin{array}{lll}\text { Table } & \text { Page }\end{array}$

3.1 Material Properties of Aluminum AL 6061-T0 25

3.2 Material Properties of Silicon Dioxide Particle 26

4.1.Erosion Loss of AL 6061-T0 36

4.2.Volume Loss of AL 6061-T0 impacted by two different particles 39 


\section{CHAPTER 1}

\section{INTRODUCTION}

Erosion and corrosion of metal parts is a major problems faced by many industries nowadays. Erosion is the removal of material by impingement of solid particles where as corrosion is the chemical phenomenon, which occurs, when a metal object is exposed to an oxidizing environment. The damage caused by these phenomena can be enormous. Hence the determination of material loss is very important to predict the failure. A clear understanding of the effect of single particle impact with various parameters is needed to understand this erosion phenomenon.

Solid particle erosion is defined as the loss or removal of material by the action of impinging solid or liquid particles. It is the loss of material that results from repeated impact of small solid particles. Some times erosion may be a useful phenomenon in some applications like sand blasting and high-speed water jet cutting. But in many engineering applications such as jet engines, fluidized bed combustion systems, large pipelines carrying slurries and caustic materials, erosion might be a serious problem and it results in material loss. Helicopters are powered by small gas turbines. Usually these helicopters hover over dusty, unimproved land areas and ingest sand and dust into each compressor every hour of low altitude operation. Consequently many high velocity abrasive dust particles impact the critical surfaces of compressor blades and vanes eroding away the thin metal edges [1]. This erosion action can be an expensive nuisance in many industrial processes that involve transportation of small bodies with a flow medium through the pipelines. This damage could be more at the bends about 10 times faster than the straight sections of pipes. This erosion can be used profitably to shape out or drill materials or to induce favorable residual stresses.

The erosion rate, $\mathrm{E}$, is the common parameter used to measure the resistance of a material to erosion and may be expressed in terms of mass or volume of the material removed per unit mass of the erodent impacted in units of $\mathrm{mg} / \mathrm{g}$.

Erosion rate shows a power law velocity dependence, which is given by

$$
\mathrm{E}=\mathrm{K} v^{\mathrm{n}}
$$


Where $\mathrm{K}$ is the constant and $\mathrm{n}$ is a velocity exponent. This velocity exponent generally depends on the material and erosion conditions. The value of $\mathrm{n}$ usually falls in the range of 2-2.9 for ductile materials [2]

Erosion rate shows a power law diameter dependence given by

$$
\mathrm{E}=\mathrm{Kd}^{\mathrm{n}}
$$

Where $\mathrm{K}$ is the constant and $\mathrm{n}$ is the diameter exponent. The value of $\mathrm{n}$ is about 3 for ductile materials.

The phenomenon by which erosion takes place is different for ductile materials than for brittle materials. Ductile material erosion takes place by considerable plastic flow and the material undergoes very large plastic strains before fracture occurs, while brittle material erosion is due to the crack propagation into the material and its interaction with other crack surfaces resultant in chipping of the material.

There are various parameters that affect the erosion phenomenon. They are erodent velocity, angle of impact, erodent shape, erodent size, properties of the target surface and the erodent and temperature. The velocity of erodent has direct effect on erosion rate. The erosion rate increases with increase in velocity for both ductile and brittle materials. The effect of angle of impact is different for ductile and brittle materials. In ductile materials the erosion loss is maximum at $20^{\circ}-30^{\circ}$ where as in brittle materials the erosion loss is maximum at $90^{\circ}$ angle. The shape of the particle makes a significant effect on erosion. The erosion loss depends on the area of contact between the target material and the erodent. The size of the erodent is directly proportional to the erosion loss up to certain critical size. Temperature rise affects the properties of the target surface.

Erosion wear of materials in practice involves long time of exposure under study state conditions. Solid particle erosion is a discrete, accumulative and complex process. This erosion is difficult to analyze because of complexity of the erosion process. So single particle impact is clearly worthy in understanding as accurately as possible. The theories developed during the single particle impact proved to be of great importance in developing the models that predict the erosion loss during multiple particle impact.

Most of the models available in the literature are based on the experimental works in various materials. Conducting experiments for different applications for different 
materials is very difficult. Hence in the current work the finite element model is proposed which takes into account various boundary conditions and material properties and predicts the erosion loss due to impact. An Aluminum 6061-T0 model was developed in INGRID and solved using a finite element code called LS-DYNA3D.This model was used to simulate the experimental work of Sheldon et al [2]. The results were viewed in LS-TAURUS and compared with the experimental results of Sheldon and a close correlation was observed. Several parameters such as velocity of erodent, shape of erodent, angle of impingement, size of erodent were varied and their influence on erosion was studied.

The information available in the literature about the phenomenon of erosion for both ductile and brittle materials, single and multiple particle erosion, and various factors effecting the erosion was studied in chapter 2 .

In chapter 3, the basic equations used to develop the model were described. The major assumptions involved with the model were listed at the end of the chapter.

Chapter 4 deals with the finite element modeling. In the beginning of the chapter the 3D finite element mesh generation in LS-INGRID and the analysis in LS-DYNA3D were discussed and later sections the mechanism of erosion was discussed in detail.

The results of the analysis were presented in chapter 5 . The results due to impact of particle of various velocities, shapes, sizes, angles of attack were presented in graphs.

Finally the major conclusions drawn from the results were presented in chapter 6 . The recommendations for the future work were discussed at the end of this chapter. 


\section{CHAPTER 2}

\section{LITERATURE REVIEW}

\subsection{EROSION MODELS}

The erosion process has been studied from several points of view by many different investigators. Basically three different approaches have been used to predict erosion behavior [3].

First approach is mainly an empirical approach in which some assumptions are taken. One of the assumptions is to introduce a parameter that controls the material removal process and these results will fit the test data. The advantage of this approach would be the systematic grouping of materials for correlating with experimental results. But the disadvantage is limited understanding of the material behavior.

In second approach, some investigators have proposed that the material behavior during erosion is unique and no common material property such as hardness or modulus of elasticity exists. These material properties can be used in describing the action of the surface under impinging particles. It is difficult to analyze this approach because of the complexity of the erosion process.

The third approach is a more conventional analysis approach and a straightforward approach. Here also some assumptions must be made because of the unknown condition of the material during impact. This approach considers the dynamic forces between the surface and the particle and predicts volume removal from wellknown material properties. This approach has been used in analyzing both erosion behavior of ductile materials and brittle materials.

\subsubsection{DUCTILE EROSION}

Ductile material erosion occurred by a process of plastic deformation in which material is removed by the displacing or cutting action of the eroding particle. Finnie [4] developed the first model of erosion of ductile materials in 1958 in which he viewed the concept of erosion as a micro-machining process. He proposed that for an isotropic, non 
work hardening, ideally ductile solid target material, hit by rigid eroding particles, the eroded volume, Q, removed by a single abrasive grain of mass was given by

$$
\begin{array}{ll}
\mathrm{Q}=\frac{\mathrm{mV}}{\sigma_{\mathrm{f}} \psi \mathrm{K}}\left(\sin 2 \alpha-\frac{6}{\mathrm{~K}} \sin ^{2} \alpha\right) & \text { if } \tan \alpha \leq \frac{\mathrm{K}}{6} \\
\mathrm{Q}=\frac{\mathrm{mV}}{\sigma_{\mathrm{f}} \psi \mathrm{K}}\left(\frac{\mathrm{K} \cos ^{2} \alpha}{6}\right) & \text { if } \tan \alpha \geq \frac{\mathrm{K}}{6}
\end{array}
$$

Where:

$\alpha$ is the angle of impact i.e. the angle between the particle trajectory and the material surface at the point of impact.

$\mathrm{V}$ is the velocity of erodent particle found by solution of the equations of motion.

$\mathrm{K}$ is the ratio of the vertical to horizontal force on the particle at impact.

$\psi$ is a constant the ratio of the length to the depth of the cut.

$\sigma_{\mathrm{f}}$ is the plastic flow stress.

This model has good agreement with experimental erosion data for low impact angles and correctly predicts a high in the erosion rate at an impact angle between $15^{\circ}$ and $30^{\circ}$. However it predicts a low erosion rate for impact angles greater than $60^{\circ}$ and contrary to observations, predicts zero erosion rate for near $90^{\circ}$ impact angles. In addition the model assumes that wear is proportional to the square of velocity while measurements show that the exponent of velocity is greater than two and increases with increase in impact angle. In a subsequent model Finnie et al., corrected this error by assuming a resultant eroding force, which acted in the center of the contact area rather than at the particle tip. A final error in the original Finnie model was the prediction of an inverse relationship between erosion rate and yield stress or material hardness, which is not observed experimentally.

Bitter [5] modeled the erosion of ductile materials due to the near normal impact of particles, noting that successive impacts cause the ductile material to become hard and brittle (by plastic deformation) until it fails by cracking. Combining energy balance arguments with Hertzian theory of elastic contact, he expressed the deformation wear in terms of $W_{D}$

Where: 


$$
\begin{array}{ll}
\mathrm{W}_{\mathrm{D}}=\frac{\mathrm{M}(\mathrm{V} \sin \alpha-\mathrm{K})^{2}}{2 \varepsilon} & \text { for } \mathrm{V} \sin \alpha>\mathrm{K} \\
\mathrm{W}_{\mathrm{D}}=0 & \text { for } \mathrm{V} \sin \alpha \leq \mathrm{K}
\end{array}
$$

$\mathrm{K}$ is the velocity of collision at which the elastic limit is just reached and below which erosion does not occur.

For spherical particles

$$
\mathrm{K}=\frac{\pi^{2}}{2 \sqrt{10 \rho_{1}}}\left(\mathrm{P}_{\mathrm{y}}\right)^{5 / 2}\left[\frac{\left(1-\mu_{1}^{2}\right)}{\mathrm{E}_{1}}+\frac{\left(1-\mu_{2}^{2}\right)}{\mathrm{E}_{2}}\right]^{2}
$$

Where

$\varepsilon$ is the energy required to remove a unit volume of target material by deformation wear. $\mathrm{P}_{\mathrm{y}}$ is the maximum contact pressure at elastic limit and has the value $1.59-3.2$ times the uniaxial yield strength of the target material.

$\mathrm{E}_{1}, \mu_{1}$ are elastic constants of a particle

$\mathrm{E}_{2,}, \mu_{2}$ are elastic constants of the target.

$\rho_{1}$ is the density of the particle.

Bitter [5] also proposed a model for cutting erosion in terms of an additional constant $\rho_{\mathrm{c}}$ representing the elastic-plastic behavior of the material. The final expression for volume erosion rate is dependent on whether the component of the velocity of the particles parallel to the target surface reaches zero after impact. If the velocity component parallel to the surface reaches zero does not reach zero, the erosion rate, as measured by volume loss per unit mass of erodent, is:

$$
\mathrm{W}_{\mathrm{c}}=\frac{2 \mathrm{C}(\mathrm{V} \sin \alpha-\mathrm{K})^{2}}{\sqrt{\mathrm{V} \sin \alpha}}\left[\mathrm{V} \cos \alpha-\frac{\mathrm{C}(\mathrm{V} \sin \alpha-\mathrm{K})^{2}}{\sqrt{\mathrm{V} \sin \alpha}} \varsigma\right]
$$

Where

$$
C=\frac{0.288}{P_{Y}}\left[\frac{\rho_{1}}{P_{Y}}\right]^{1 / 4}
$$


On the other hand, if the velocity parallel to the surface becomes zero before the particles leave the specimen, the erosion rate is

$$
\mathrm{V}_{\mathrm{C} 2}=\frac{\left[\mathrm{V}^{2} \cos ^{2} \alpha-\mathrm{K}_{1}(\mathrm{~V} \sin \alpha-\mathrm{K})^{3 / 2}\right]}{2 \rho_{\mathrm{c}}}
$$

where

$$
\mathrm{K}_{1}=0.82 \mathrm{P}_{\mathrm{Y}}^{2} \sqrt{\frac{\mathrm{P}_{\mathrm{Y}}}{\rho_{1}}}\left[\left(\frac{1-\mu_{1}^{2}}{\mathrm{E}_{1}}\right)+\left(\frac{1-\mu_{2}^{2}}{\mathrm{E}_{2}}\right)\right]^{2}
$$

Total wear, $\mathrm{V}$, for the two cases is given by

$$
\begin{gathered}
\mathrm{V}=\mathrm{V}_{\mathrm{d}}+\mathrm{V}_{\mathrm{c} 1} \\
\text { Or } \\
\mathrm{V}=\mathrm{V}_{\mathrm{d}}+\mathrm{Vc}_{2} \quad \text { respectively }
\end{gathered}
$$

In 1969 G.P.Tilly [6] investigated some facts on ductile material erosion. The mechanism involved in ductile metals is scraping and extrusion of material to form ridges which are vulnerable to attack by other particles. Erosion rates are linear for soft materials like aluminum. Erosion in ductile materials is governed by different material dependences. Ductile erosion decreases with increase in hardness of the ductile materials. In 1972 G.P.Tilly [7] developed a two-stage model of the erosion process in ductile materials. In the first stage, when the particles indenting the target surface, chips are removed and some material is gouged and extruded around the scar. In the second stage particles break up on impact so that fragments are projected radially from the surface. The first stage predominates in glancing impacts and the second stage predominates in normal impacts. In 1972 G.L Sheldon and Ashok Kanhere [2] studied single particle erosion on ductile materials such as aluminum. They postulated a model in which material removal occurred due to flowing material from and around the impacting single particle rather than cutting a chip. This postulation was based on indentation hardness 
characteristics of material and energy balance equation. They expected that material removal per particle would be

$$
\mathrm{W}=\mathrm{D}^{3} \mathrm{~V}^{3} \rho^{3 / 2} / \mathrm{H}_{\mathrm{v}}{ }^{3 / 2}
$$

Where
$\mathrm{D}$ is the spherical particle diameter
$\mathrm{V}$ is the particle velocity
$\rho$ is particle density
$\mathrm{H}_{\mathrm{v}}$ is the Vickers hardness value of the material

From this postulation velocity exponent 3 was predicted rather than 2 as expected from energy considerations. They compared these results with the experimental results and found a close match. They also observed that material removal action by single particle has the same characteristics as that of multiple particle erosion of surfaces by particles larger than $100 \mu \mathrm{m}$.

In 1974 I.M. Hutchings and R.E.Winter [8] explained that material removal mechanism was the shearing of one of the surface layers of the ductile metal target in the direction of motion of the projectile. In this process an overhanging lip may be formed and removed. They assumed that this removal results from adhesion between lip and ball or from extrusion of the lip material between the ball and the underlying metal. This mechanism occurs when the particles impact the target with highly negative rake angles. This mechanism would not be expected when the particles impact with more positive rake angles. In their studies, work hardening effects the lip formation. The target material is more readily removed from fully work-hardened metals than from annealed metals. This is because in work hardened metals flow is concentrated in the surface layers and intense localized shearing occurs to form lip. 


\subsubsection{BRITTLE MATERIAL EROSION}

For ductile materials, the volume of material removed was estimated from the equations of motion and particle trajectory. This approach was not possible for brittle materials because this approach only predicts the initial fracture in the material. In brittle materials, once fracture occurs the material removal process depends on the propagation of the fracture surface into the material and its interaction with other fracture surfaces. For a better way of understanding the erosion behavior of brittle materials, Finnie [4] examined the conditions leading to initial cracking and the influence of particle velocity and direction. He conducted several experiments on brittle material erosion in which he used glass as a target surface and steel sphere as an erodent. He considered elastic sphere striking perpendicularly onto a brittle material (glass), which remains elastic until fracture occurs. He showed that maximum tensile stress in the material occurs at the surface in a radial direction around the periphery of the contact area. The magnitude of this maximum radial stress was given by the following equation

$$
\sigma_{\mathrm{r}}=0.187\left(1-2 \mu_{2}\right) \rho^{1 / 5} V^{1 / 5}\left(\frac{1-\mu_{1}^{2}}{E_{1}}+\frac{1+\mu_{2}^{2}}{E_{2}}\right)^{-4 / 5}
$$

Where

$\rho=$ density of the impacting sphere.

$\mathrm{V}=$ velocity of the sphere

$\mu_{1}$ and $\mathrm{E}_{1}=$ Poisson's ratio and modulus of elasticity of the sphere.

$\mu_{2}$ and $\mathrm{E}_{2}=$ Poisson's ratio and modulus of elasticity of the surface.

This equation shows that the erosion resistance of brittle materials will increase with decreasing elastic modulus and increasing poisson's ratio. He expected a ring crack in glass, formed right angles to the maximum tensile stress (around the circumference of the contact area). The cone shaped fracture surfaces intersected with the ring cracks with an increasing number of impacts and finally the material was removed [4].

In 1966,G.L Sheldon [3] compared one analysis in which particles impacting normal to the surface with the test results conducted by Sheldon, G.L., and Finnie, I. and got good agreement with the test results. In this analysis relation for material removed per particle is given [9] 


$$
\mathrm{W}=\mathrm{K}_{1} r^{a} V^{b}
$$

Where $r=$ radius of the particle

$V=$ velocity of the impacting particle

And exponents $\mathrm{a}$ and $\mathrm{b}$ are given by

$$
\begin{array}{ll}
a=3(m-0.67) /(m-2) & \text { for round particles. } \\
a=3.6(m-0.67) /(m-2) & \text { for angular particles. } \\
a=2.4(m-0.67) /(m-2) & \text { for either shapes. }
\end{array}
$$

$\mathrm{b}$ is velocity exponent 2 or 3 depending on the shape of the particle.

For particles much stiffer than the target the constant $\mathrm{K}_{1}$ is given by

$$
\mathrm{K}_{1}=\frac{\mathrm{E}^{0.8\left(\frac{\mathrm{m}+1}{\mathrm{~m}-2}\right)}}{\sigma_{0}^{\frac{2 m}{m-2}}} \rho^{1.2\left(\frac{m-0.67}{m-2}\right)}
$$

Where $\quad$ E is modulus of elasticity of the target.

$\rho$ is the density of the particle.

$\mathrm{m}$ is the mass of the particle.

This analysis shows the dependence of material removal in erosion on the radius and velocity of the impacting particle to be obtained from bending tests.

Evans et al., [10] proposed another model, which assumes that the erosion rate is proportional to the amount of material removed by each impact. The volume loss $\mathrm{V}$ per impact is calculated from the depth $h$ of penetration and the maximum size of the lateral cracks formed during impact. Since the lateral size is proportional to the radial crack size $c$, the volume loss $\mathrm{V}$ is given by the following equation

$$
\mathrm{V}=\pi c \mathrm{r}^{2} h
$$

Wiederhorn et al. [11] used the elastic-plastic theory and assumed that the lateral crack size was proportional to the radial crack size and the depth of the lateral cracks proportional to the maximum particle penetration. The volume loss is given by

$$
\mathrm{V} \propto \mathrm{V}_{0}^{22 / 9} \mathrm{r}^{11 / 3} \rho^{11 / 9} \mathrm{~K}_{\mathrm{c}}^{-4 / 3} \mathrm{H}^{1 / 9}
$$

Where

$\mathrm{V}$ is the volume loss by particle impact

$\mathrm{V}_{0}$ is the particle velocity 
$r$ is the radius of the particle

$\rho$ is the density of the particle.

$\mathrm{K}_{\mathrm{c}}$ is the material toughness

$\mathrm{H}$ is the material hardness

Mehrothra et al. [12] showed that the material removal process was occurred by the interaction of cone cracks followed by chipping. Sharp and angular particles generally produced radial cracks. These cracks lie perpendicular to the surface and were formed during loading. Upon unloading the lateral vent cracks were formed by the stresses generated by the plastically compressed zone. These stresses initiated beneath the indentation traveled upward to the surface resulting in material removal from the surface.

\subsection{FACTORS THAT INFLUENCE THE DUCTILE MATERIAL EROSION}

For complete understanding of ductile erosion we should understand and predict the role of the most of the following factors, which may influence ductile material erosion.

1. Erodent size.

2. Erodent shape.

3. Erodent velocity.

4. Angle of impingement.

5. Surface properties of target material and the erodent.

6. Temperature.

\subsubsection{Erodent Size}

According to Finnie's observations [13], ductile material erosion that is measured as the volume removed by a given mass of abrasive particles is independent of particle size for particles larger than about $100 \mu \mathrm{m}$. But the erosion rate decreases rapidly with decreasing particle size below $100 \mu \mathrm{m}$.For brittle materials a strong dependence of erosion rate and strength degradation on particle size is predicted and the size of erodent is directly proportional to the erosion rate. The larger the size of the erodent, the greater the volume of material removed by impact. G.P.Tilly [6] proposed a power law relation with erosion for brittle materials like glass, which was given by 


$$
\varepsilon=\operatorname{ad}^{2}
$$

Where $\varepsilon$ is erosion of the brittle materials like glass

$a$ is a constant

$d$ is the diameter of the erodent.

\subsubsection{Erodent Shape}

The shape of the impacting particle also has a great significance on the erosion rate. The shape of the particle determines the contact area between the particle and the target surface during the impact. Providing all other properties same, sharp angular particles will produce more erosion than spherical particles for both ductile and brittle materials. Finnie [4] conducted sandblasting tests using both round and sharp particles at $45^{0}$ to the surface. In which sharp particles produced four times more wear than round particles. He concluded that the ratio of vertical to horizontal force components $(\mathrm{K})$ on the particle might change with the change of particle shape. The parameter $\mathrm{K}$ will increase as the particles become less angular and more nearly spherical. The erosion loss decreases with increase of $\mathrm{K}$.

\subsubsection{Erodent velocity}

The erodent velocity plays very important role in the erosion process and is directly proportional to the erosion rate. As the velocity increases the initial kinetic energy of the particle increases which causes more erosion loss than a particle with less velocity. Experiments were conducted to determine the erosion loss per impact with change in velocity, on a various number of materials. According to G.P.Tilly et al., [14] influence of velocity on erosion by the simple power law was given by

$$
\varepsilon=\mathrm{aV}^{\alpha}
$$

Where $a$ is the material constant characterizing the relative erosiveness. For particles 25-125 $\mu \mathrm{m}$ quartz, the exponent $\alpha$ was found to be 2.0. For $125-150 \mu \mathrm{m}$, the exponent $\alpha$ was found to be increase from 2.0 to 2.3 for metals and plastics. 
In 1960 I.Finnie [4] based on his work on annealed SAE 1020 Steel with silicon carbide particles at $20^{\circ}$ angle reported that weight loss was proportional to the simple power of the erodent velocity. That is

$$
\mathrm{W}=\mathrm{b} \mathrm{V}^{\mathrm{n}}
$$

Where $\mathrm{V}$ is the velocity of the erodent and $n$ was 2.0 and this equation gave a good fit to the experimental data. He reported that at low velocities, particles would produce only elastic stresses in the target surface and the weight loss would decrease more rapidly than predicted by the simple power law equation. After many careful observations on different materials and different cases he reported later in 1972 that the velocity exponent was higher than 2.0, typically about 2.3 or 2.4. This was because of the particle fragmentation and rotation at high velocities.

\subsubsection{Angle of Impingement}

The effect of impact angle on erosion is easily understood for ductile materials and brittle materials by several experimental studies. For ductile materials, the maximum erosion usually occurs at $20^{\circ}-30^{\circ}$ of impingement where as in brittle materials, the maximum erosion occurs at normal $\left(90^{\circ}\right)$ impingement. This general behavior in ductile and brittle materials is shown in Figure 2.1.

\subsubsection{Surface properties of Target and the Erodent}

Hardness of the erodent and target material plays very important role in finding the erosion loss. It is usually considered that erosion decreases with increases in the hardness of the target surface. G.P.Tilly [6] analyzed the erosion of a variety of materials with hardness properties in which he found that the some brittle materials tended to become less resistant at higher harnesses whereas ductile materials tended to become more resistant at higher harnesses. B.F.Levin et al. [15] concluded that materials with high hardness and tensile toughness at high strain rates showed good erosion resistance. Here hardness is necessary to reduce energy transferred from the particle into the material and toughness is the ability of the material to absorb this energy without fracture. 


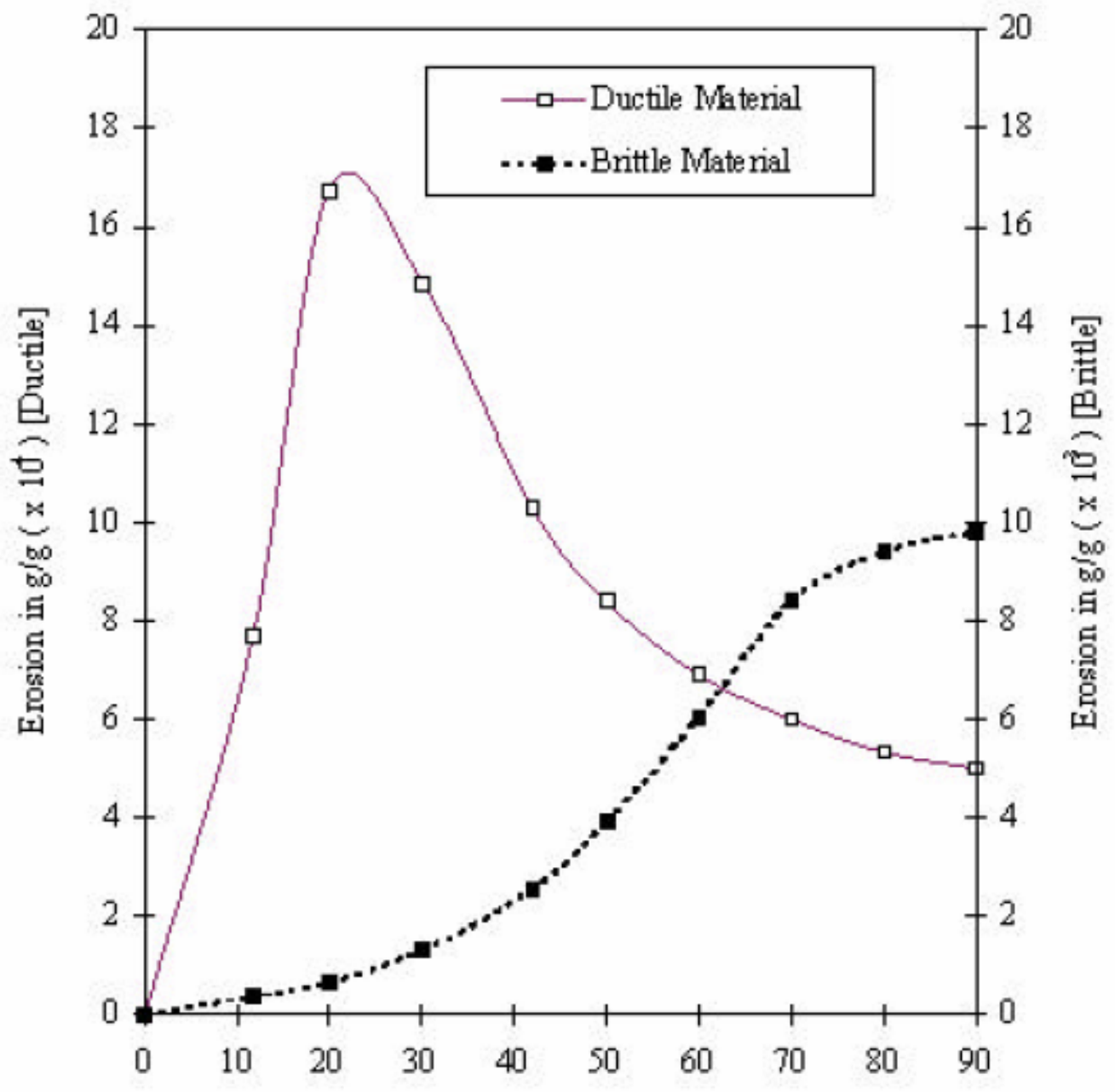

Angle of Attack in degrees.

Figure 2.1. Erosion Behavior of ductile and brittle materials [16]

\subsubsection{Temperature}

I.M.Hutchings et al. [17] proposed that when the erosive particles impact the surface, temperature rises in the near surface, which causes stress relieving or anneals the material and softens it. They suggested that work hardened region immediately beneath the soft layer acts as an anvil, which increases the tendency for the erosion loss. Where as I.M. Hutchings and A.V. Levy [18] have suggested that the temperature rise in the uppermost surface layer of material is sufficient to remove the effects of prior thermal treatment in steels and that is responsible for the negligible effect on erosion rate. Iain 
Finnie [19] reported that the influence of elevated temperature on ductile erosion is small because adiabatic heating occurs at high strain rates. G.P.Tilly [20] concluded that erosion might increase or decrease at elevated temperatures depending on the material properties.

\subsection{SINGLE PARTICLE EROSION}

Single particle erosion is the effect of impact of a single solid particle. Generally erosion of materials involves long time of exposure under study state conditions. So single particle impact is worth understanding as accurately as possible. In the literature different models are available to model the single particle erosion of ductile and brittle materials. Most of them are empirical models based on experimental results.

Finnie [21] proposed and derived erosion model from an analysis of the equations of motion of a single particle impacting the ductile surface. The particle trajectory through the material was used to estimate the volume of surface material displaced by the particle. This model was subjected to following assumptions.

1. Cutting of the surface is produced by plastic deformation only.

2. No cracks arise in the eroded surface ahead of the cutting particle.

3. Material removal is entirely due to the displacing action of the erodent.

Finnie's single particle impact erosion model is as follows

$$
w=\left(\rho m V^{2} / p \psi K\right) F(\alpha)
$$

Where

$$
F(\alpha)=\left\{\begin{array}{ll}
\sin 2 \alpha-\frac{6}{K} \sin ^{2} \alpha & \text { for } \tan (\alpha)<K / 6 \\
\frac{K}{6} \cos ^{2} \alpha & \text { for } \tan (\alpha)>K / 6
\end{array}\right\}
$$

$w$ is the mass of the material removed from the surface by the single particle impact. $\rho$ is the density of the surface material and $m$ is the mass of the impacting particle. The parameter $p$ is the horizontal component of the contact stress also termed as plastic flow 
stress. It is assumed that constant plastic flow stress is reached immediately upon contact. The parameter $K$ is the ratio of vertical to horizontal force component acting on the particle. The parameter $\psi$ is the ratio of the length over which the abrasive particle contacts the surface to the depth of cut made by the particle and this ratio was also assumed to be constant during the cut. Scratch test experiments have shown a variation in the value of the force ratio $K$ from 1.6 to 2.4 for ductile materials and the maximum value up to $6 . \psi$ values ranging from 2 to 10 have been observed in metal cutting experiments for different angles of impact $\alpha$. Finnie's model inadequately described the erosion process because no erosion was predicted at zero degrees and 90 degrees impact angles.

Sheldon and Kanhere [2] used a linear gas gun to accelerate the individual abrasive particles of steel, glass shot and silicon carbide grit at different velocities from about $120 \mathrm{~m} / \mathrm{s}$ to $360 \mathrm{~m} / \mathrm{s}$ on to both annealed and work hardened surfaces. They observed that considerable evidence of deformation adjacent to the crater in annealed material. Observations on the impact craters showed that the displaced crater material appear to have flowed in the direction of the particle incidence until the material fractured at high accumulated strains. They found a small difference in the velocity dependence on material loss between eroded and uneroded surface. The displaced lip material detached earlier on previously eroded surfaces than uneroded surfaces.

Hutchings and Winter [8] explained the erosion process by emphasizing on the geometry and the mechanism of material removal. They used large steel sphere of $3 \mathrm{~mm}$ diameter and aluminum surface in their experiments. They studied metal removal in detail and showed that material removal resulting from one of shearing of the surface layers of the target in the direction of the projectile.

Ives et al. [22] studied particle impact damage by using transmission electron microscope in 1978. They observed high dislocation density zone typically a few micrometers thick around an impact crater. They also found that the localized damage occurred near the craters measured by using electron-channeling method. 


\subsection{MULTIPLE PARTICLE EROSION}

The effect of impact of multiple solid particles is termed as multiple particle erosion. In most of the applications, a stream of particles usually carries out the erosion in a study state long-term regime. When compared to single particle erosion, more complex aspects are added to this multiple particle erosion. These complex aspects include particle impact with in the stream, particle fragmentation, particle embedding and surface shielding due to rebounding particles. So multiple particle erosion exposures must be conducted in order to measure meaningful erosion rates of materials for application purpose.

The design techniques used in many experiments on the multiple particle impact erosion are basically two types. In the first one, the specimen is moved under controlled velocity through a slowly moving erosive stream. Here the exposure may be intermittent but can continue for a long period of time. In the second one, a stream of particles is moving slowly over a stationary specimen. A nozzle or flight tube is used to confine a stream of particles. Measuring an accurate impact velocity is very important because the erosion rate is proportional to the square or cube of the particle velocity in both the cases.

Hutchings [23] developed a model for erosion of metals by spherical particles impacting at normal incidence predicting mass wear per unit mass of impacting particles. The mechanism of material removal was the formation and detachment of platelets of the material. They assumed that detachment occurred only after the plastic strain in the deformed material reached a maximum or critical strain.

Sundararajan and Shewmon [24] derived a model for erosion produced by particles impacting at normal angles using the criterion of a critical plastic strain needed for material removal. They assumed that the extruded lip of material formed and subsequently removed along the rim of the indentation crator. This model showed better correlation with experimental results compared to Hutchings model.

\subsection{ENERGY LOSS DURING SINGLE PARTICLE IMPACT}

In the single particle impact erosion, particle moves with an initial velocity at an angle with the surface of the target material and impacts the target material. Before 
impacting, particle has $100 \%$ kinetic energy and after impacting particle kinetic energy transformed into plastic work and elastic wave energy.

Hutchings, [23] proposed a simple analytical model, which illustrates the energy balance for a single particle impact at $90^{\circ}$. In this model, he proposed "critical strain" as a failure criterion to determine the failure i.e. when the maximum plastic strain with in the fragment reaches a critical strain $\varepsilon_{\mathrm{c}}$, removal of fragment occurs. Hutchings illustration of energy balance for a single particle impact is shown in Figure.2.2

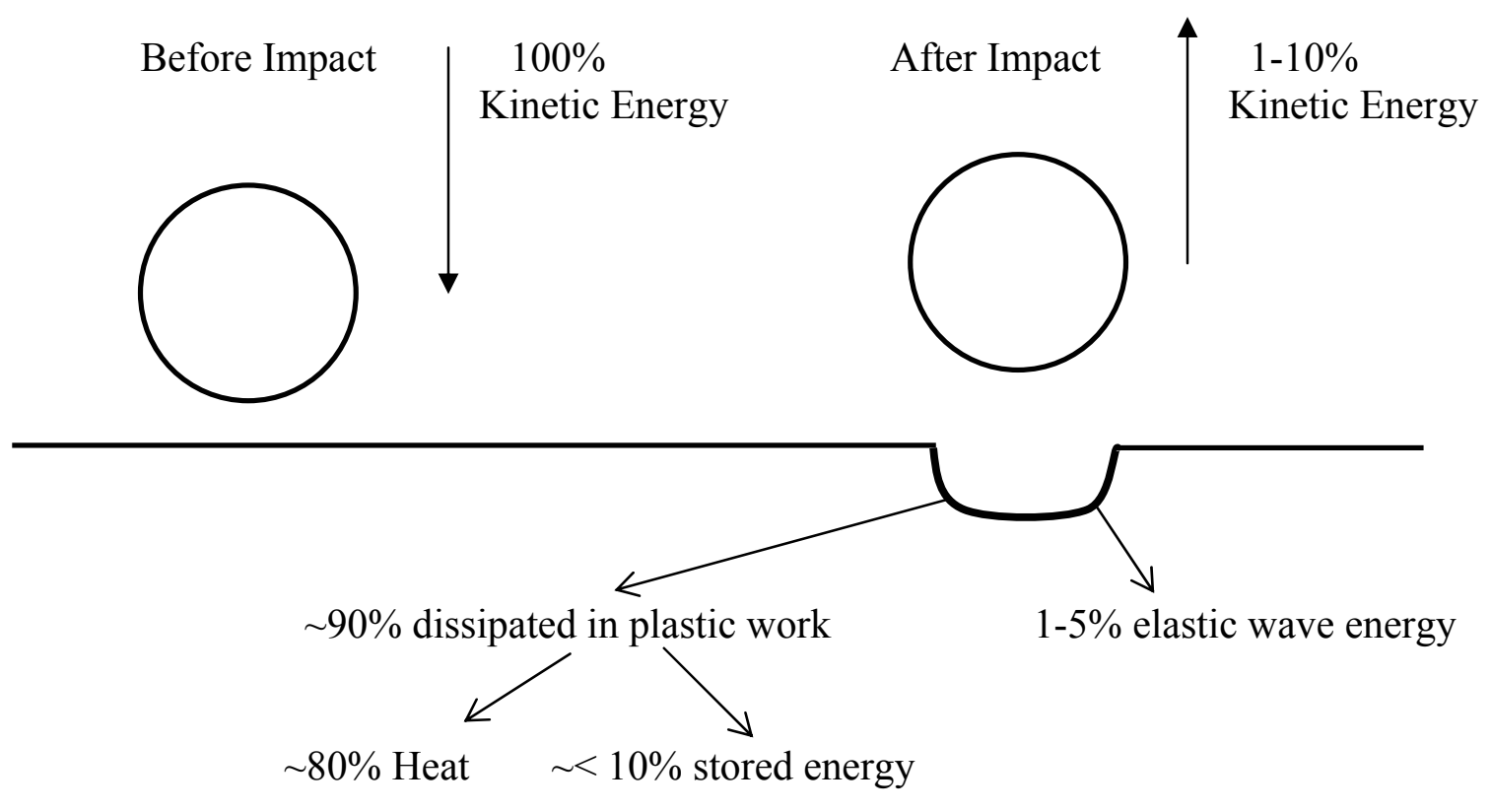

Figure 2.2 Energy Balance for a single particle impact

Hutchings derived erosion loss by considering energy equation. He considered a large number of spherical projectiles distributed at random over the surface struck the target surface. These projectiles were traveling at the same velocity and causing the same pattern of plastic deformation in the target upon impact. He assumed that the whole volume deformed plastically by each impacting sphere is subjected to a plastic strain increment $\Delta \varepsilon_{\mathrm{p}}$ of the same magnitude and that strains are directed with circular symmetry about the line of impact of the sphere as shown in figure 2.3. 


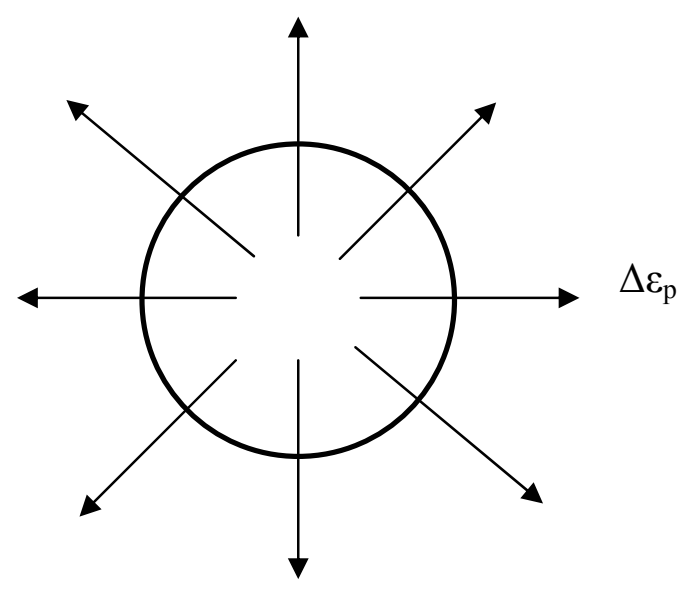

The plastic strain associated with one impact is assumed to be directed radially outwards in the plane of the surface [23]

Figure 2.3 Plastic Strain Associated with Single Particle Impact

Therefore at any point on the surface will be subjected to successive increments of strain of magnitude $\Delta \varepsilon_{\mathrm{p}}$ randomly oriented in the plane of the surface. After $\mathrm{N}$ impacts the expectation value of the resultant strain at the point may be shown from random walk theory to be $\Delta \varepsilon_{\mathrm{p}} \mathrm{N}^{1 / 2}$.If $\mathrm{N}_{\mathrm{f}}$ is the mean number of impacts needed to cause detachment of material then application of the failure criterion is given by

$$
\varepsilon_{\mathrm{c}}=\Delta \varepsilon_{\mathrm{p}} \mathrm{N}^{1 / 2}
$$

Hutchings assumed the target metal being eroded as perfectly plastic solid with no work hardening. The eroding particles were assumed to be rigid non-deforming spheres of radius $r$ and density $\rho$. Therefore the mass of the sphere is given by

$$
M=\frac{4}{3} \pi r^{3} \rho
$$

And the sphere moving with a velocity $v$ therefore its kinetic energy is $\mathrm{mv}^{2} / 2$ 
The behavior of the metal target was assumed to resist indentation with a constant pressure $\mathrm{P}$ that is similar to the quasi-static indentation hardness. Here elastic forces were ignored. Energy balance during the impact indicated that at least $90 \%$ of the initial kinetic energy of the particle is dissipated in plastic deformation in the target, which is permissible. For the purpose of calculating the plastic deformation, elastic effects were ignored. Assuming that all the initial kinetic energy of the particle is available to form indentation, therefore the volume $V$ of particle is given by

$$
\mathrm{V}=\mathrm{mv}^{2} / 2 \mathrm{P}
$$

This relationship will be approximately true for the impact on metal by any shape of erosive particles at various impact velocities i.e. 10 to $500 \mathrm{~m} / \mathrm{sec}$, provided that the particle does not deform or fracture and elastic effects are neglected. He assumed that the metal volume, which is plastically deformed around an indentation, is some fraction $\alpha$ of the volume of indentation. Therefore the volume of material, which is plastically strained by each impact, is $\alpha \mathrm{mv}^{2} / 2 \mathrm{P}$ called elementary volume. After $\mathrm{N}_{\mathrm{f}}$ impacts the volume loss per impact is $\alpha \mathrm{mv}^{2} / 2 \mathrm{PN}_{\mathrm{f}}$. If the target material has density $\rho$ then the erosion loss $\mathrm{E}$ defined as the mass loss of the target per unit mass of impinging particles is given by

$$
\mathrm{E}=\alpha \rho v^{2} / 2 \mathrm{PN}_{\mathrm{f}}
$$

For a quasi-static indentation by a rigid sphere of radius $r$, Tabor [25] has shown that the average strain introduced in a metal is given by

$$
\varepsilon=0.2 a / r
$$

Where $a$ is the final chordal radius of the indentation and $\varepsilon$ is the strain in an equivalent uniaxial compression test.

By equating the initial kinetic energy of the impacting sphere with the work done in forming the indentation, it was shown that

$$
\alpha=2^{1 / 2} r v^{1 / 2}\left(\frac{2 \sigma}{3 P}\right)^{1 / 4}
$$

By combining the above equations, the erosion is given by 


$$
E=0.033 \frac{\alpha \rho \sigma^{1 / 2} v^{3}}{\varepsilon_{c}^{2} P^{3 / 2}}
$$

Where

$\alpha$ is fraction of volume of indentation, which is plastically deformed.

$\varepsilon_{\mathrm{c}}$ is the critical strain

$r$ is radius of the particle

$P$ is constant pressure of resistance by the target material for indentation

$v$ is impact velocity

$\rho$ is density of the target material

$\sigma$ density of the particle

\subsection{ASSUMPTIONS}

The following assumptions were considered in the present Finite Element Analysis

1. Single particle erosion was considered

2. Particle does not break upon impact.

3. Target material was assumed to be ductile metal.

4. The erodent was assumed to be rigid body in this analysis.

5. Temperature rise in the target during impact is not significant enough to cause change in its mechanical properties.

6. Vibrations effects during impact were neglected.

7. Impacting particle is spherical in shape and assumed to be having point contact with the target material.

8. The strain rate effects were neglected. 


\section{CHAPTER 3}

\section{FINITE ELEMENT SIMULATION}

\subsection{INTRODUCTION}

The main purpose of this chapter is to develop a numerical model simulating solid particle erosion on ductile material by considering all of the available parameters and boundary conditions. Finding the volume loss of an aluminum plate by solid particle impact is necessary in selecting the most economical materials of construction and operating conditions in the design of equipment. In this thesis, effort has been made to develop a model and be able to predict the volume loss at particular conditions accurately. The model was developed in LS-INGRID and solved in LS-DYNA3D. The final results were viewed in LS-TAURUS.

\subsection{FINITE ELEMENT MODEL}

Finite element analysis has three stages as shown in Figure 3.1

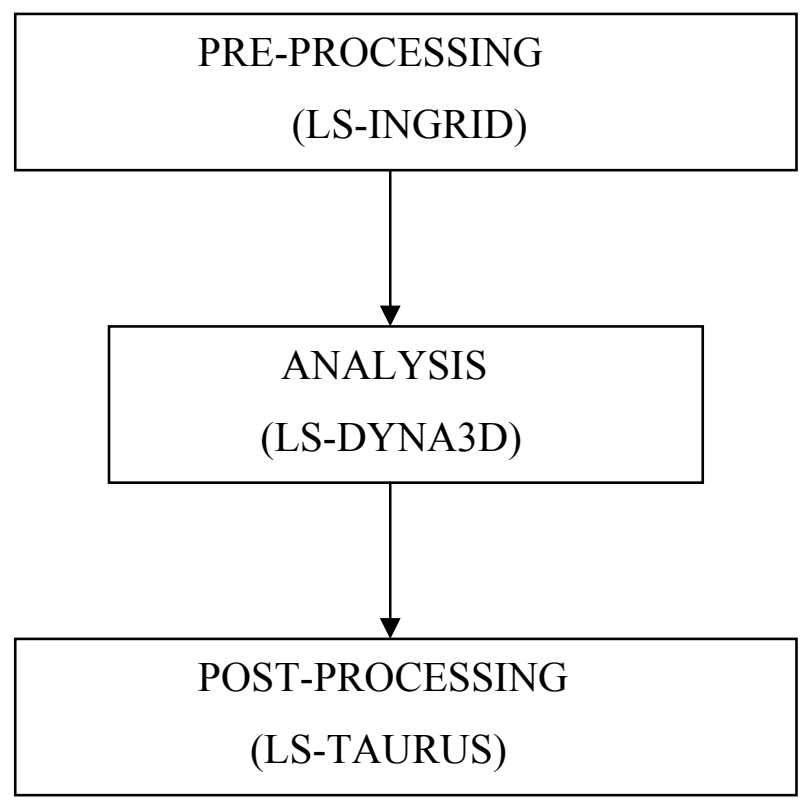

Figure 3.1 Three stages of Finite Element Analysis 


\subsection{MESH GENERATION}

The first step in finite element modeling was mesh generation. LS-INGRID was used in generating mesh for the current model. INGRID provides the capability to generate complex models for non-linear finite element analysis. An input file must be created in order to build an INGRID model and this file must contain global control commands, part definitions and material commands. We can modify or change the mesh structure, boundary conditions, sliding interfaces by using interactive graphics in INGRID. The unit system must be consistent and this software does not make any assumptions about the units in the given input file. The current model was developed with user defined system of Newton, millimeter, millisecond and gram for force, length, time and mass respectively. Index progression was used for creating mesh for the model. For meshing the dimensions of the target material and the erodent were required. When compared to target material, the erodent size was very small. So target material should be considered as an infinite medium for analytical purposes. But this analysis cannot handle infinite dimensions and hence proper dimensions have to be assumed for the target material. The Schematic model consisting of ductile metal substrate and spherical particle is shown in Figure 3.2

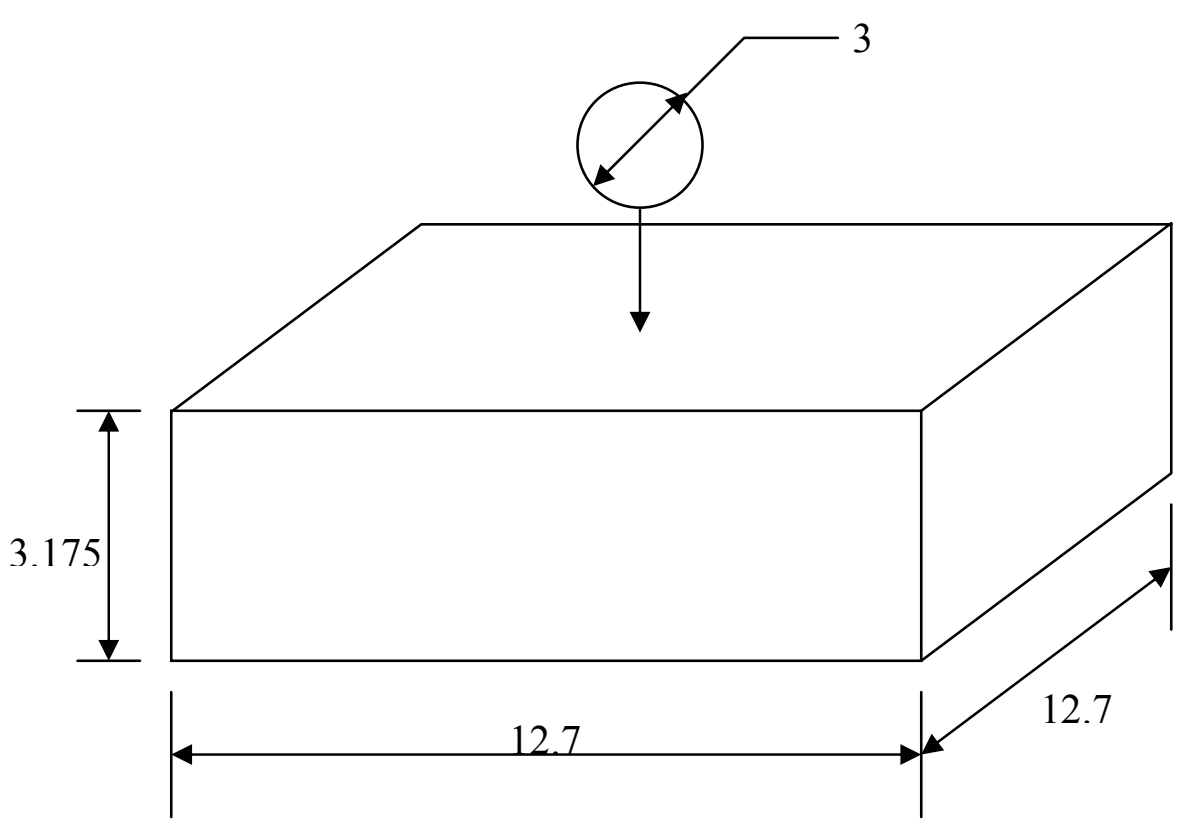

All dimensions are in $\mathrm{mm}$

Figure 3.2. Schematic model of single particle impact 
The erodent, and the metal substrate were modeled using 8 noded hexahedron (Single point integration and Brick) elements. Since the area of interest and the total time for completing the analysis, Fine mesh was created near the point of contact and course mesh was created away from the point of contact. The dimensions of the target metal and the erodent used in this model were same as the dimensions of the test specimen used in Sheldon's experimental work. These dimensions were $12.7 \mathrm{~mm}$ square by $3.175 \mathrm{~mm}$ thick for target metal and $3 \mathrm{~mm}$ in diameter for the glass particle.

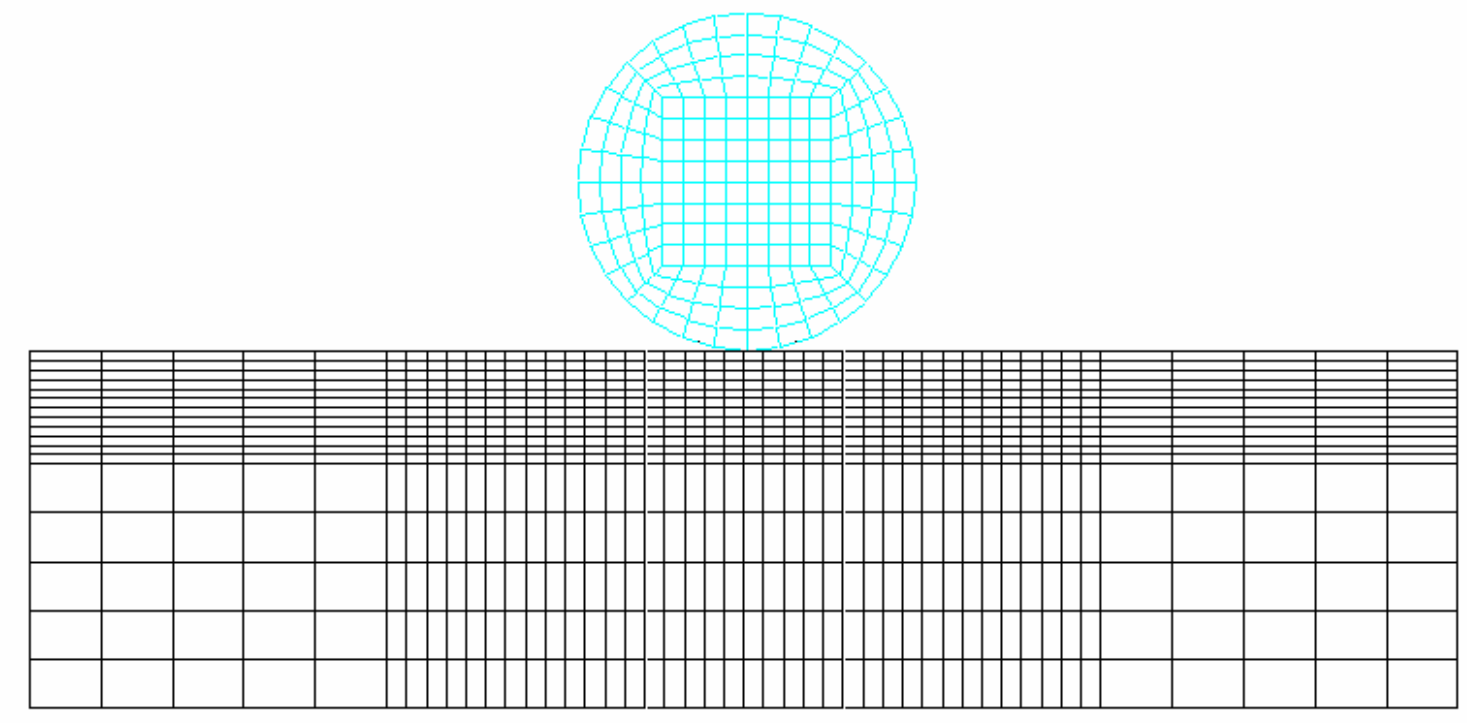

Figure 3.3 AL 6061-T0 Model mesh generation

\subsection{MATERIAL MODELS}

The next step after generating mesh in this analysis was to define the material properties of the metal and the particle. This step was crucial because the results of the analysis depend on how accurately the material models were defined. There are several material models available in LS-DYNA3D. Material models were defined in INGRID input file itself and further modifications can be done by using interactive commands For metal substrate, pre defined material 'piecewise linear isotropic plasticity' (type 24) was assigned For this material type 24 the properties required are listed in Table 3.1 


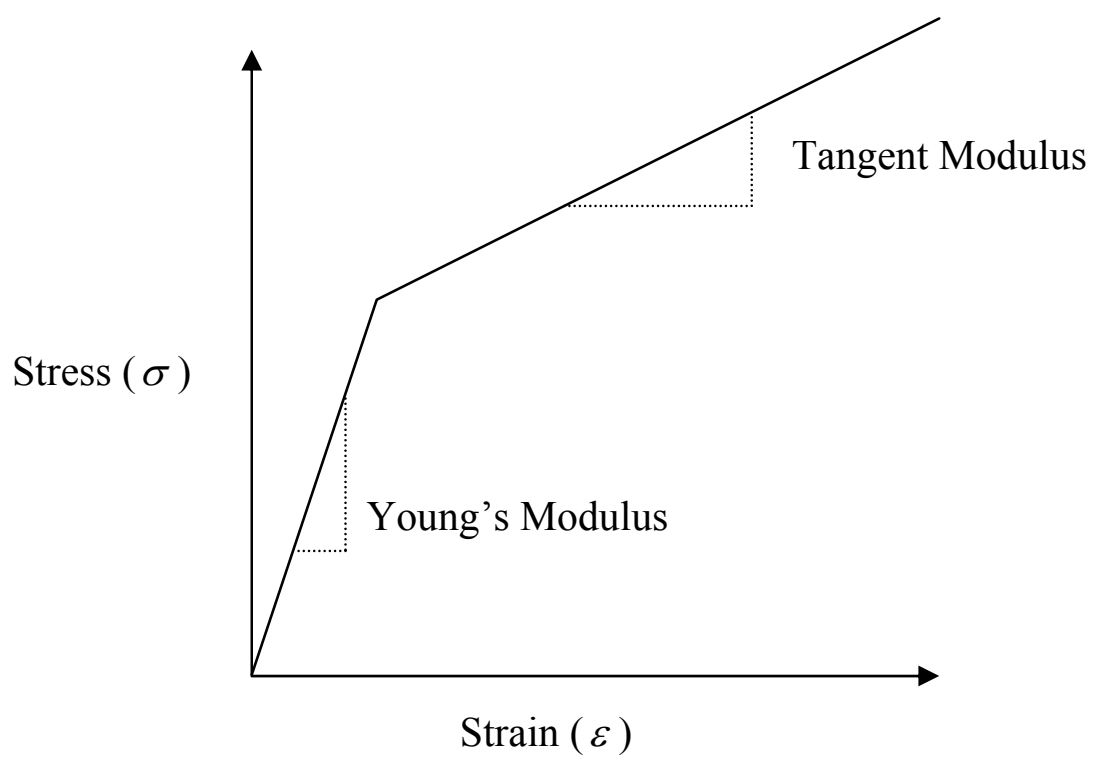

(All Dimensions are in Millimeters)

\begin{tabular}{|ll|l|}
\hline \multicolumn{2}{|c|}{ Properties of AL 6061-T0 } \\
\hline Mass density & $\left(\mathrm{kg} / \mathrm{m}^{3}\right)$ & 2700 \\
\hline Yield Stress & $(\mathrm{Mpa})$ & 55.2 \\
\hline Young's Modulus & $(\mathrm{Gpa})$ & 68.9 \\
\hline Tangent Modulus & $(\mathrm{Gpa})$ & 1.06 \\
\hline Poisson Ratio & & 0.33 \\
\hline
\end{tabular}

Table 3.1 Material Properties of Aluminum AL 6061-T0

In this thesis, the main concentration was on target medium and effect of impact on particle is neglected. Hence the particle was assumed to be a rigid body and assigned rigid material type 20 . This type of material takes into account all the properties of the particle except it won't show the deformation and other results of the particle. Rigid elements are bypassed in the element processing and no storage is required for storing history variables. Hence the rigid material type is very cost efficient. The properties required to define rigid material type are shown in Table 3.2 
Properties of the Glass particle:

\begin{tabular}{|ll|l|}
\hline \multicolumn{2}{|l|}{ Properties of Silicon Dioxide Particle $\left(\mathrm{Sio}_{2}\right)$} \\
\hline Mass density & $\left(\mathrm{kg} / \mathrm{m}^{3}\right)$ & 2110 \\
\hline Young's Modulus & $(\mathrm{Gpa})$ & 68 \\
\hline Poisson Ratio & & 0.19 \\
\hline
\end{tabular}

Table 3.2 Material Properties of Silicon Dioxide Particle

\subsection{INITIAL AND BOUNDARY CONDITIONS}

This model was symmetrical about XZ plane shown in Figure 3.4. By taking advantage of the symmetry, only half of the model was considered to save the computational time. When the single particle impact was considered only local contact area had deformation and far from the contact area the target medium had negligible deformation. Therefore all the nodes on the boundary away from the region of contact were totally restrained from any kind of deformation. Sliding with friction definition was used to define the sliding contact between the target surface and the impacting particle. This particular sliding interface shown in Figure 3.5 was designated as a type III algorithm. This is the most generally applicable option and large relative motions are permitted and by default coulomb friction is included. Metal target nodes were taken as slave nodes where as spherical particle nodes were taken as master nodes. The impacting particle was given velocity in negative direction on to the target surface. This initial velocity was assigned in vector form

$$
\text { i.e. } v=v_{x} i+v_{y} j+v_{z} k \text {. }
$$



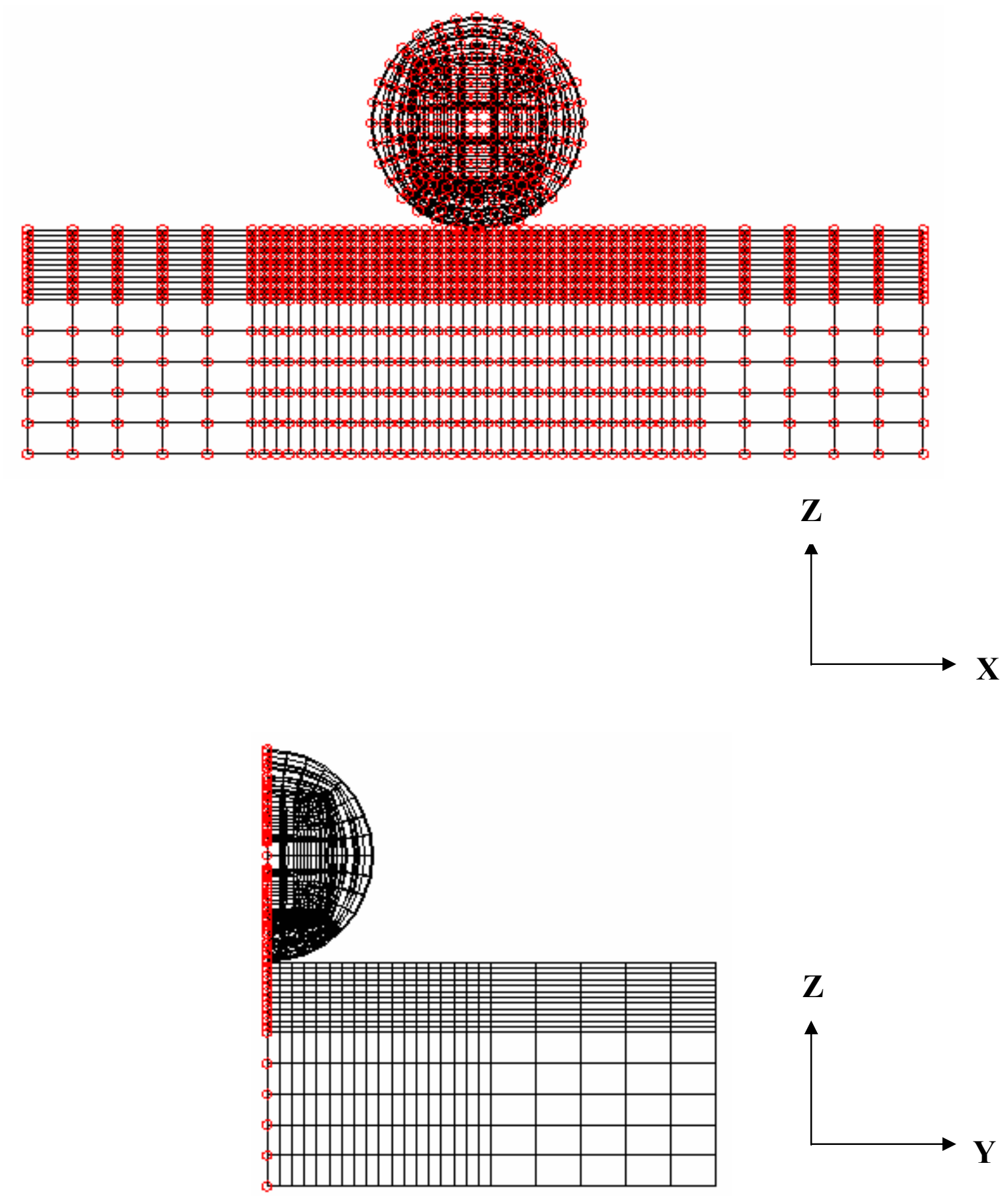

Figure 3.4. Symmetric plane of a model 


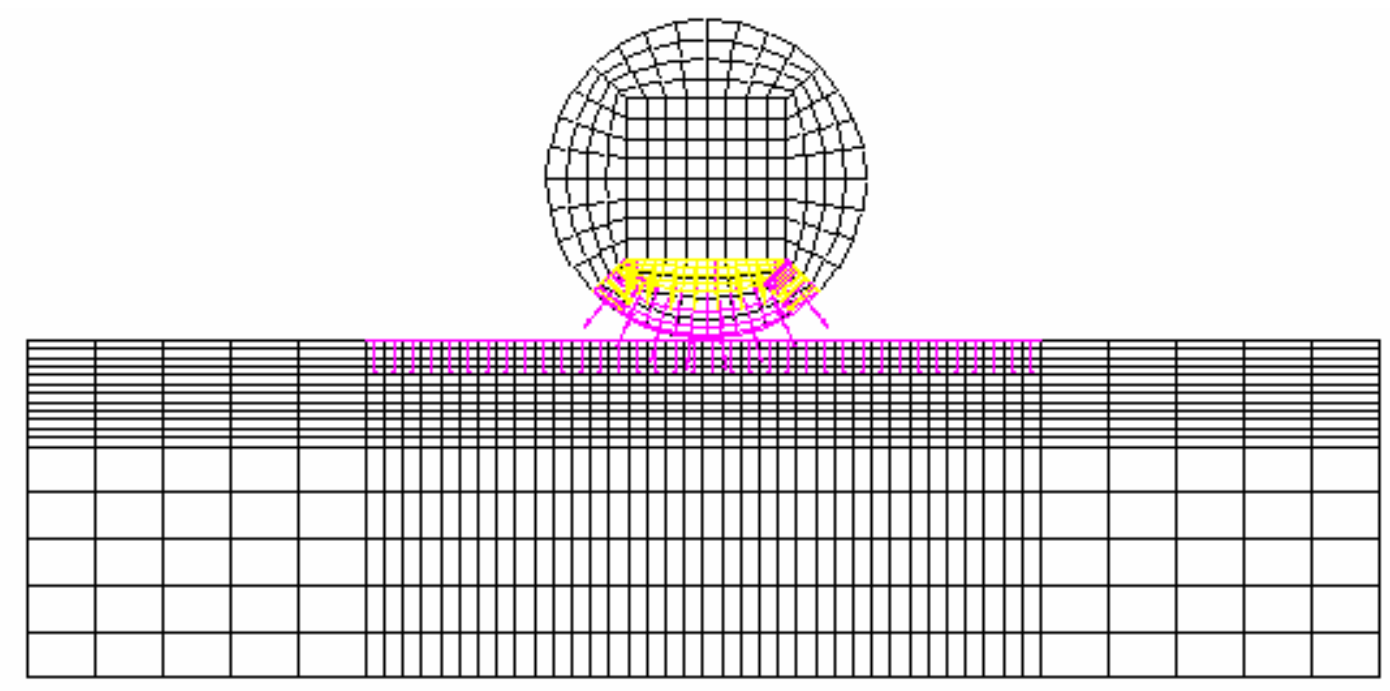

Figure 3.5. Contact surfaces between target metal and the erodent

\subsection{MODEL SOLUTION}

Input file must be written to develop a model in Ingrid. In this input file Material properties, boundary conditions and contact interfaces were specified and there was no need to specify these properties again in LS-DYNA file. We can modify these specifications by using graphics interactive commands in Ingrid itself. The output of the Ingrid was converted to LS-DYNA input file by using OUTPUT (Code Output), DN3D (Dyna3D Code), KW93 (LS930 Keyword Format) and CONTINUE Commands. LSDYNA3D is a fully vectorized, explicit, nonlinear, three dimensional, dynamic analysis code capable of solving problems involving large deflections and high rates of deformation. [26]. In LS-DYNA3D the time step computed for this analysis was based on the smallest element size in the model. Default Hour glassing was added in this analysis and simulation was run until the time specified. The termination time given was based on the time in which erodent rebounds. The results can be viewed in the post processor called LS-TAURUS. 


\subsection{POST PROCESSING}

LS-TAURUS was used as a post processor in this analysis. It is powerful, interactive and user-friendly software that can read binary and time history files which are generated by LS-DYNA3D. LS-TAURUS has 3 phases to display results in various forms like line plots, contour plots data plots, time history reports and XY graph plots. The three phases are [27]

Phase 1: geometry, animation, Fringe and Contour plots

Phase 2: Time History Processing

Phase 3: ASCII Database Results

In the present work the required results for the failure analysis were effective stresses and plastic strains. The strain results provided the qualitative estimation of the erosion loss and stress results provided the quantitative estimation of the erosion loss. One of the commands in phase I of the TAURUS, 'Profile' gives plot of effective stresses or Von Mises stresses and effective strains against the element numbers or against the node numbers at a particular time step during analysis shown in Figure 3.6 and 3.7 and prints the data in HSPBULL file with two-column format or four-column format. These graphs and data were used and compared with failure stresses and strains in the estimation of volume loss in the target metal due to particle impact. In phase III the binary plot files GLSTAT and MATSUM are used for the energy plots shown in Figure 3.8 that give the kinetic, internal and default (hourglassing, damping etc.) energies with respect to the total energy. This energy plots data can be printed in HSPBULL file. 


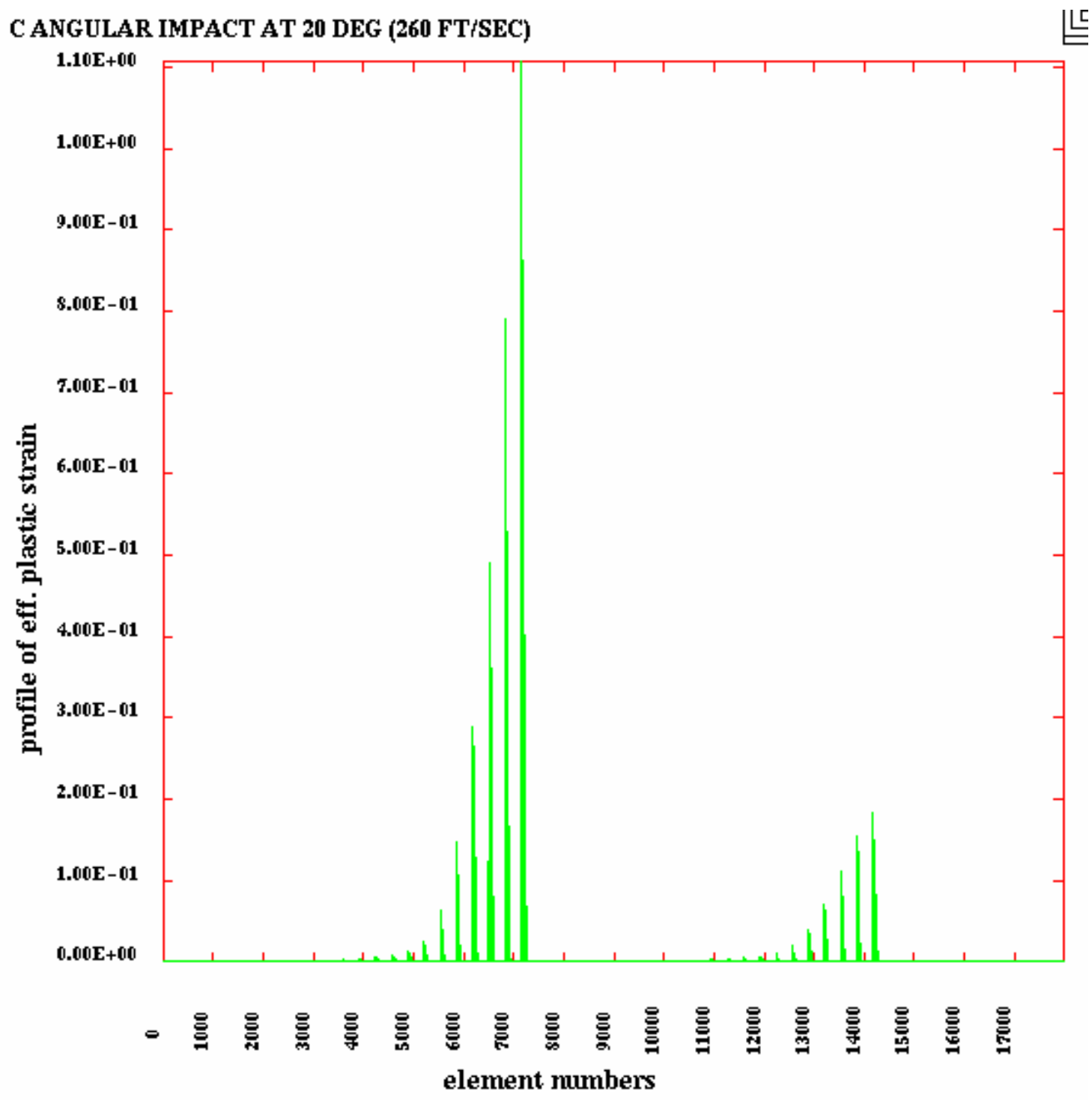

minimum $=0.0000 \mathrm{E}+00$ at element 17986 maximum $=1.1078 \mathrm{E}+00$ at element 7150

Figure 3.6 Profile of Effective Plastic Strains 


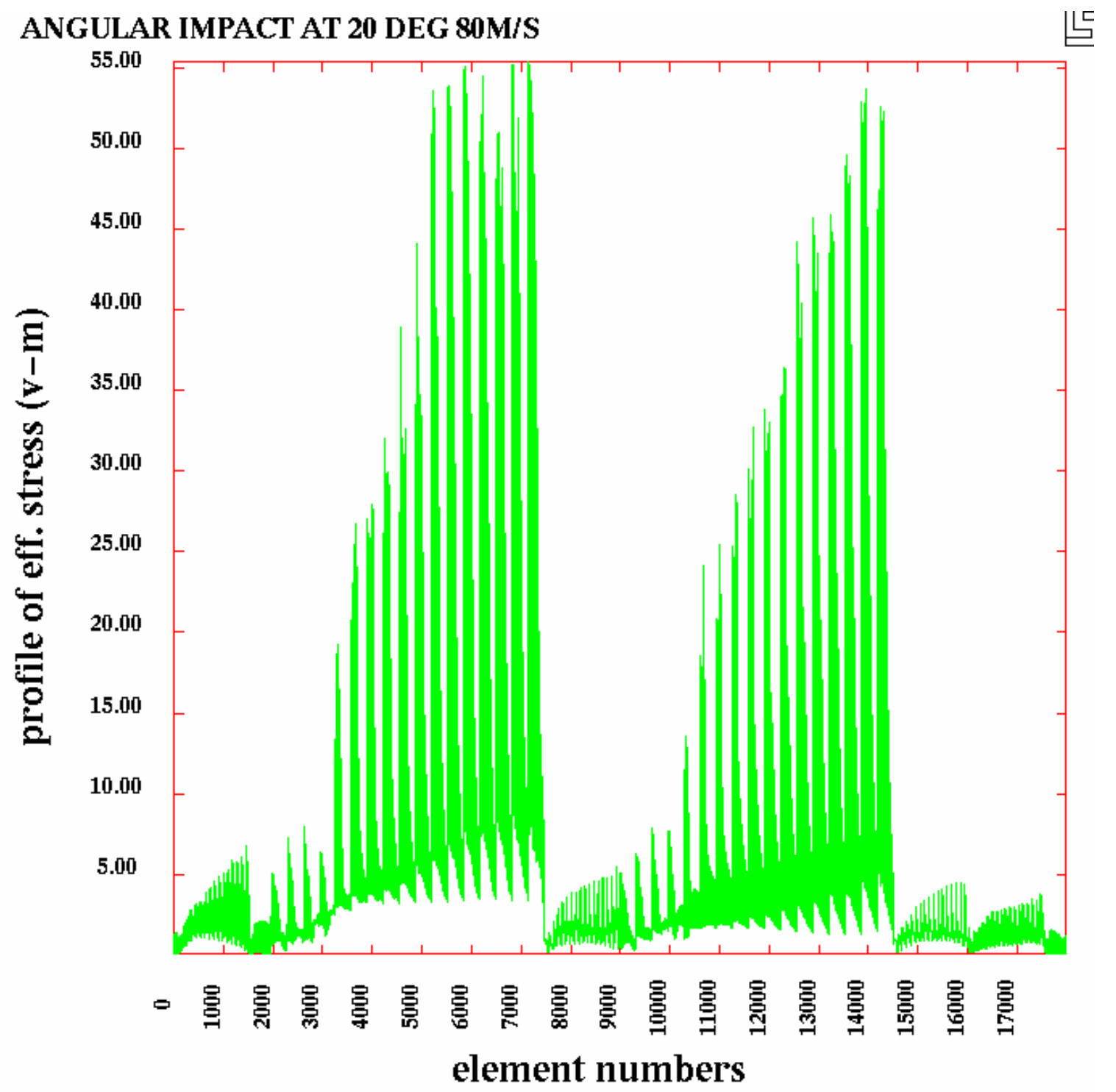

minimum $=3.7245 \mathrm{E}-02$ at element 1926 maximum $=5.5360 \mathrm{E}+01$ at element 7149

Figure 3.7 Profile of Effective Stresses

\subsection{FAILURE MECHANISMS AND MATERIAL LOSS ESTIMATION}

In this thesis two failure criteria were used separately to estimate the erosion loss and these results were compared with the Sheldon's experimental results. These failure criteria were

1. Distortion energy criteria

2. Critical strain failure criteria 
For finding the erosion loss in the target material the same procedure was used to both failure criteria. The procedure was as follows

The maximum internal energy point of the system was taken as the time step where the target experiences maximum damage. At this particular time interval the plot between Von Mises effective stress profile and the elements was obtained and data reports were printed in HSPBULL file. A program was written in AWK programming language to estimate the erosion loss for a particular condition. This programming language scans the HSPBULL file for the elements whose stress values are more than that of the failure stress and gives the output file as a count of failed elements. Each element volume was calculated by using a built in command in LS-TAURUS. By multiplying each element volume with the total number of failed elements gives the volume loss for the half model in $\mathrm{mm}^{3}$ units and finally the erosion loss was calculated in $\mathrm{mg} / \mathrm{g}$ units.

But in this criterion the stress level in some elements exceeded the threshold stress during the initial contact with the erodent and did not have the same stress level at the point of maximum internal energy since the erodent was making glancing impact and moving away from these elements. So these elements were not picked up as critical elements.

The other failure criterion was critical strain criteria, which was consistent with the experimental results of Sheldon. The same procedure was adopted as distortion energy failure criteria in finding the erosion loss. The AWK program scans the HSPBULL file to pick up the elements, which have exceeded the critical failure strain, and using these elements erosion loss is found in $\mathrm{mg} / \mathrm{g}$ units. The critical failure strain for AL 6061-T0 material was obtained by performing the tensile test using the Instron Machine in Materials Laboratory at WVU [28] In this analysis progressive failure was not considered which means the elements that exceed the critical strain were not deleted during the analysis. After yielding strain increment $d \varepsilon$ which is composed of an elastic contribution $d \varepsilon^{e}$ and a plastic contribution $d \varepsilon^{p}$, so that $\mathrm{d} \varepsilon=\mathrm{d} \varepsilon^{\mathrm{e}}+\mathrm{d} \varepsilon^{\mathrm{p}}$. The elements that have reached the yield stress at any instance would still retain the unrecoverable plastic strain during unloading also.

This analysis for the current model was an energy conserved system. The total energy in the system should remain same for any time, which was equal to the initial kinetic energy of the erodent. A typical energy balance curve for an analysis is shown in Figure 
3.8. When the particle impacts the target surface the kinetic energy comes down and the internal energy goes up. Default hourglass energy added is shown in Figure 3.8.

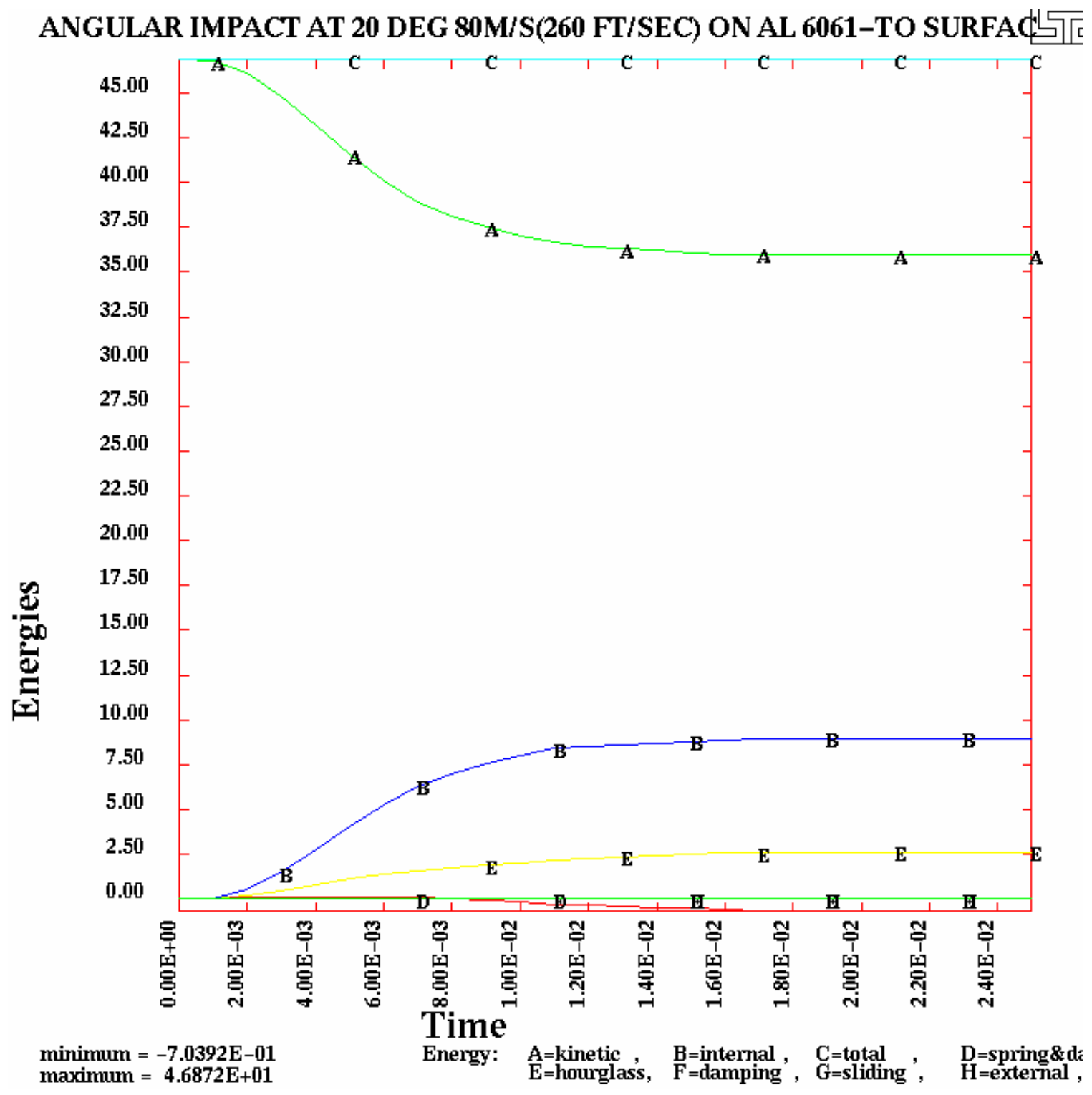

Figure 3.8 Energy Balance for a model 


\subsection{Strain Hardening Effect on Erosion}

When the particle impacts the target material the yield strength of the material is exceeded at the point of contact which causes plastic deformation takes place in the vicinity of the impact. After multiple impacts, a plastically deformed surface layer may form near the eroded surface. Therefore the yield strength of the material increases due to strain hardening. Upon further deformation, the yield strength at the surface of the material will eventually become equal to its fracture strength and no further plastic deformation will occur. At this point the material surface becomes brittle and its fragments may be removed by the subsequent impacts. Because of the work hardening, the material hardness will increase in the vicinity of the eroded surface and the strain introduced by each impact will be reduced.

Strain hardening rate is not considered in this analysis. If strain-hardening effect were considered, the erosion loss results in FEM analysis would have been reduced and closer to the experimental results. 


\section{CHAPTER 4}

\section{RESULTS AND DISCUSSIONS}

\subsection{INTRODUCTION}

The main objective of this chapter is to compare the results between the experimental wear rates and the developed finite element model to assess the values of the numerical model in depicting the behavior of the ductile erosion.

The results based on the finite element model developed in chapter 3 are presented here in terms of the following parameters.

1. Velocity of Erodent

2. Size of Erodent

3. Angle of impact

4. Shape of Erodent

The results were compared with the experimental results of Sheldon et al. The erosion loss results obtained from the FEM model were not exactly same as experimental results of Sheldon. But the other results for erosion loss dependence on velocity of erodent, size and shape of erodent showed good correlation with the experimental results.

\subsection{PARAMETRIC RANGES}

The following cases were studied

- Angular Impact with diameter of erodent $3 \mathrm{~mm}$ in the velocity range of $20-90 \mathrm{~m} / \mathrm{s}$ in steps of $10 \mathrm{~m} / \mathrm{s}$

- Angular Impact at $80 \mathrm{~m} / \mathrm{s}$ and $20 \mathrm{deg}$ with diameter of erodent, varying diameter of the erodent from 1.5-3.5 in steps of $0.5 \mathrm{~mm}$

- Angular Impact with diameter of erodent $3 \mathrm{~mm}$, velocity $80 \mathrm{~m} / \mathrm{s}$ varying the angle of attack from 20-90 deg in steps of $10 \mathrm{deg}$.

- Angular Impact with spherical and octahedral shapes of the erodent at $80 \mathrm{~m} / \mathrm{s}$ and $20 \mathrm{deg}$ 


\subsection{MODEL VALIDATION}

The present model consists of an aluminum metal plate and a glass particle. The dimensions of the target plate are $12.7 \times 12.7 \times 3.175 \mathrm{~mm}$. The erodent is spherical in shape with $3 \mathrm{~mm}$ diameter. These dimensions were taken from Sheldon's experimental model. The material properties of the target metal and erodent were taken from material handbooks.

In the current work finite element method was used to simulate the experimental work. The model was developed in LS-INGRID and analysis was performed in LSDYNA3D. In the present model, the target material was impacted with a velocity $80 \mathrm{~m} / \mathrm{s}$ at 20 and $90 \mathrm{deg}$ angles of attack as shown in Figures 4.2-4.17. The erosion loss values for aluminum (AL 6061-T0) obtained from the current model were compared with the erosion loss values for the aluminum obtained from Sheldon's experimental work. The FEM model was quantitatively verified with the experimental results of Sheldon et al. The erosion loss values obtained from the current work are shown below.

\begin{tabular}{|l|ll|ll|cc|}
\hline No & \multicolumn{2}{|l|}{ Erodent Velocity and Angle } & \multicolumn{2}{|l|}{ Current FEM Results } & \multicolumn{2}{l|}{ Sheldon Experimental Results } \\
\hline 1 & $80 \mathrm{~m} / \mathrm{s}$ and $20^{0}$ & 0.92 & $\mathrm{mg} / \mathrm{g}$ & 0.12 & $\mathrm{mg} / \mathrm{g}$ \\
\hline 2 & $244 \mathrm{~m} / \mathrm{s}$ and $20^{0}$ & 14.47 & $\mathrm{mg} / \mathrm{g}$ & 1.8 & $\mathrm{mg} / \mathrm{g}$ \\
\hline 3 & $244 \mathrm{~m} / \mathrm{s}$ and $90^{\circ}$ & 28.80 & $\mathrm{mg} / \mathrm{g}$ & 1.8 & $\mathrm{mg} / \mathrm{g}$ \\
\hline
\end{tabular}

Table 4.1. Weight of critical volume per gram of particle for AL 6061-T0

The erosion loss is measured in terms of weight of critical volume per gram of particle. When these FEM results were compared with the experimental results, FEM results showed some variation. Some of this variation in erosion values might be attributed to the experimental error and rounding error in the FEM erosion estimation method. The volume loss was estimated finding the volume of the critical elements, which were above a certain critical strain. This volume of critical elements may not be lost due to erosion, only a fraction, $10-15 \%$ of this critical volume, may actually be lost when the elements above the critical strain are strained enough to fracture. Here critical strain value taken from the uniaxial tension test was used as failure strain value. This 
failure strain value obtained from the tension test must be less than the plastic strain value in the FEM model, which was under dynamic loading and multiaxial state of stress. So a large number of elements were picked as critical elements thus giving the large value for critical volume loss.

\subsection{EFFECT OF ERODENT VELOCITY}

Analysis was performed at $20^{\circ}$ angle with $3 \mathrm{~mm}$ diameter of the spherical particle at several velocities ranging from 40 to $90 \mathrm{~m} / \mathrm{s}$ to determine the volume loss in order to obtain the trend lines. A plot of critical volume against velocity is shown in Figure 4.18. The critical volume was found to increase with increase in velocity, which was consistent with theories of volume loss dependence on erodent velocity. The velocity exponent obtained from the graph for volume loss vs. velocity was 2.65 , which was consistent with the velocity exponent values for ductile erosion predicted in theory. The theory predicted that the velocity exponent would be in between 2 and 2.9. Sheldon predicted a velocity exponent value of 3 for ductile erosion in his experimental work.

\subsection{INFLUENCE OF PARTICLE SIZE}

Erodent sizes from $1-3.5 \mathrm{~mm}$ at $20^{\circ}$ with $80 \mathrm{~m} / \mathrm{s}$ were considered in this analysis. The plot of volume loss vs. erodent diameter is shown in Figure 4.19. Here the volume loss increased linearly with the erodent size. The particle diameter exponent obtained from the plot for volume loss vs. erodent diameter was 3.12, which was consistent with the experimental results obtained by Sheldon. He predicted that diameter exponent would be about 3. After a certain critical size the volume loss is independent of size of the erodent.

\subsection{EFFECT OF IMPACT ANGLE}

The analysis was performed at different angles from 20-90 deg for 3mm diameter of the spherical particle keeping the velocity constant at $80 \mathrm{~m} / \mathrm{s}$. Fewer elements were

picked up as critical elements at $20^{\circ}$ than at 90 deg angle of attack as shown in Figures 
4.20 and 4.21. At lower angles only a small number of elements were picked as critical elements because the contact surface area was less at glancing angles. At 90 deg impact, the contact surface area of the particle with the metal surface was more hence more elements were picked up as critical elements. But the actual volume loss for the normal impact could be less than 20 deg impact for ductile materials as the material evenly flows around the indentation crater. For 20 deg impact a lip is formed in front of the crater, which may be lost subsequently when strained to fracture. The plot shows maximum critical elements at normal impact may not qualitatively represent the dependence of volume loss on angle of attack for ductile materials shown in Figure 4.22.

\subsection{EFFECT OF ERODENT SHAPE}

The shape of the particle determines the contact area between the particle and the target surface during the impact. Two different erodent shapes were considered in this analysis by keeping the velocity and angle of attack constant at $80 \mathrm{~m} / \mathrm{s}$ and $20^{\circ}$ respectively. The shapes are

1. Spherical shape which has a point contact with the target surface

2. Octahedral shape, which has a line contact with the target surface.
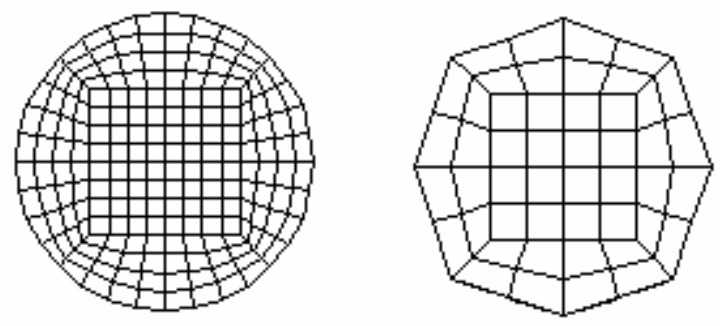

Figure 4.1.Two different shapes of the particle

The volume loss was more in the Aluminum plate when it was impacted by a particle with line contact than by a particle with point contact. The area of contact was more with the octahedral particle than with the spherical particle. Table 4.2 shows the volume loss for the two different shapes. The strain contours on AL6061-T0 metal when impacted by octahedral shape particle were shown in Figure 4.23-4.26. The profile of plastic strain for the aluminum model impacted by octahedral shape particle is shown in Figure 4.27. 


\begin{tabular}{|l|l|l|l|}
\hline S.No & Particle Shape & Type of Contact & $\begin{array}{l}\text { Volume loss } \\
\text { (cubic millimeter) }\end{array}$ \\
\hline 1 & Sphere & Point & 0.28 \\
\hline 2 & Octahedron & Line & 0.50 \\
\hline
\end{tabular}

Table 4.2. Volume Loss of AL 6061-T0 impacted by two different particles

\section{ANGULAR IMPACT AT 20 DEG 80M/S}

time $=0.00000 \mathrm{E}+00$

ringes of eff. plastic strain

fringe levels

$0000+00$ ?

$\min =0.000 \mathrm{E}+00$ in element 19010

$\max =0.000 \mathrm{E}+00$ in element 19010

LOOOE-20 >

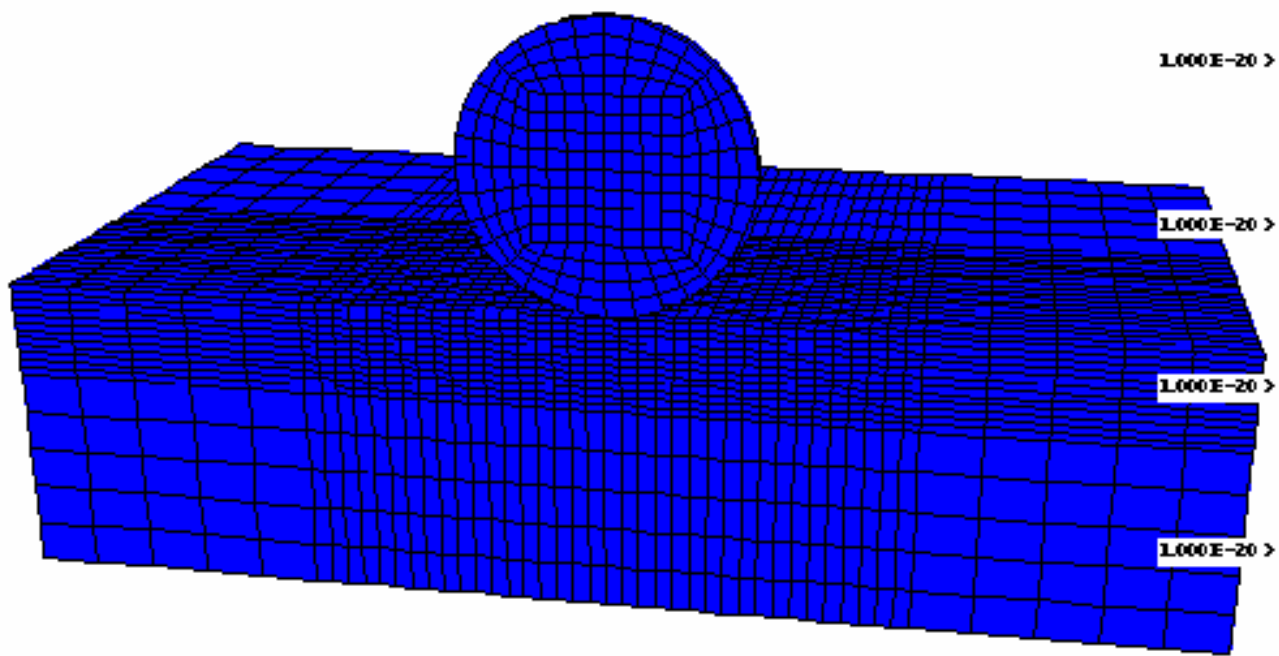

LOC0E-203

LOCOE-20 >

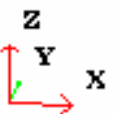

2000E-203

Figure 4.2. Fringes of plastic strain for AL 6061-T0 plate impacted by $3 \mathrm{~mm}$ particle at $20 \mathrm{deg}$ with a velocity of $80 \mathrm{~m} / \mathrm{s}$ 
ANGULAR IMPACT AT 20 DEG 80M/S

time $=9.92606 \mathrm{E}-04$

binges of eff. plastic strain

min $=0.000 \mathrm{E}+00$ in element 19010

$\max =4.373 \mathrm{E}-02$ in element $715 \mathrm{~F}$

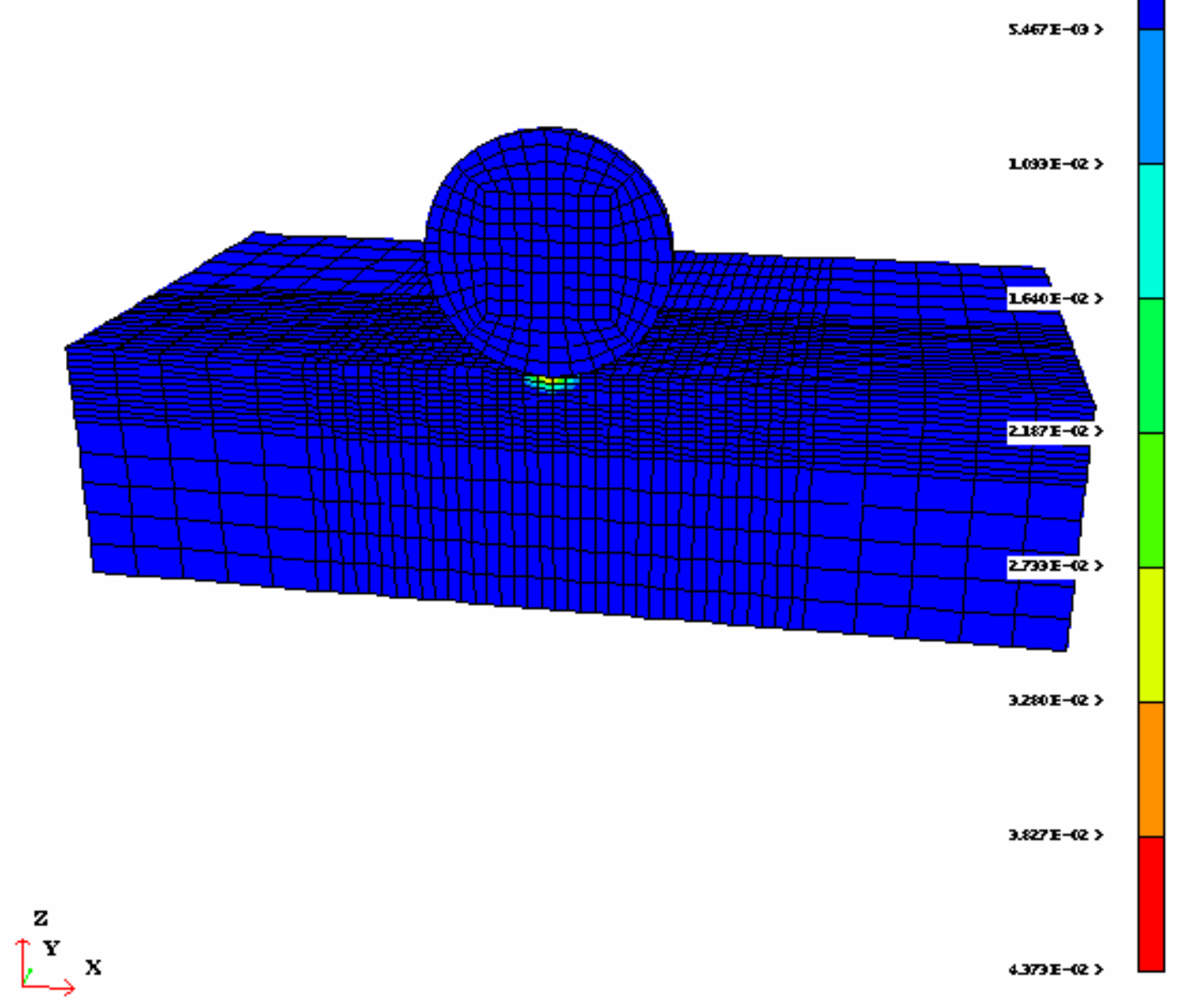

Figure 4.3. Fringes of plastic strain for AL 6061-T0 plate impacted by $3 \mathrm{~mm}$ particle at $20 \mathrm{deg}$ with a velocity of $80 \mathrm{~m} / \mathrm{s}$ 
ANGULAR IMPACT AT 20 DEG 80M/S

time $=1.99898 \mathrm{E}-03$

fringes of eff. plastic strain

fringe levels

$0000 \times 00$ ?

$\min =0.000 \mathrm{E}+00$ in element 19010

$\max =1.576 \mathrm{E}-01$ in element 7157

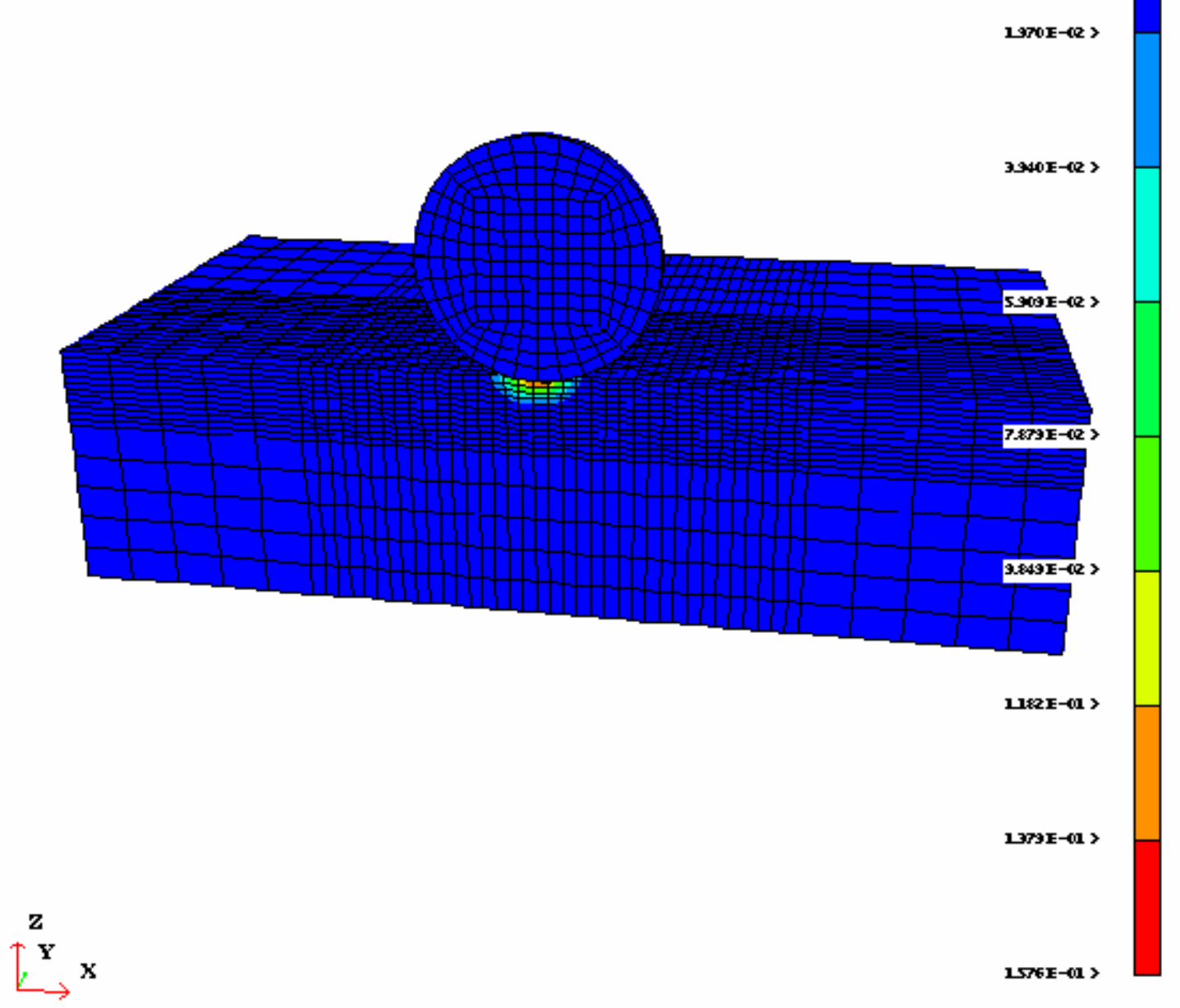

Figure 4.4. Fringes of plastic strain for AL 6061-T0 plate impacted by $3 \mathrm{~mm}$ particle at $20 \mathrm{deg}$ with a velocity of $80 \mathrm{~m} / \mathrm{s}$ 
ANGULAR IMPACT AT 20 DEG 80M/S

time $=1.89992 \mathrm{E}-02$

ringes of eff. plastic strain

لـ

$\min =0.000 \mathrm{E}+00$ in element 19010

$\max =1.108 \mathrm{E}+00$ in element 7150

bringe levels

$0000+60$ ?

LaSE-0 >

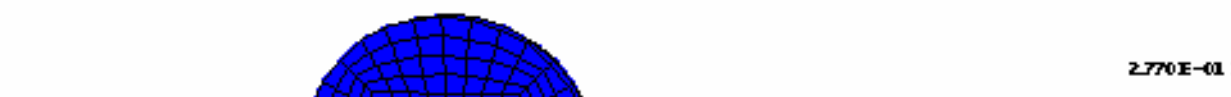

ZTOE-G >
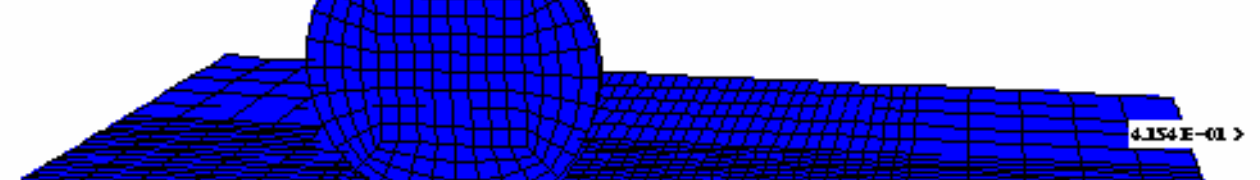

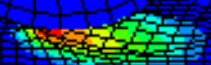

\$S3E-01,

6-324E-01 >

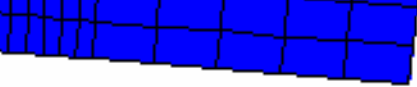

$8300 \mathrm{E}-\mathbf{0 1}$ )

$\mathbf{Z}$

$\mathbf{Y} \mathbf{x}$

LOEE*60)

Figure 4.5. Fringes of plastic strain for AL 6061-T0 plate impacted by $3 \mathrm{~mm}$ particle at $20 \mathrm{deg}$ with a velocity of $80 \mathrm{~m} / \mathrm{s}$ 
ANGULAR IMPACT AT 20 DEG 80M/S

time $=2.50002 \mathrm{E}-02$

fringe levels

tringes of eff. plastic strain

acoseros?

$\min =0.000 \mathrm{E}+00$ in element 19010

$\max =1.108 \mathrm{E}+00$ in element 7150

135E-01 >

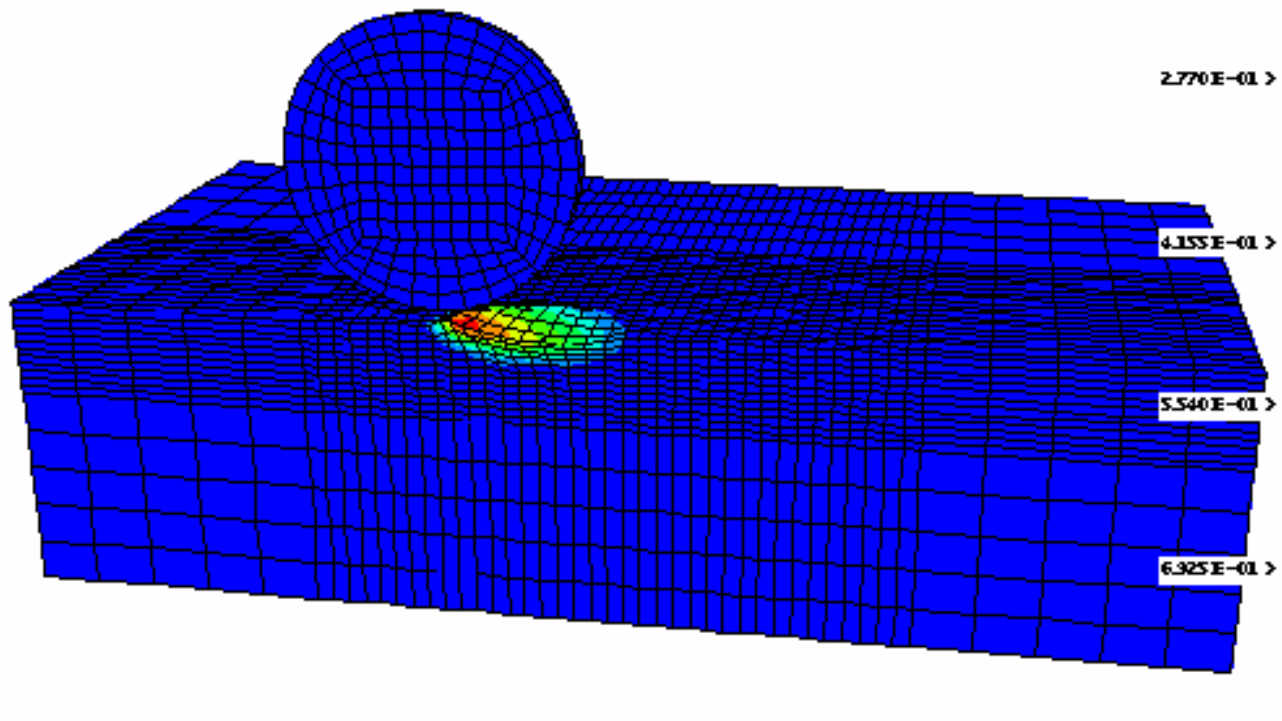

8310E-01 >

M.655E-0 3

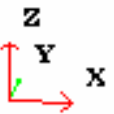

LOEF+00 ?

Figure 4.6. Fringes of plastic strain for AL 6061-T0 plate impacted by $3 \mathrm{~mm}$ particle at $20 \mathrm{deg}$ with a velocity of $80 \mathrm{~m} / \mathrm{s}$ 
ANGULAR IMPACT AT 20 DEG 80M/S

Гكاك

time $=2.99308 \mathrm{E}-03$

fringes of eff. stress $(\mathrm{r}-\mathrm{m})$

tringe levels

$\min =0.000 \mathrm{E}+00$ in element 19010

$\max =5.746 \mathrm{E}+01$ in element 7154

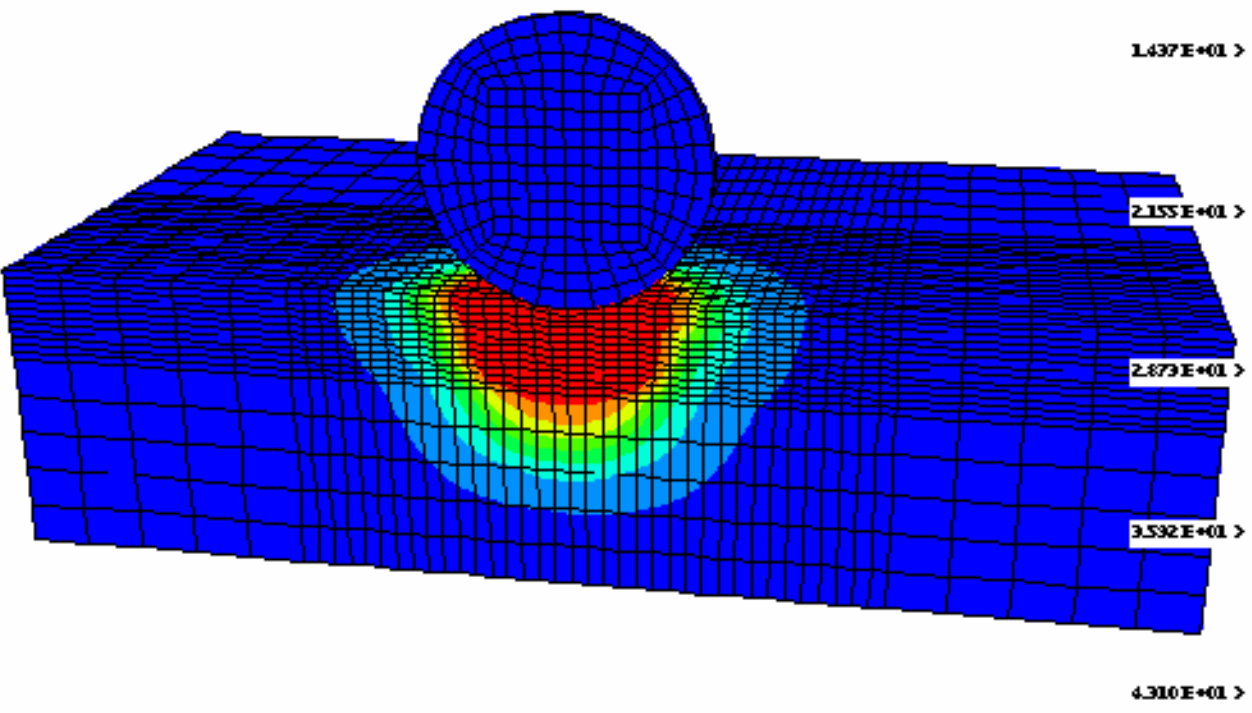

$\operatorname{li}_{\rightarrow}^{\mathbf{Y}} \mathrm{x}$

S.746E*01 >

Figure 4.7. Fringes of Von Mises stresses for AL 6061-T0 plate impacted by $3 \mathrm{~mm}$ particle at $20 \mathrm{deg}$ with a velocity of $80 \mathrm{~m} / \mathrm{s}$ 
ANGULAR IMPACT AT 20 DEG 80M/S

time $=7.99711 \mathrm{E}-03$

binges of eff. stress $(*-m)$

屿

$\min =0.000 \mathrm{E}+00$ in element 19010

$\max =5.65 \% \mathrm{E}+01$ in element 7151

tringe levels

aco0en+o0s?

$7.002+00$ >

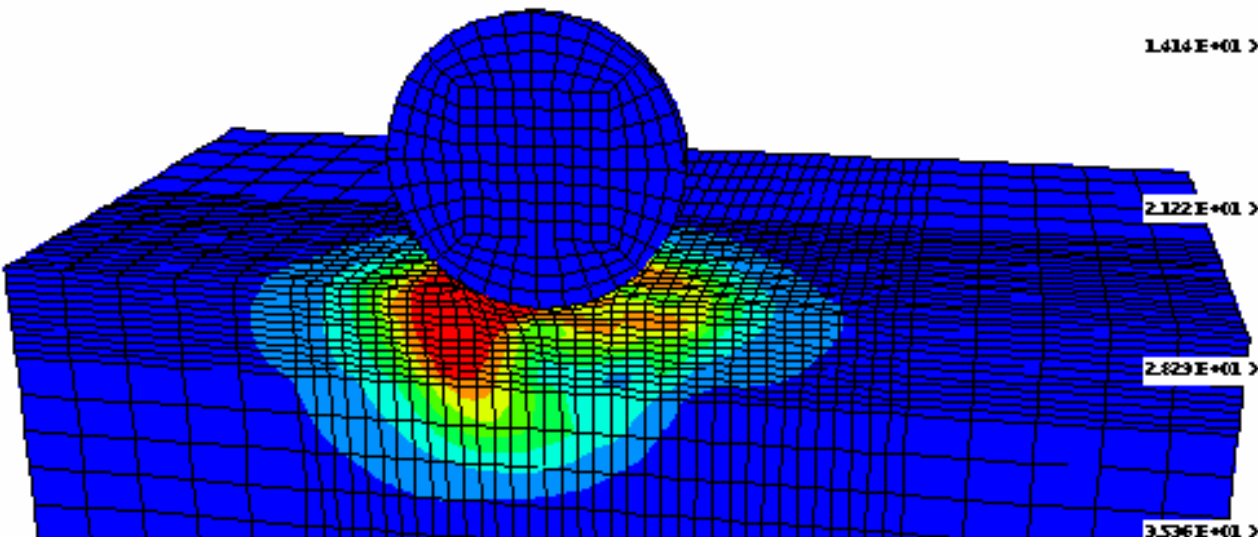

35S6E+4,

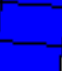

$240 \mathbf{3 E * 0 1}>$

$\mathbf{z}$

$\overbrace{\rightarrow}^{\mathbf{y}} \mathrm{x}$

$\operatorname{s.SSE+012}$

Figure 4.8.Fringes of Von Mises stresses for AL 6061-T0 plate impacted by $3 \mathrm{~mm}$ particle at $20 \mathrm{deg}$ with a velocity of $80 \mathrm{~m} / \mathrm{s}$ 
ANGULAR IMPACT AT 20 DEG 80M/S

time $=1.99995 \mathrm{E}-02$

tringe levels

bringes of eff. stress $(v-m)$

ac00E+cos?

$\min =0.000 \mathrm{E}+00$ in element 19010

$\max =5.495 \mathrm{E}+01$ in element 14236

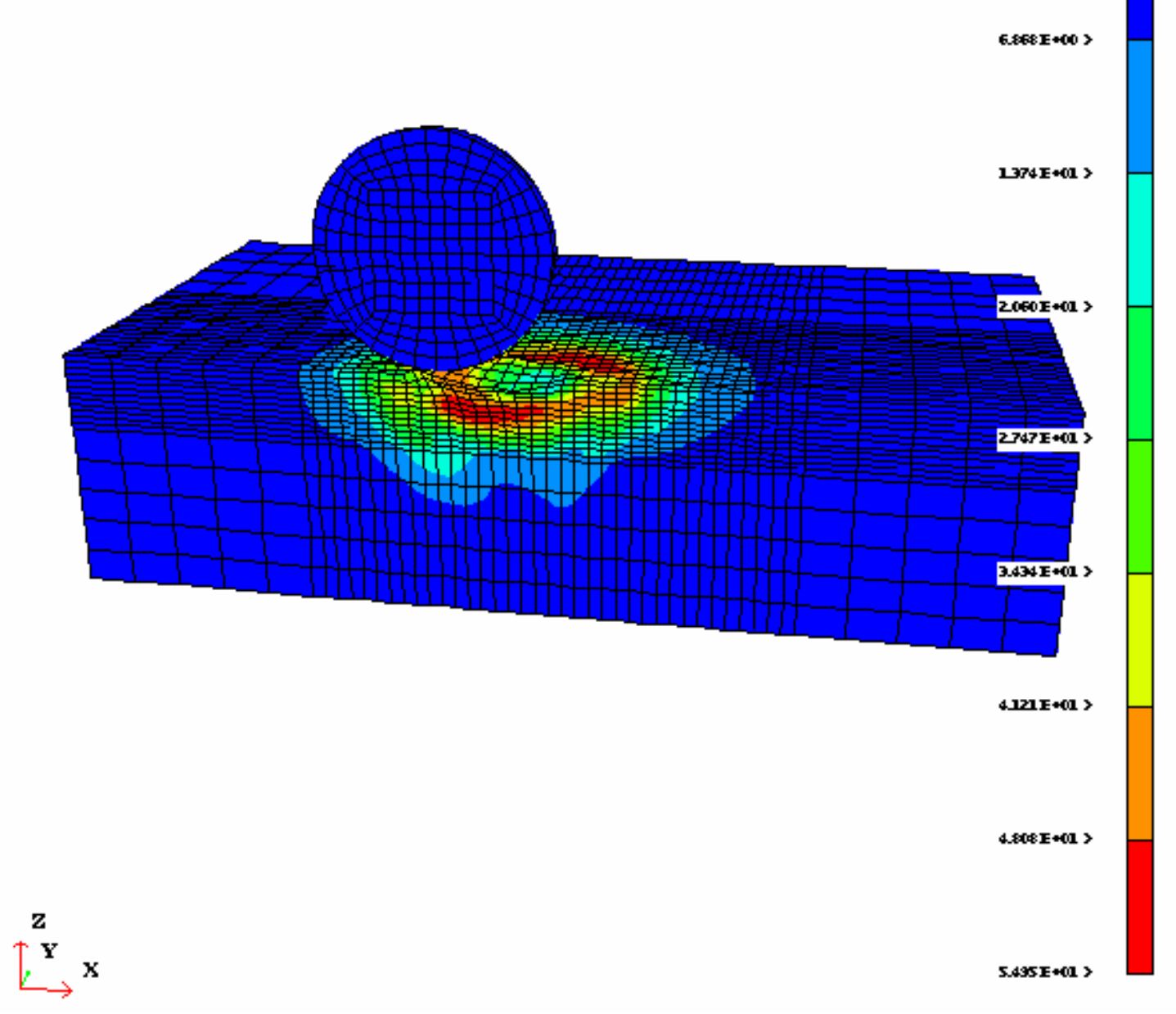

Figure 4.9. Fringes of Von Mises stresses for AL 6061-T0 plate impacted by 3mm particle at $20 \mathrm{deg}$ with a velocity of $80 \mathrm{~m} / \mathrm{s}$ 


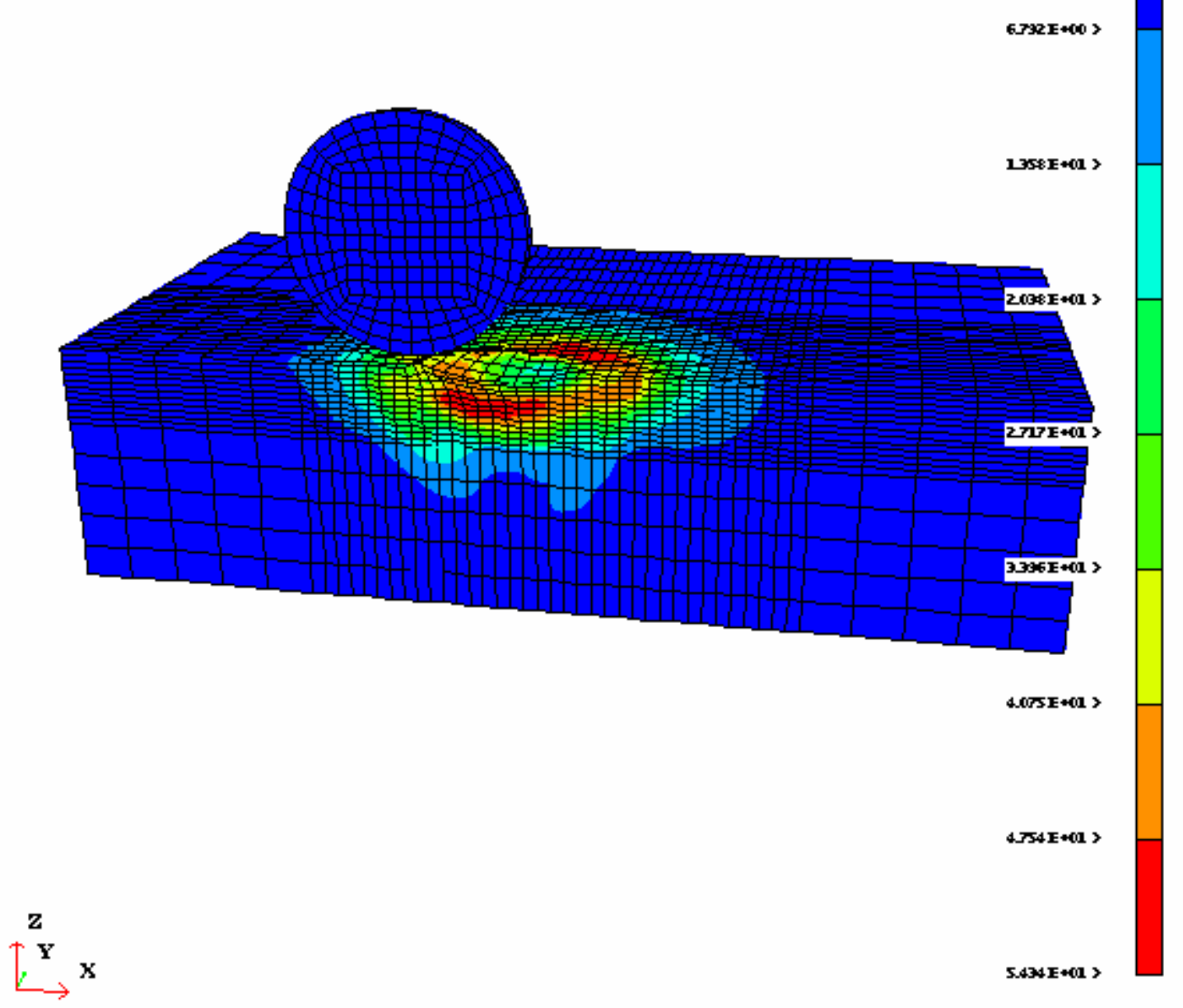

Figure 4.10 Fringes of Von Mises stresses for AL 6061-T0 plate impacted by $3 \mathrm{~mm}$ particle at $20 \mathrm{deg}$ with a velocity of $80 \mathrm{~m} / \mathrm{s}$ 
ANGULAR IMPACT AT 90 DEG 80M/S

time $=0.00000 \mathrm{E}+00$

bringes of eff. plastic strain

tringe levels

$\min =0.000 \mathrm{E}+00$ in element 19010

$\max =0.000 \mathrm{E}+00$ in element 19010

L

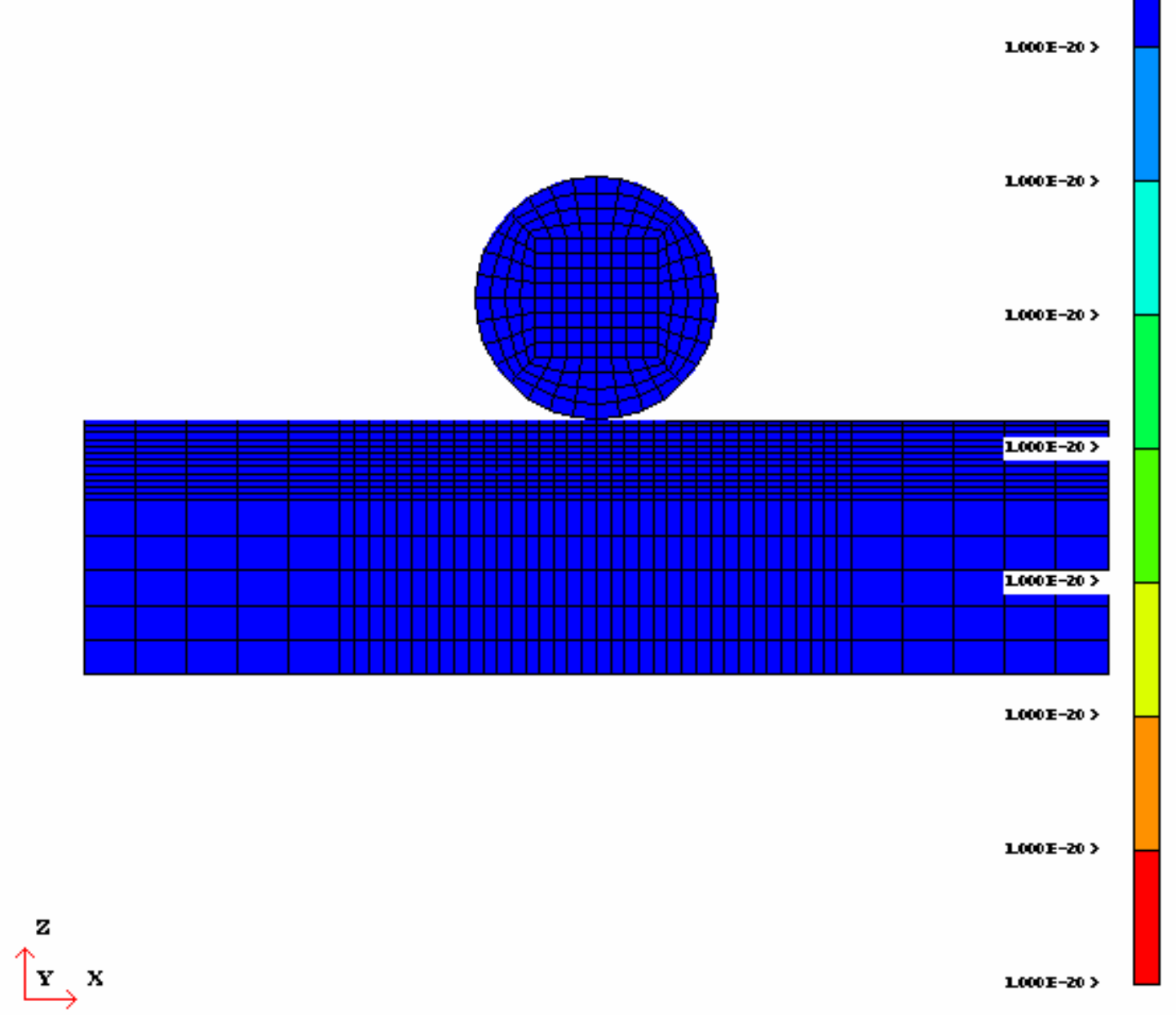

Figure 4.11. Fringes of plastic strain for AL 6061-T0 plate impacted by $3 \mathrm{~mm}$ particle at $90 \mathrm{deg}$ with a velocity of $80 \mathrm{~m} / \mathrm{s}$ 
acosecos?

$\min =0.000 \mathrm{E}+00$ in element 19010

$\max =2.307 \mathrm{E}-01$ in element $715 \%$

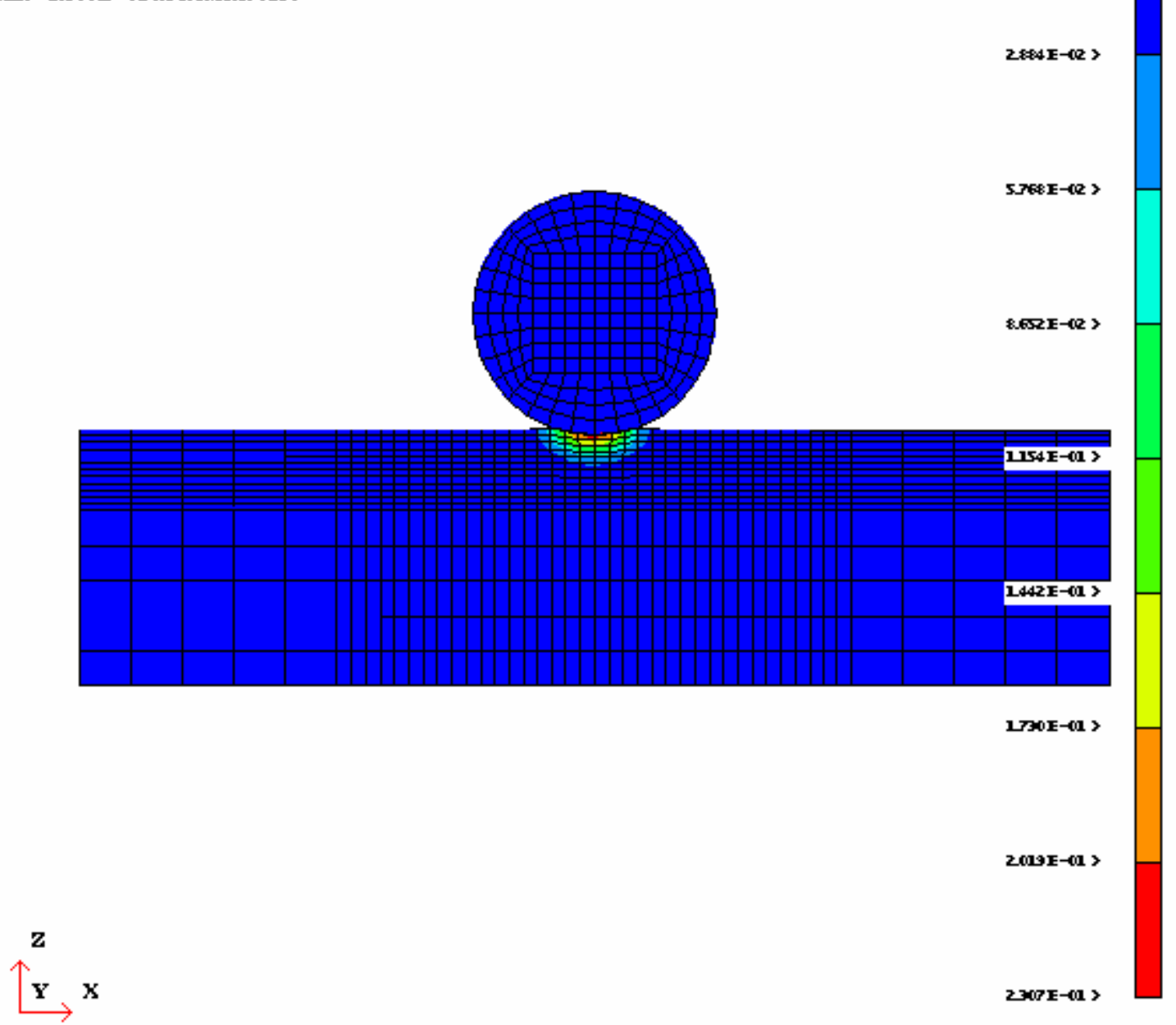

Figure 4.12 Fringes of plastic strain for AL 6061-T0 plate impacted by 3mm particle at $90 \mathrm{deg}$ with a velocity of $80 \mathrm{~m} / \mathrm{s}$ 
ANGULAR IMPACT AT 90 DEG 80M/S

time $=1.99724 \mathrm{E}-03$

돈

ringes of eff. plastic strain

tringe levels

$\min =0.000 \mathrm{E}+00$ in element 19010

$\max =4.673 \mathrm{E}-01$ in element 7157

acoosecos?

S.:41E-QR ?

LEEE-G >

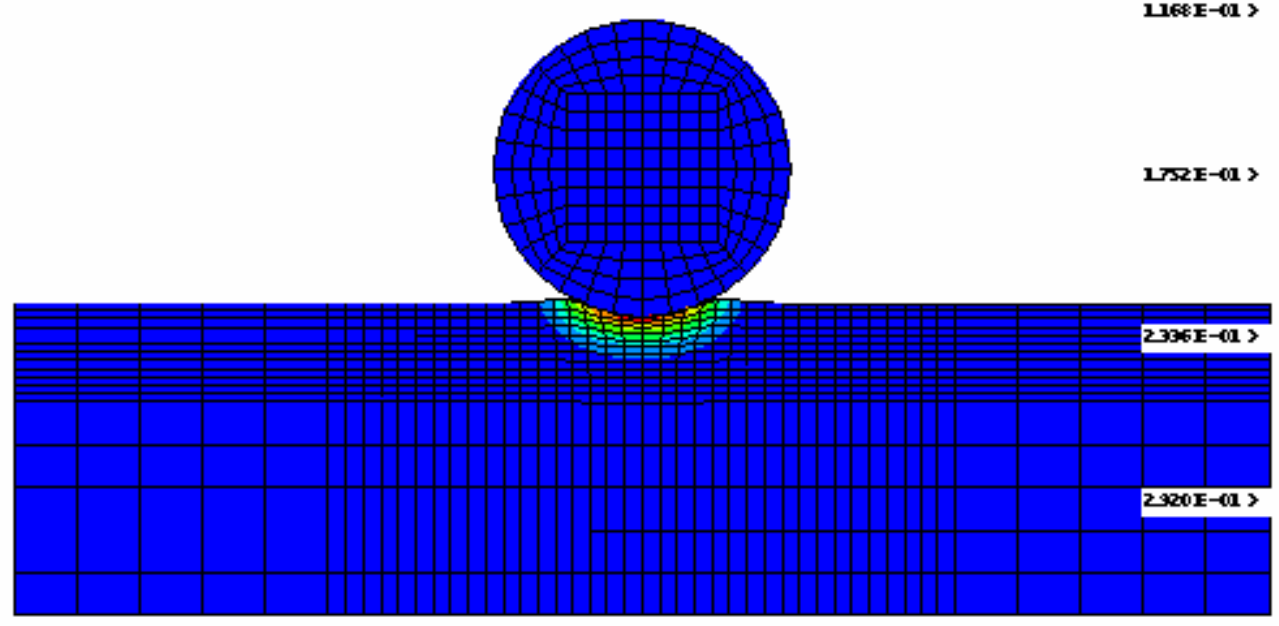

$3504 E-01$ >

$4.063 E-013$

Z

r $\mathrm{x}$

4.67FE-01 >

Figure 4.13 Fringes of plastic strain for AL 6061-T0 plate impacted by 3mm particle at $90 \mathrm{deg}$ with a velocity of $80 \mathrm{~m} / \mathrm{s}$ 
ANGULAR IMPACT AT 90 DEG 80M/S

time $=3.99626 \mathrm{E}-03$

ringes of eff. plastic strain

binge levels

$\min =0.000 \mathrm{E}+00$ in element 19010

$\max =1.010 \mathrm{E}+00$ in element $715 \%$

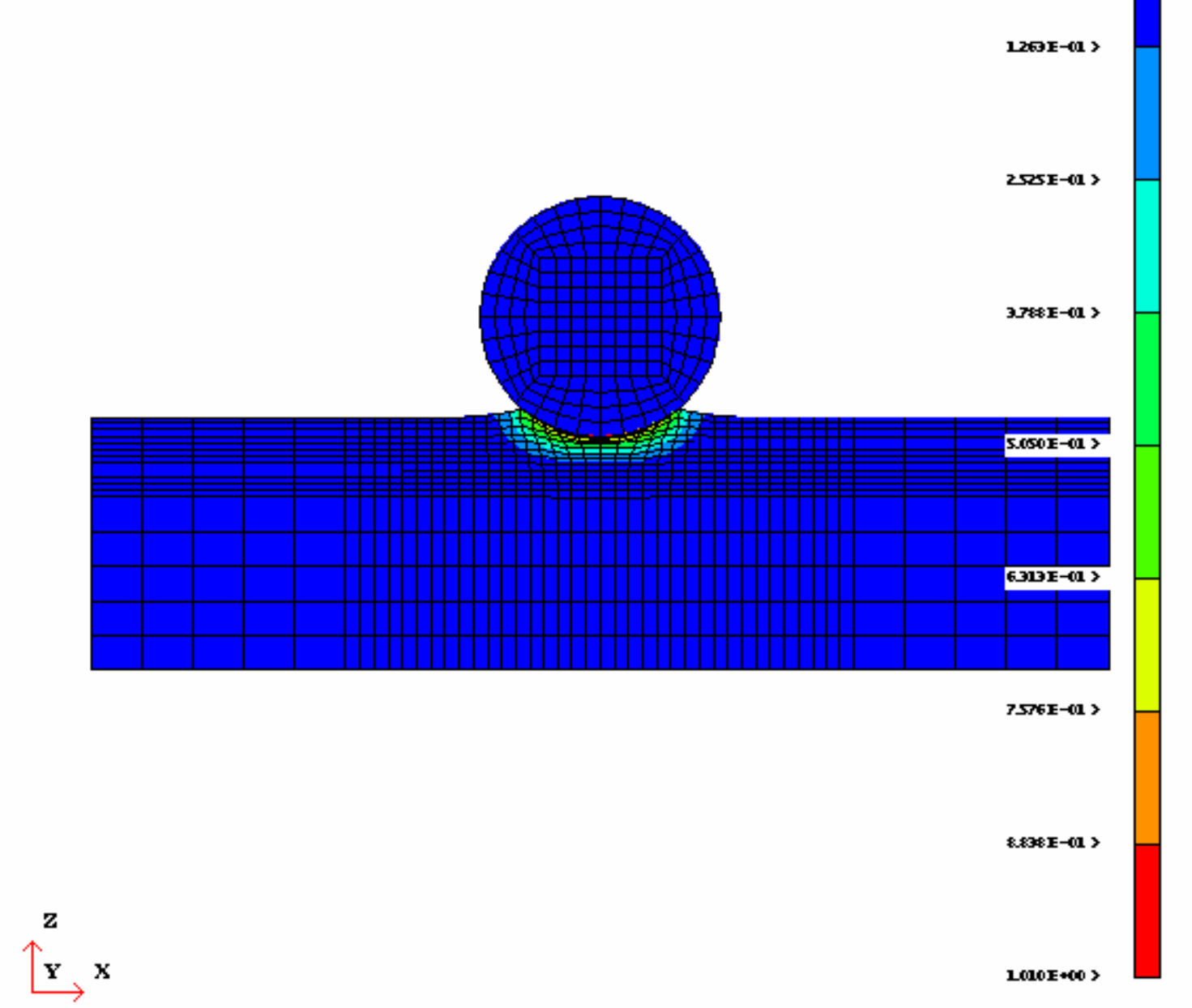

Figure 4.14 Fringes of plastic strain for AL 6061-T0 plate impacted by 3mm particle at $90 \mathrm{deg}$ with a velocity of $80 \mathrm{~m} / \mathrm{s}$ 
ANGULAR IMPACT AT 90 DEG 80M/S

time $=6.99923 \mathrm{E}-03$

tringes of eff. plastic strain

Ginge levels

ac00E*00 >

$\min =0.000 \mathrm{E}+00$ in element 19010

$\max =1.276 \mathrm{E}+00$ in element $715 \%$

LSSE-01 >

3.131E-01 >

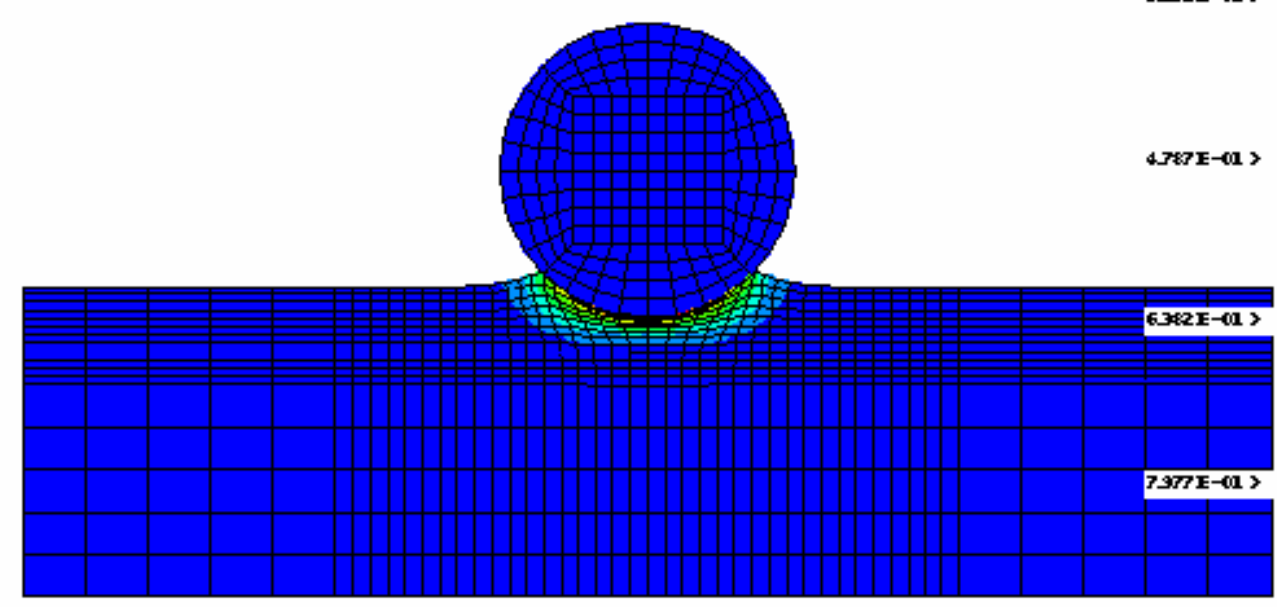

3STE-O1 >

U13E*00 >

$\mathbf{Z}$

$\stackrel{\mathbf{Y}}{\mathrm{x}}$

$12765 * 00$

Figure 4.15 Fringes of plastic strain for AL 6061-T0 plate impacted by 3mm particle at $90 \mathrm{deg}$ with a velocity of $80 \mathrm{~m} / \mathrm{s}$ 
ANGULAR IMPACT AT 90 DEG 80M/S

time $=2.50010 \mathrm{E}-02$

finges of eff. plastic strain

fringe levels

$0000 \mathrm{E}+00$ s

$\min =0.000 \mathrm{E}+00$ in element 19010

$\max =1.279 \mathrm{E}+00$ in element $715 \gamma$

LY9E-G >

3.\$E-0,

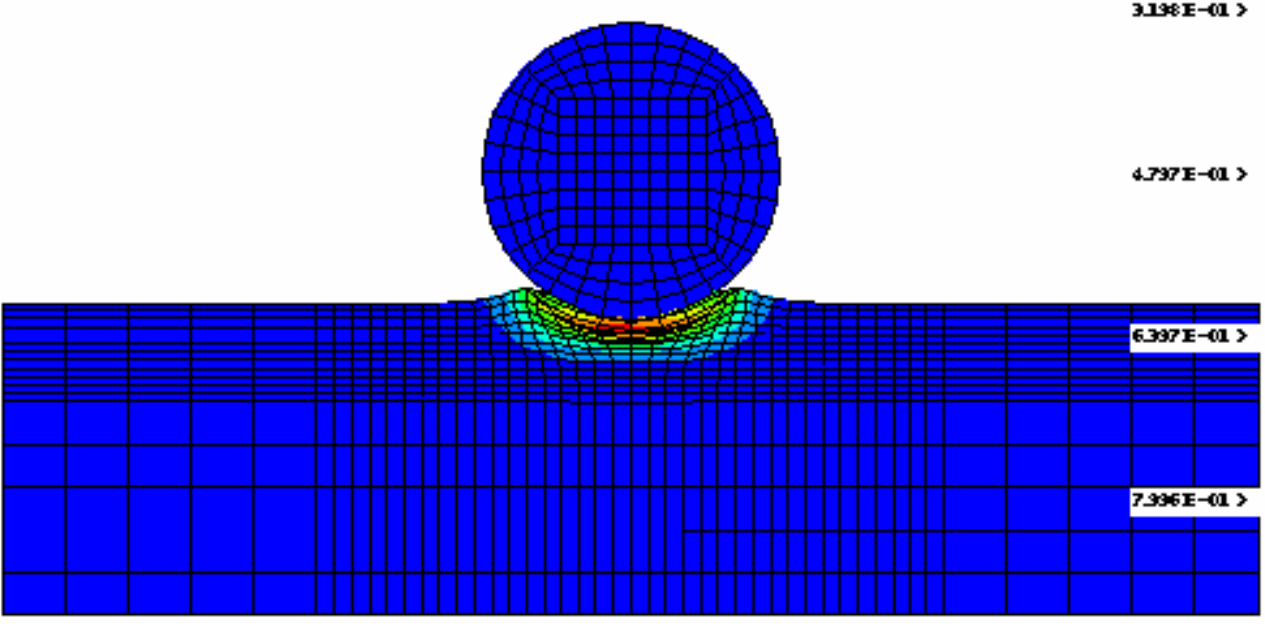

3SYSE-01 >

$\mathbf{Z}$

$\mathbf{Y}, \mathbf{x}$

L273F*00 >

Figure 4.16. Fringes of plastic strain for AL 6061-T0 plate impacted by $3 \mathrm{~mm}$ particle at $90 \mathrm{deg}$ with a velocity of $80 \mathrm{~m} / \mathrm{s}$ 


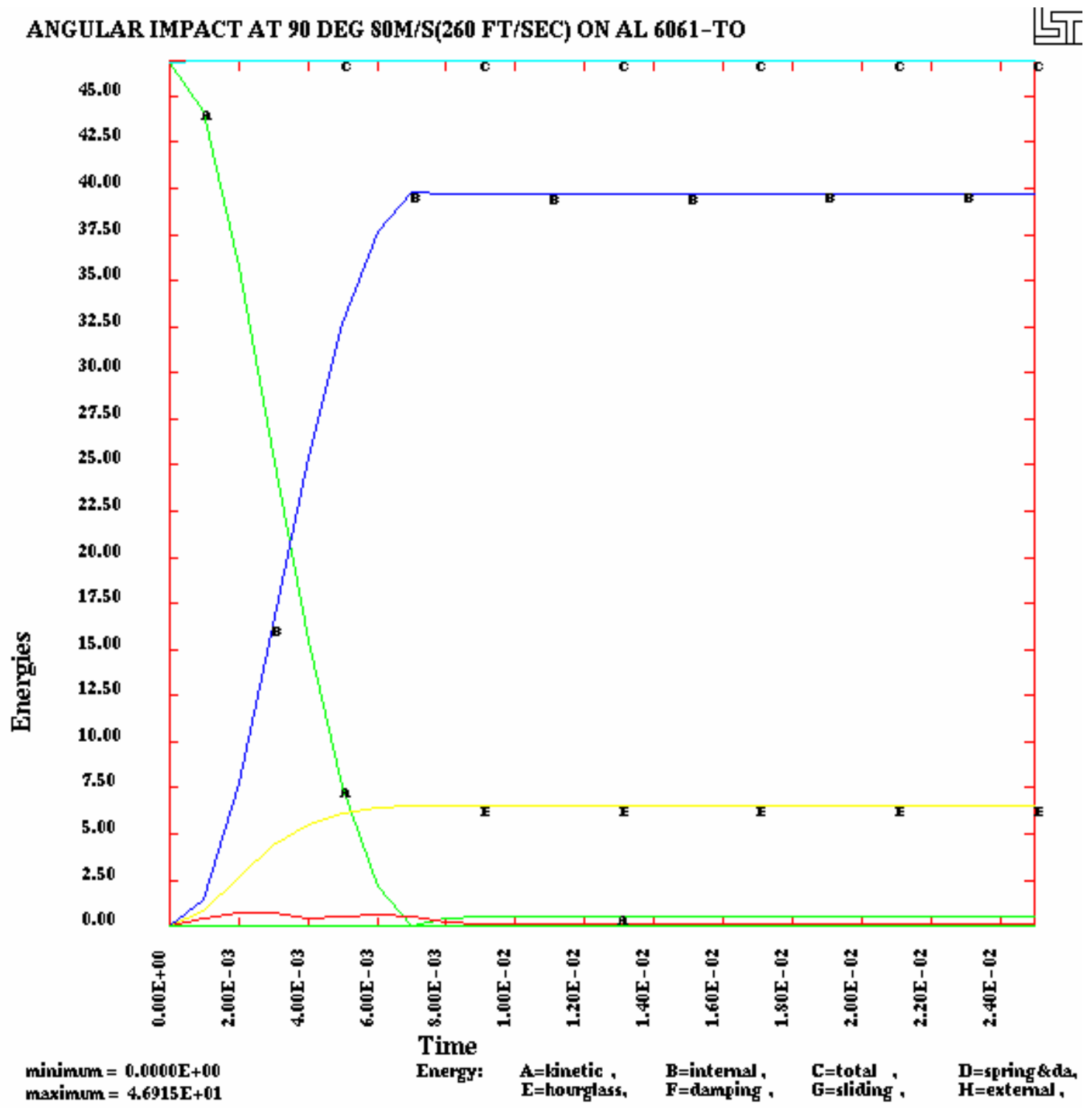

Figure 4.17. Energies Versus Time for normal impact 


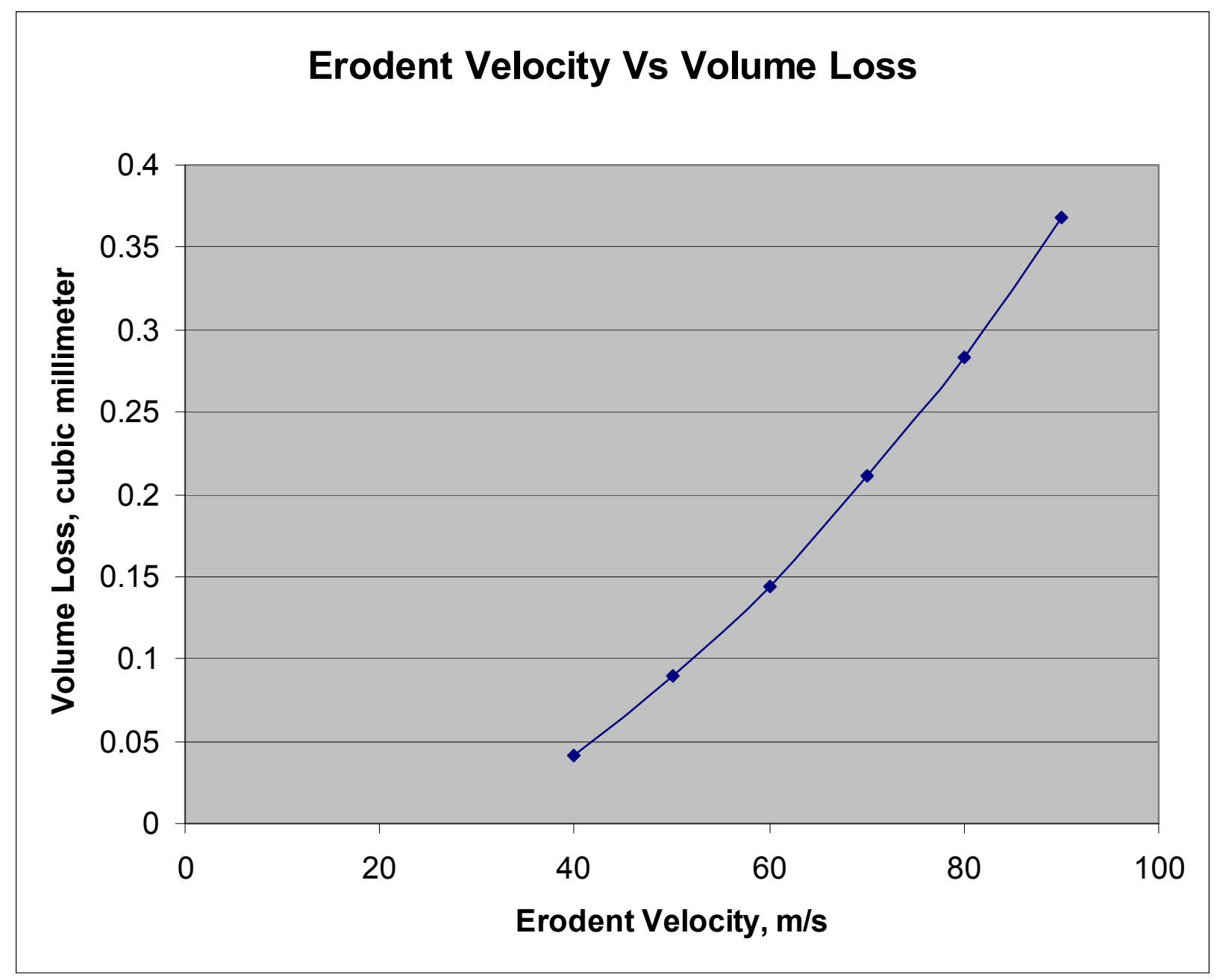

Figure 4.18 Erodent Velocity Vs Volume loss 


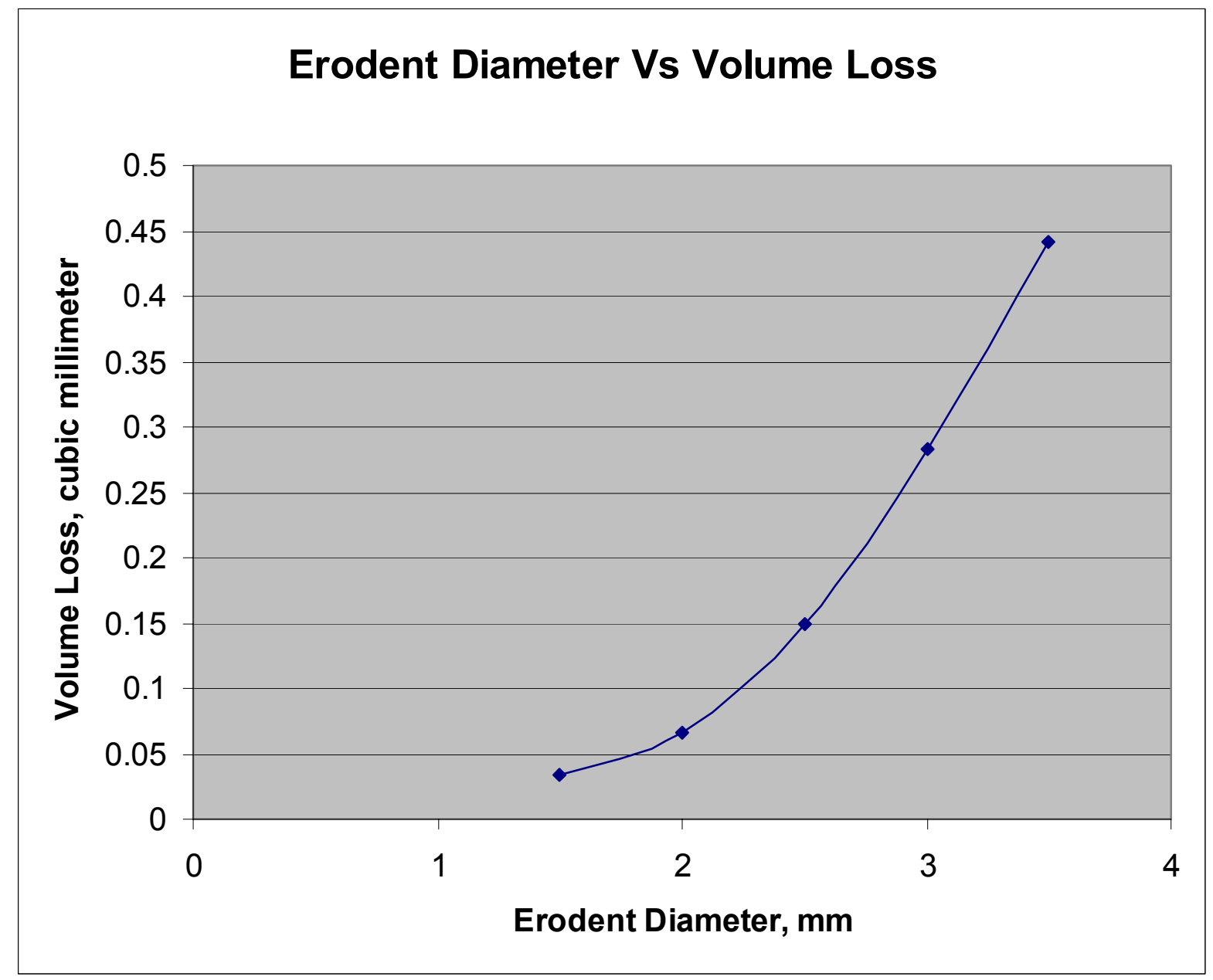

Figure 4.19 Erodent Diameter Vs Volume Loss 


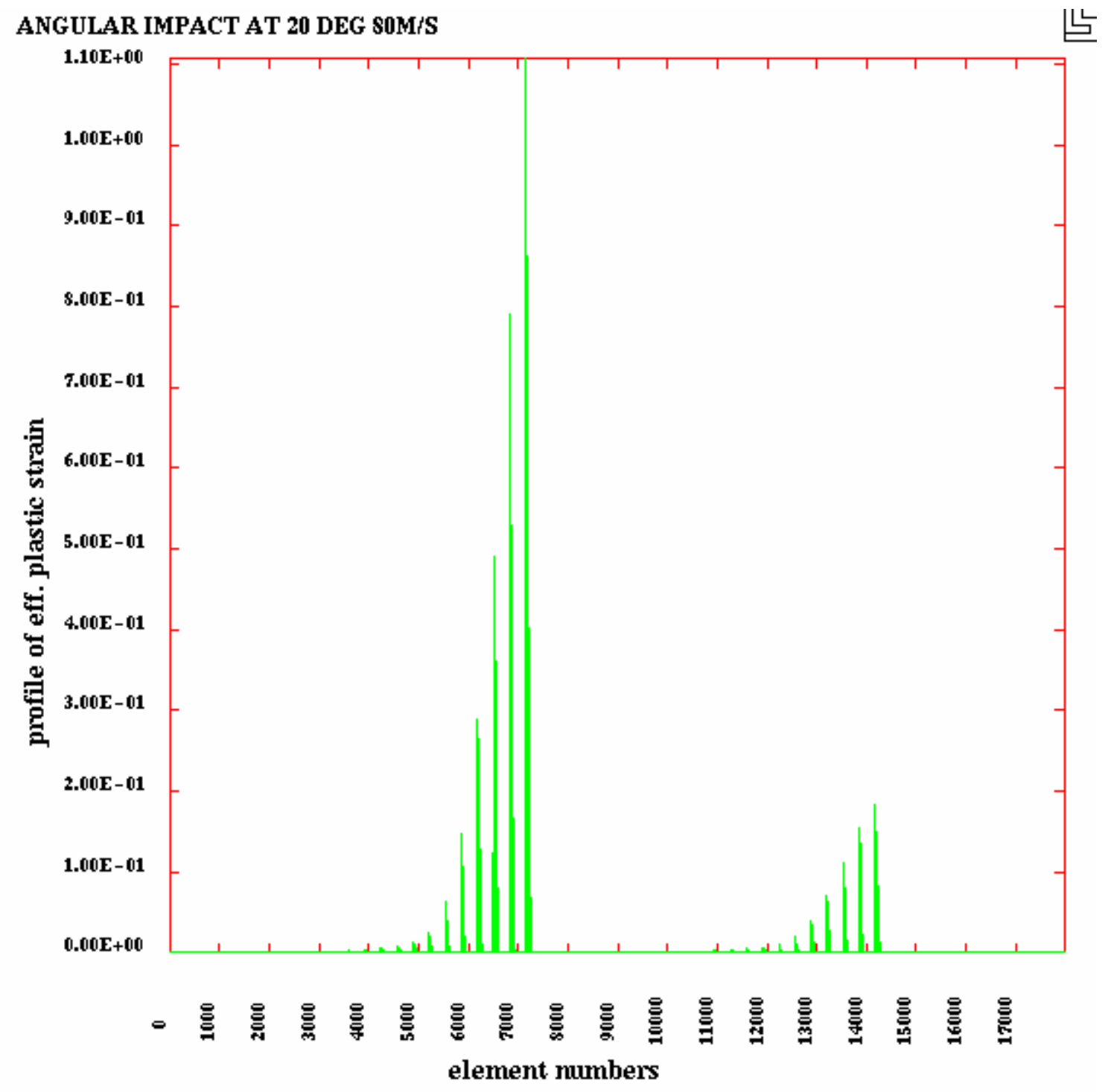

minimum $=0.0000 \mathrm{E}+00$ at element 17956 maximum $=1.1078 \mathrm{E}+00$ at element 7150

Figure 4.20. Profile of effective plastic strain AL 6061-T0 plate impacted by $3 \mathrm{~mm}$ particle at $20 \mathrm{deg}$ with a velocity of $80 \mathrm{~m} / \mathrm{s}$ 
ANGULAR IMPACT AT 90 DEG S0M/S

لـ

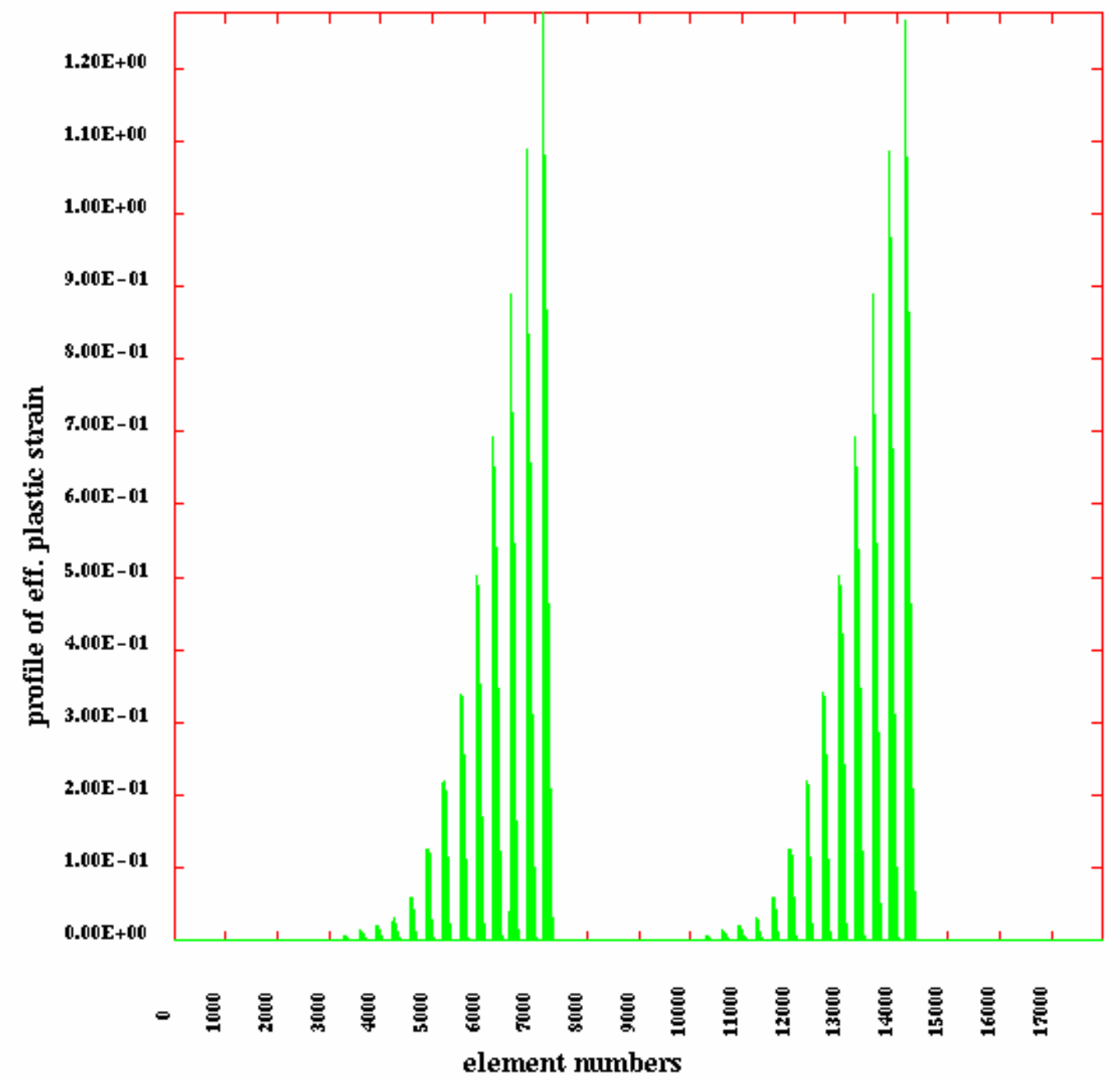

minimum $=0.0000 \mathrm{E}+00$ at element 17986 maximum $=1.2764 \mathrm{E}+00$ at element 7157

Figure 4.21. Profile of effective plastic strain AL 6061-T0 plate impacted by $3 \mathrm{~mm}$ particle at $90 \mathrm{deg}$ with a velocity of $80 \mathrm{~m} / \mathrm{s}$ 


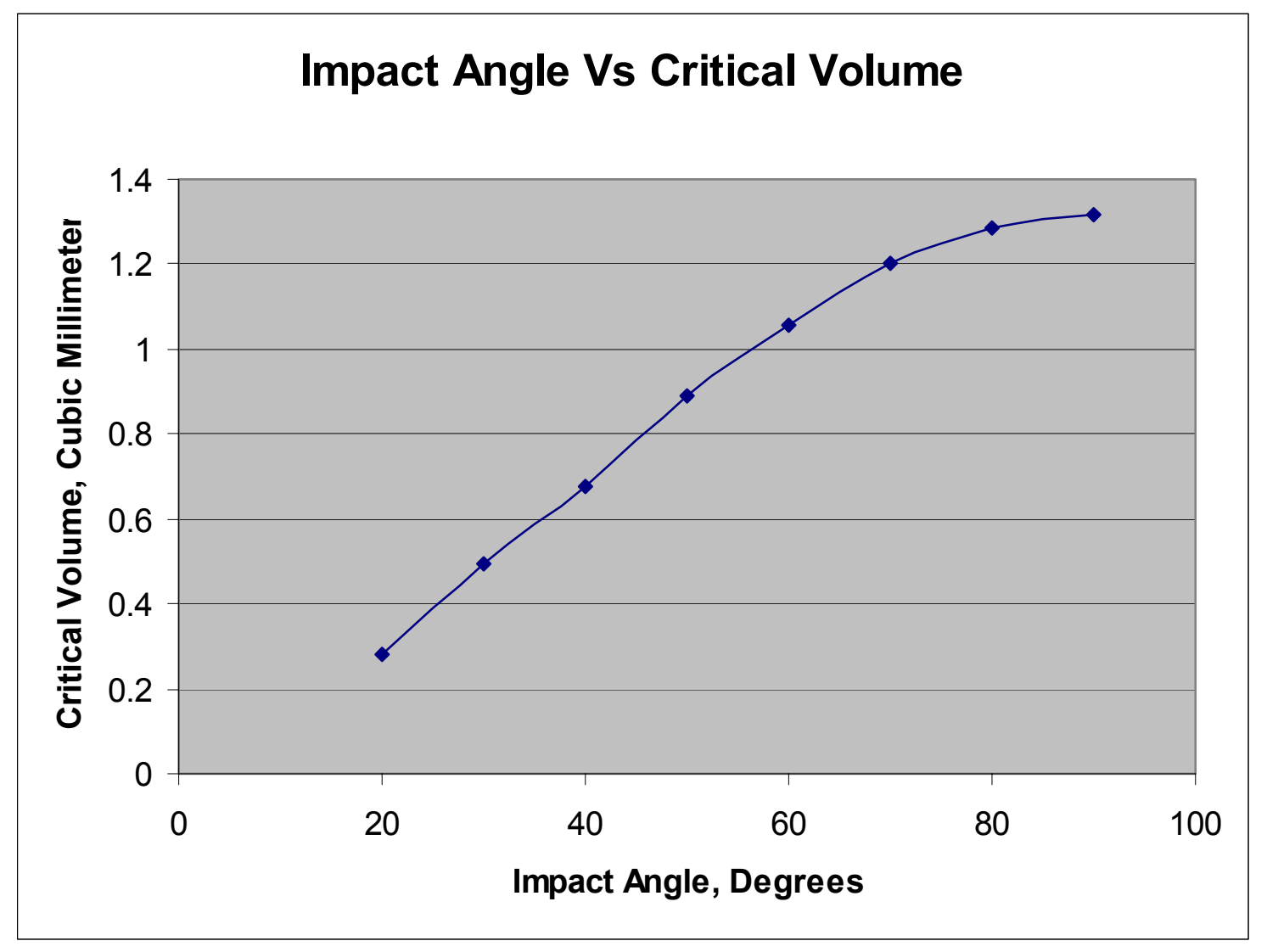

Figure 4.22 Impact Angle Vs Volume Loss

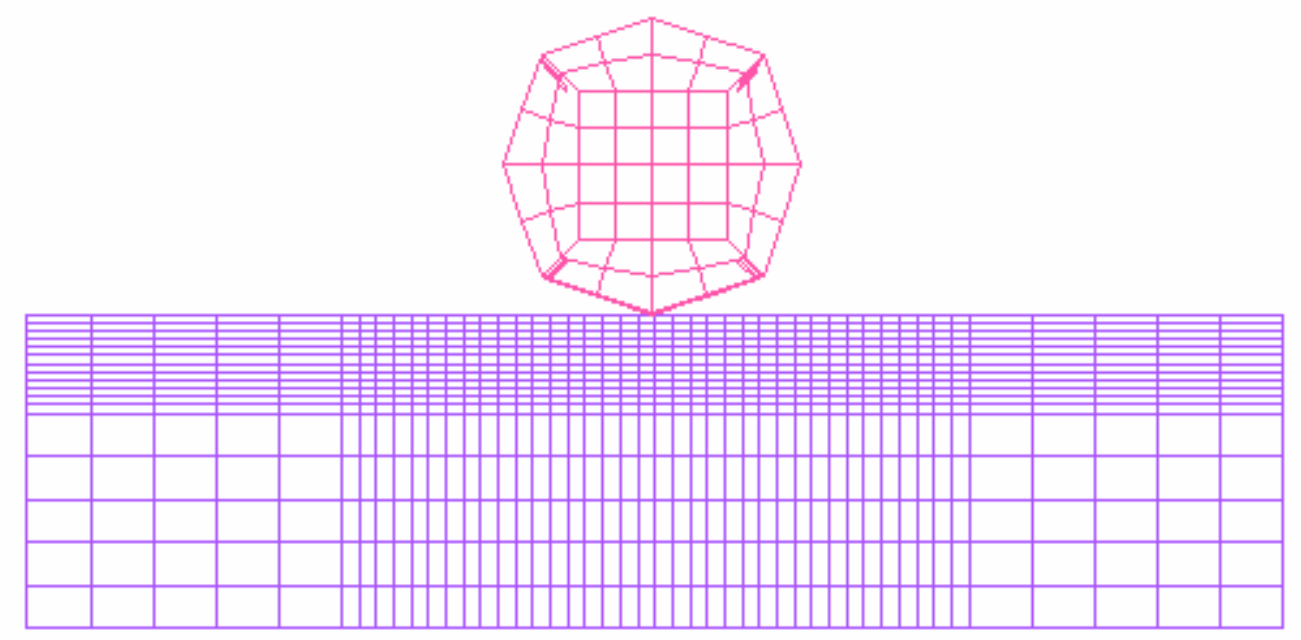

Figure 4.23. AL 6061-T0 Model with Octahedral Erodent 


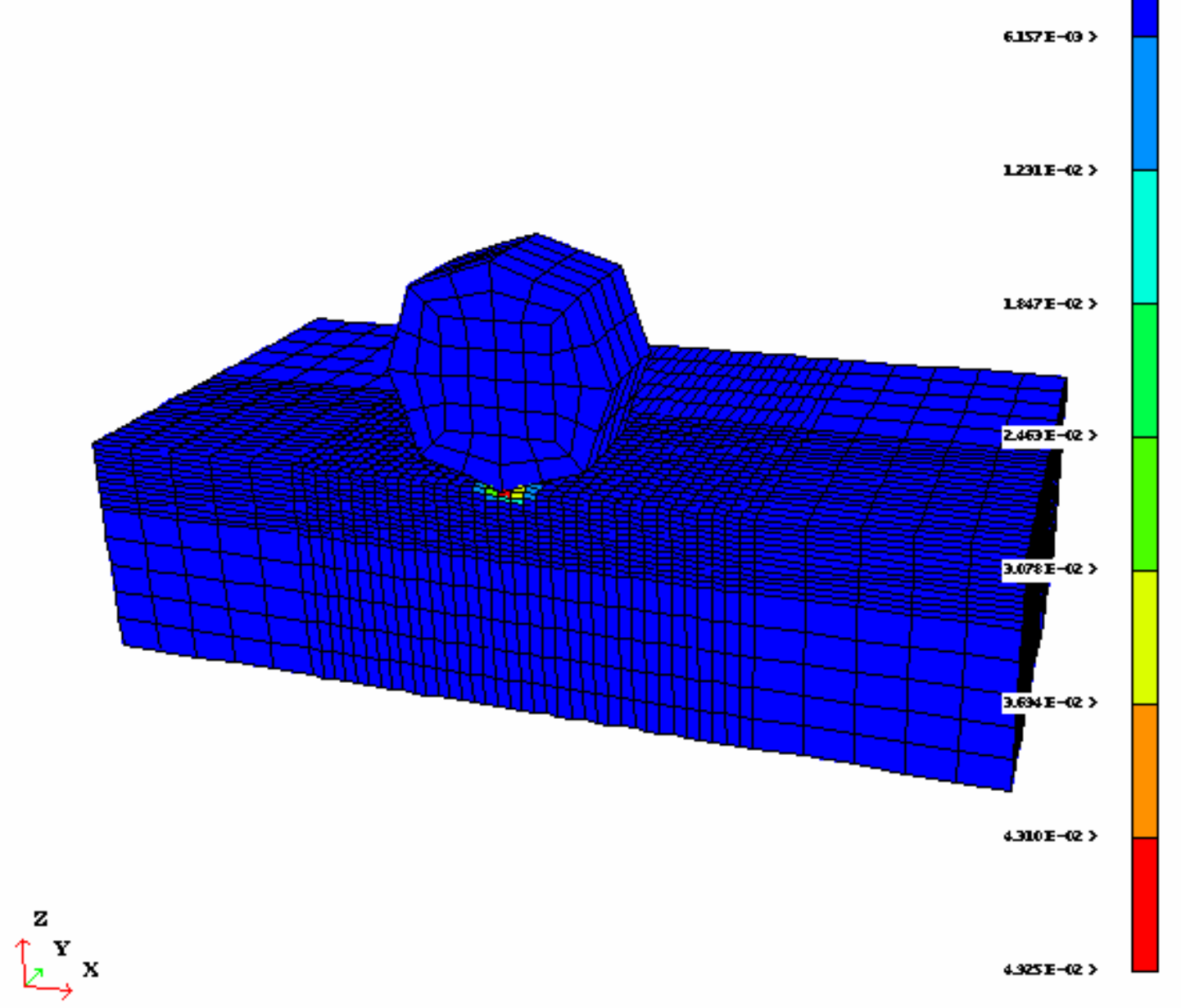

Figure 4.24. Fringes of plastic strain for AL 6061-T0 plate impacted by Octahedral Particle at $20 \mathrm{deg}$ with a velocity of $80 \mathrm{~m} / \mathrm{s}$ 
time = 7.99647E -03

bringes of eff. plastic strain

fringe levels

ac00E*00?

$\min =0.000 \mathrm{E}+00$ in element 17986

$\max =8.302 \mathrm{E}-01$ in element 7191

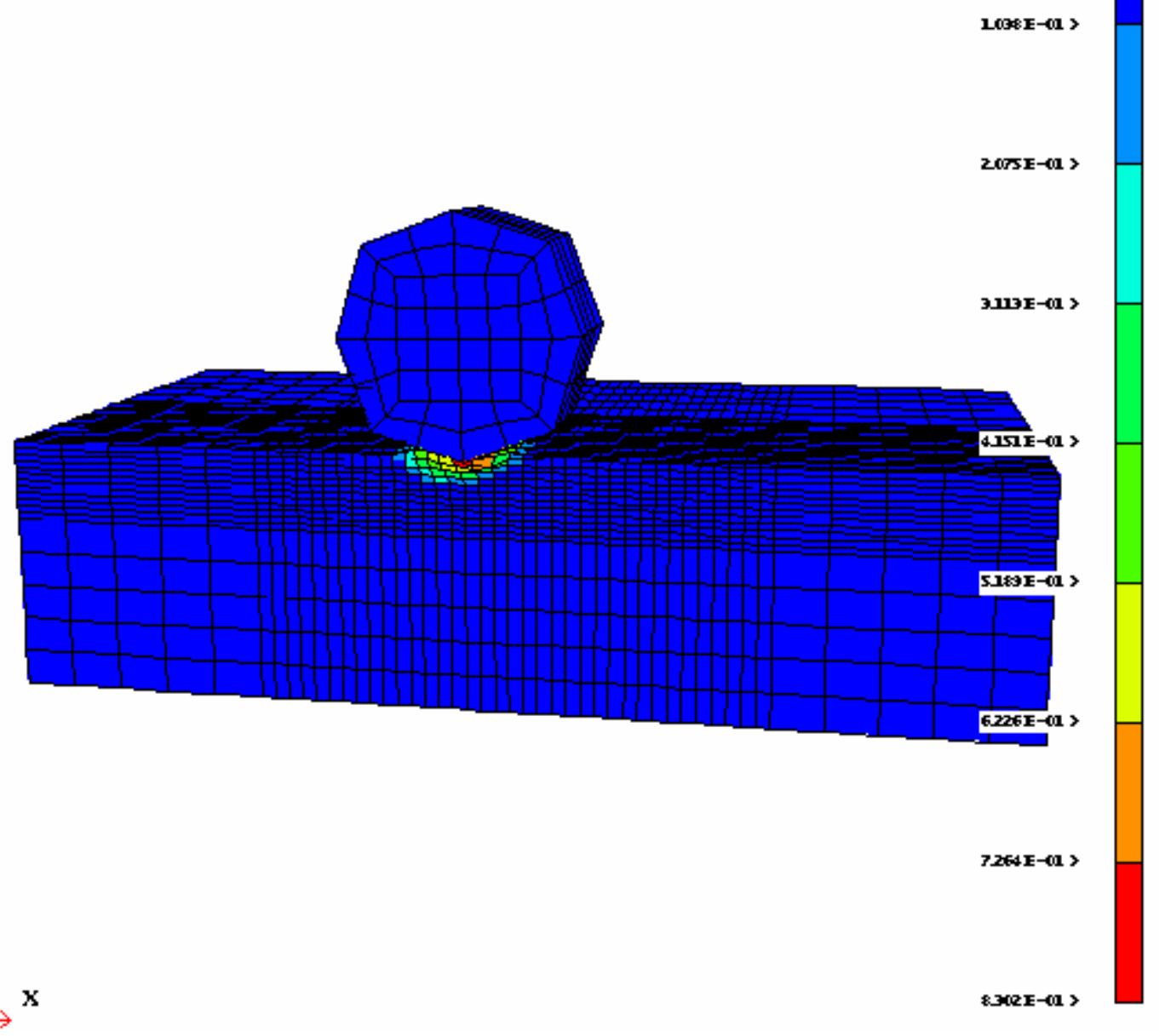

Figure 4.25. Fringes of plastic strain for AL 6061-T0 plate impacted by Octahedral particle at $20 \mathrm{deg}$ with a velocity of $80 \mathrm{~m} / \mathrm{s}$ 
time $=2.50056 \mathrm{E}-02$

tringe levels

tringes of eff. plastic strain

aco0entors

$\min =0.000 \mathrm{E}+00$ in element 17956

$\max =8.364 \mathrm{E}-01$ in element 7299

LOSSE-01 >

20031E-01 >

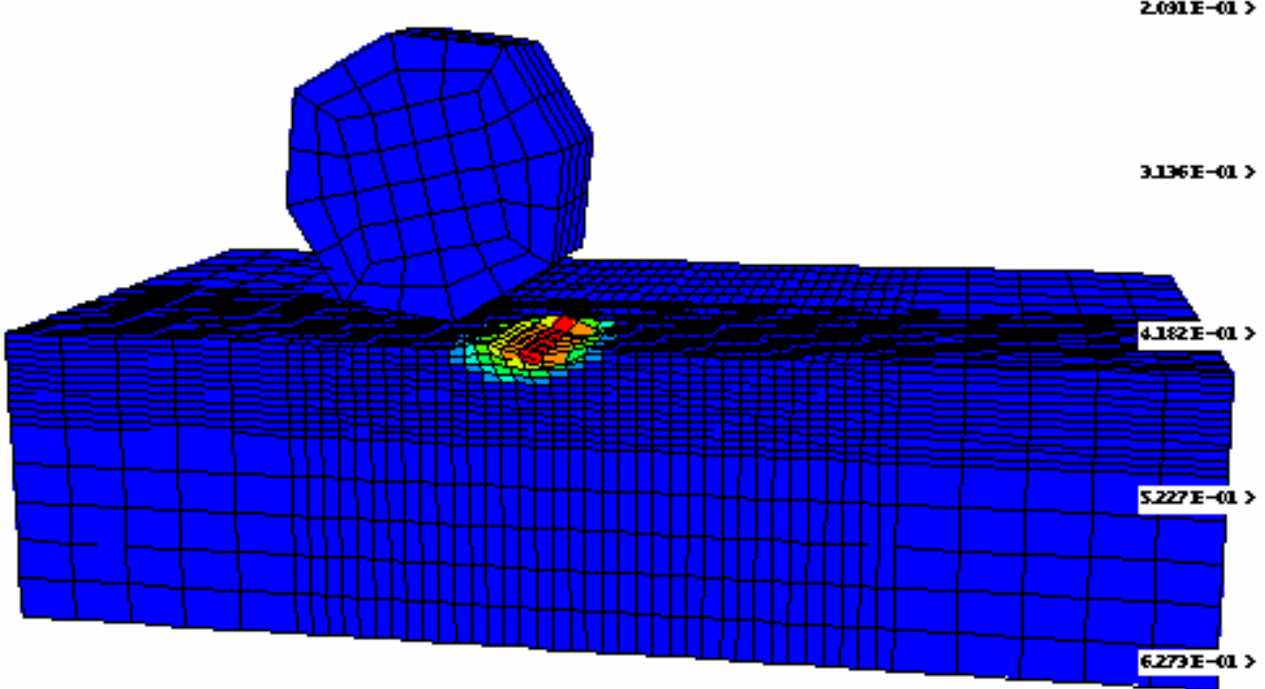

73ME-0) >

$\mathbf{z}$

$\lim _{\rightarrow} \mathbf{x}$

8364E-9) >

Figure 4.26 Fringes of plastic strain for AL 6061-T0 plate impacted by Octahedral particle at $20 \mathrm{deg}$ with a velocity of $80 \mathrm{~m} / \mathrm{s}$ 


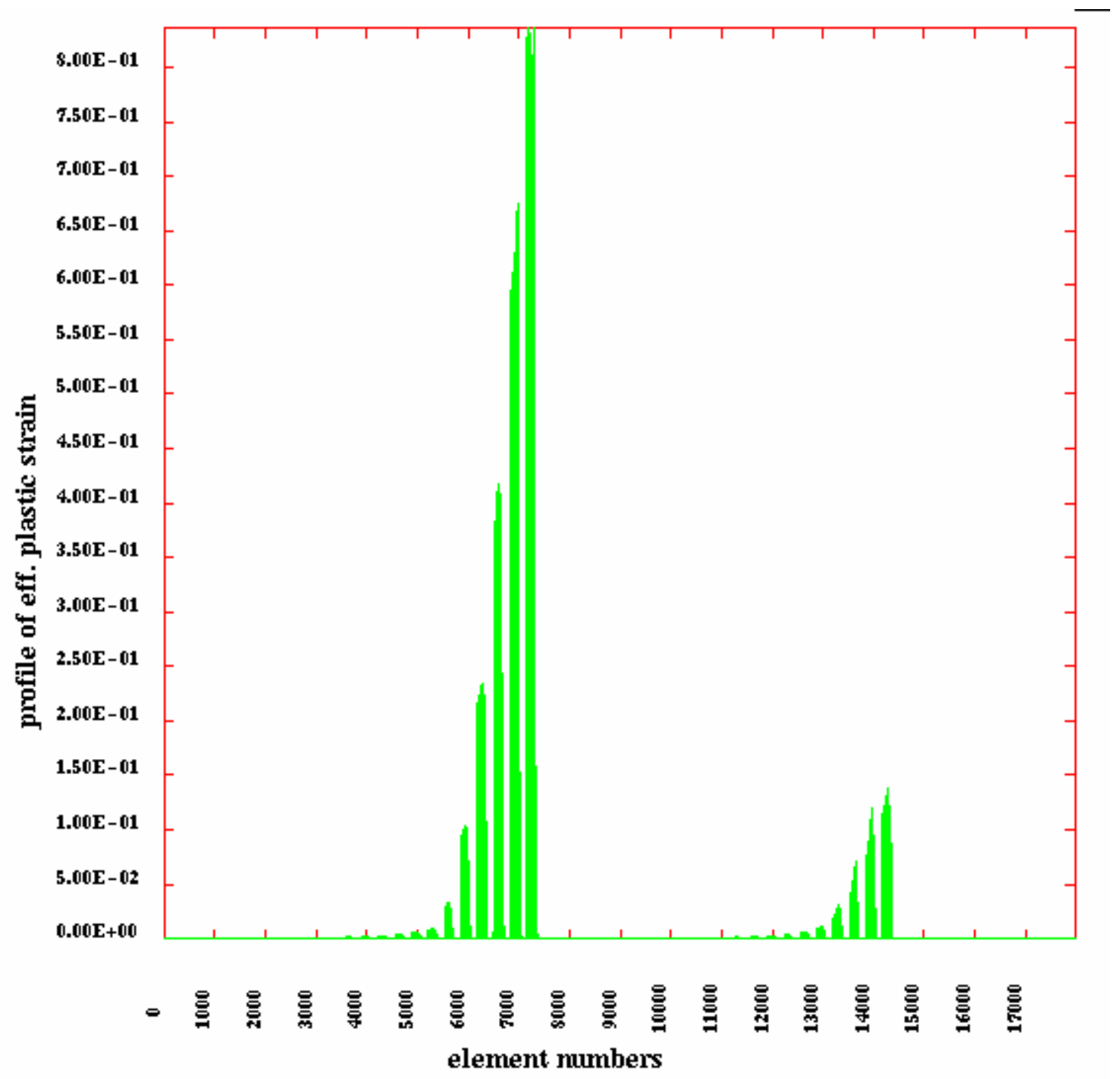

minimum $=0.0000 \mathrm{E}+00$ at element 17986 maximum $=8.3632 \mathrm{E}-01$ at element 7299

Figure 4.27. Profile of effective plastic strain AL 6061-T0 plate impacted by Octahedral particle at $20 \mathrm{deg}$ with a velocity of $80 \mathrm{~m} / \mathrm{s}$ 


\section{CHAPTER 5}

\section{CONCLUSIONS AND RECOMMENDATIONS}

\subsection{CONCLUSIONS}

The finite element results of Aluminum 6061-T0 model were compared quantitatively with the experimental results of Sheldon. The erosion loss of the finite element model showed variation with the experimental results. This variation was accounted to the rounding error in Finite Element Method because the erosion loss was estimated finding the volume of the critical elements, which were above a certain critical strain. This volume of critical elements may not be lost due to erosion only a fraction of this critical volume, may actually be lost when the elements above the critical strain are strained enough to fracture. Here critical strain value taken from the uniaxial tension test was used as failure strain value. This failure strain value obtained from the tension test must be less than the plastic strain value in the FEM model, which was under dynamic loading and multiaxial state of stress. So a large number of elements were picked as critical elements thus giving the large value for critical volume loss.

The other factors velocity, size and shape of erodent dependence on volume loss were in consistent with the theoretical studies. The effect of angle of impact on volume loss showed a little variation with the theoretical results.

The Finite Element results of erodent size, velocity and impact angle dependence on volume loss were compared qualitatively with the theoretical results.

The major parameter that was tested was velocity of the impacting particle. The analysis was performed for several velocities ranging from 40 to $90 \mathrm{~m} / \mathrm{s}$. The $3 \mathrm{~mm}$ diameter of the particle was impacted on to the target at $20^{\circ}$ angle. The maximum volume loss occurred at the maximum kinetic energy of the particle with $3 \mathrm{~mm}$ diameter. The volume loss increased with the increase in the velocity of the particle. The velocity exponent obtained from Finite Element Method was 2.65, which was in good agreement with that given in theoretical studies.

The variation of volume loss with the size of the particle ranging from 1.5-3.5 mm

was studied by keeping the velocity and angle of attack constant at $80 \mathrm{~m} / \mathrm{s}$ and at $20^{\circ}$. The 
volume loss of the target material increases with the size of the particle, which is also consistent with the theory for erosion loss dependence on erosion sizes for ductile materials. The size exponent obtained from the erodent size vs volume loss graph was 3.12 , which is in good agreement with the value obtained from the theory. According to this theory erosion loss increases up to certain critical size after that it is independent of the size.

The third parameter that was studied was effect of angle of impact on volume loss of the target material with a velocity of $80 \mathrm{~m} / \mathrm{s}$. The angle of impact varied from $20-90$ deg by keeping the particle size constant at $3 \mathrm{~mm}$. There was a variation between the FEM results and theoretical results with volume loss dependence on angle of attack. This is because of more elements picked at normal incidence and very low elements picked at glancing angles.

The shape of the particle was studied at constant velocity $80 \mathrm{~m} / \mathrm{s}$ and impact angle

$20^{\circ}$. The analysis was performed with two different shapes in which one has point contact and the other one has line contact. The volume loss was more when the Aluminum plate was impacted by the particle with line contact than with point contact. Since the area of contact more in line contact particle with the target metal surface.

\subsection{RECOMMENDATIONS FOR FUTURE WORK}

A failure criterion was based on the critical plastic strain than von mises stress for ductile materials to estimate the erosion loss of the material. This erosion loss estimation would be better by improving the failure strain criteria. Here single particle impact was considered and no previous impacts on the target material. But in real life multiple particles impact the surfaces and pipe bends. So this work can be extended to multiple particle impacts. In the current work low velocities were considered so that temperature was neglected. Temperature should be considered for particles impacting with ballistic velocities. 


\section{BIBLIOGRAPHY}

1. C.E. Smeltzer, M.E. Gulden, W.A. Compton, "Mechanisms of Metal Removal by Impacting Dust Particles," Transactions of the ASME, 1970, p. 639-654.

2. Sheldon, G.L. and Kanhere, A., "An Investigation of Impingement Erosion using Single Particles,” Wear, Vol. 21, 1972, p.195-209

3. G.L.Sheldon, "Similarities and Differences in the Erosion Behavior of Materials," Journal of Basic Engineering Vol. 92, 1970, p. 619-626.

4. Iain, Finnie, "Erosion of Surfaces by Solid Particles," Wear Vol. 3, 1960, p. 87103

5. J.G.A. Bitter, “A Study of Erosion Phenomena Part II," Wear, Vol.6, 1963, p.169190

6. G.P.Tilly, "Sand Erosion of Metals and Plastics: A Brief Review," Wear, Vol.14, 1969, p.241-248.

7. G.P. Tilly, "A Two Stage Mechanism of Ductile Erosion," Wear, Vol. 26, 1973, p. $87-96$

8. Hutchings, I.M. and Winter, R.E., "Particle Erosion of Ductile Metals: A Mechanism of Material Removal," Wear, Vol. 27, 1974, p. 121-128

9. Sheldon, G.L., and Finnie, I., "The Mechanism of Material Removal in the Erosive Cutting of Brittle Materials," Journal of Engineering for Industry, Trans. ASME, Series, Vol.88, 1966, p.387.

10. Evans, A.G., Gulden, M.E., and Rosenblatt, M., "Impact Damage in brittle Materials in the Elastic-Plastic Response Regime," Proc. R. Soc. (London) A, Vol. 361, 1978, pp. 343-365.

11. Wiederhorn, S.M. and Lawn, B.R., "strength Degradation of Glass Impacted with Sharp Particles," Journal of American Ceramics Society, Vol. 62, 1979.

12. Mehrotra, P.K., Sargent, G.A., and Conrad, H., “ A Model for the Multi-Particle Erosion of Brittle Solids by Spherical Particles," Corrosion-Erosion Behavior of Materials, TMS-AIME, 1980, p. 127-145.

13. Finnie, I., "Some Observations on the Erosion of Ductile Metals," Wear, Vol. 19, 1972, p. $81-90$ 
14. G.P.Tilly and Wendy Sage, "The Interaction of Particle and Material Behavior in erosion Processes,” Wear, Vol. 16,1970,p.447-465.

15. B.F.Levin, K.S.Vecchio, J.N.Dupont, and A.R.Marder, “ Modeling Solid-Particle Erosion of Ductile Alloys," Metallurgical and Materials Transactions A, Vol. 30A, July 1999, p.1763-1774.

16. Shanmuga S. Balasubramaniyam, "Computational Modeling of Brittle Impact Erosion Mechanisms," Master's Thesis, Dept. of Mech Engg, West Virginia University, Morgantown, December 1998.

17. Hutchings IM, Winter RE, Field JE., "Solid Particle Erosion of Metals: The Removal of Surface Material by Spherical Projectiles,” Proc R Soc London, Ser A, Vol. 348, 1976, pp. 379-392.

18. I.M. Hutchings and A.V. Levy, "Thermal Effects in the Erosion of Ductile Metals," Wear, Vol.131, 1989, p.105-121.

19. Iain, Finnie, "Some Reflections on The Past And Future of Erosion," Wear Vol. 186-187, 1995, p. 1-10

20. G.P.Tilly, "Erosion Caused by Airborne Particle," Wear, Vol.14, 1969, p.63-79

21. Finnie, I., "The Mechanism of Erosion in Ductile Materials," Proc. of the Third US National Congress of Applied Mechanics, Hagthormthwaite, R.M., Ed., ASME, New York, 1958, p. 70-82

22. Ives, L.K. and Ruff, A.W., Wear, Vol. 46, p. 149-162.

23. Hutchings, I.M., "A Model for the Erosion of Metals by Spherical Particles at Normal Incidence,” Wear, 1981, Vol. 70, p. 269-281

24. Sundararajan, G. and Shewmon, P.G., "A New Model for the Erosion of Metals at Normal Incidence,” Wear, 1983, Vol. 84, p.237-258

25. Tabor, D., “The hardness of Metals," Clarendon, oxford, 1951.

26 Livermore Software Technology Corporation, "LS-DYNA3D Theoretical Manual," May 1998

27 Livermore Software Technology Corporation, "LS-TAURUS User'sManual,'1998 
28 Chandrakant Rai, "Computational Model of Ductile Erosion by Single Particle Impact," Master's Thesis, Dept. of Mechanical Engineering, West Virginia University, Morgantown, 2000. 


\section{APPENDIX A}

\section{SAMPLE INPUT INGRID FILE}

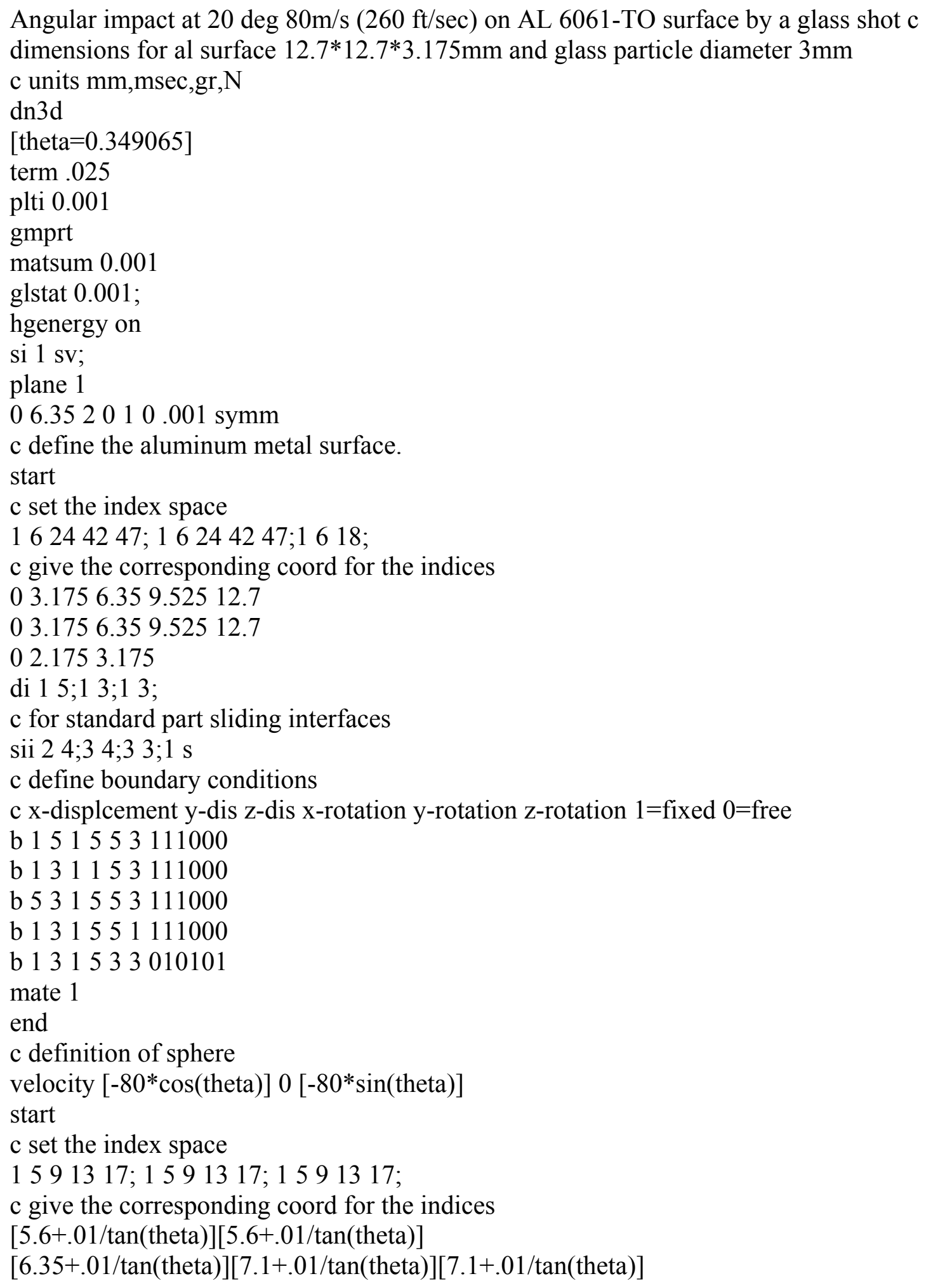


5.65 .66 .357 .17 .1

3.9353 .9354 .6855 .4355 .435

$\mathrm{c}$ delete the regions at the edges of the cube

di $12045 ; 12045$; ;

di 12045 ; ; 1204 5;

di ;1 $2045 ; 12045$;

c project the boundary to a spherical surface

sfi -1 -5; -1 -5; -1 -5; sp [6.35+.01/tan(theta)] 6.354 .6851 .5

$\mathrm{c}$ define the slinding interface

sii $-1-5 ; 3-5 ;-1-2 ; 1 \mathrm{~m}$

c delete the symmetry part of the sphere

d 111535

b 131535010101

mate 2

end

c define the material properties

mat 124

pr .33

e $68.9 \mathrm{e}+03$

ro $2.7 \mathrm{e}-03$

sigy 55.2

etan $1.06 \mathrm{e}+03$

endmat

mat 220

pr.19

e $68 \mathrm{e}+03$

ro $2.11 \mathrm{e}-03$

endmat

end 


\section{*KEYWORD}

\section{APPENDIX B \\ SAMPLE INPUT FILE FOR LS-DYNA3D}

*TITLE

Angular impact at $20 \mathrm{deg} 80 \mathrm{~m} / \mathrm{s}(260 \mathrm{ft} / \mathrm{sec})$ on AL $6061-\mathrm{TO}$ surface by a glass particle

*CONTROL_TERMINATION

$0.0250000-00.0000000 \quad 00.0000000$

*CONTROL_TIMESTEP

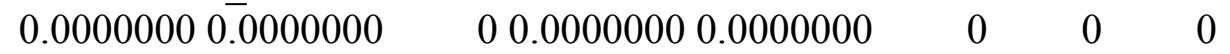

*CONTROL SHELL

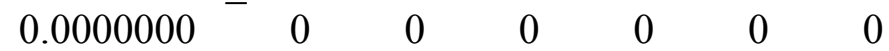

*CONTROL_DAMPING

$00.00000000 .00000000 .00000000 .0000000 \quad 00.0000000 \quad 0$

*CONTROL_CONTACT

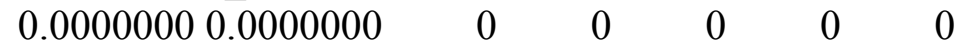

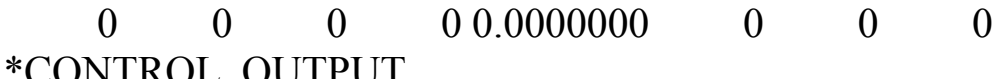

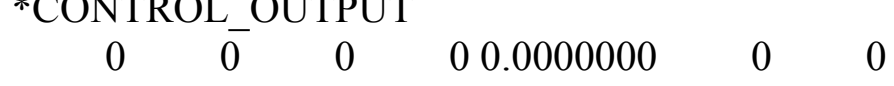

*CONTROL_ENERGY

$\begin{array}{llll}2 & 2 & 1 & 1\end{array}$

*DATABASE_BINARY_D3PLOT

1.00000-3

*DATABASE_EXTENT_BINARY

$\begin{array}{llllllll}0 & 0 & 0 & 0 & 0 & 0 & 0 & 0\end{array}$

*DATABASE_GLSTAT

1.00000-3

*DATABASE_MATSUM

1.00000-3

*CONTROL_CPU

0.0000000

*MAT_PIECEWISE_LINEAR_PLASTICITY

$12.70000-368900.0000 . \overline{3} 30000055.2000011060 .00000 .00000000 .0000000$

$0.00000000 .0000000 \quad 0 \quad 0$

0.00000000 .00000000 .00000000 .00000000 .00000000 .00000000 .00000000 .0000000

0.00000000 .00000000 .00000000 .00000000 .00000000 .00000000 .00000000 .0000000

*MAT_RIGID

2 2.11000-3 68000.000 0.1900000 0.0000000 0.00000000 .0000000

0.00000000 .00000000 .0000000

0.00000000 .00000000 .00000000 .00000000 .00000000 .00000000 .00000000 .0000000

*SECTION_SOLID

*SECTION_SOLID

20 


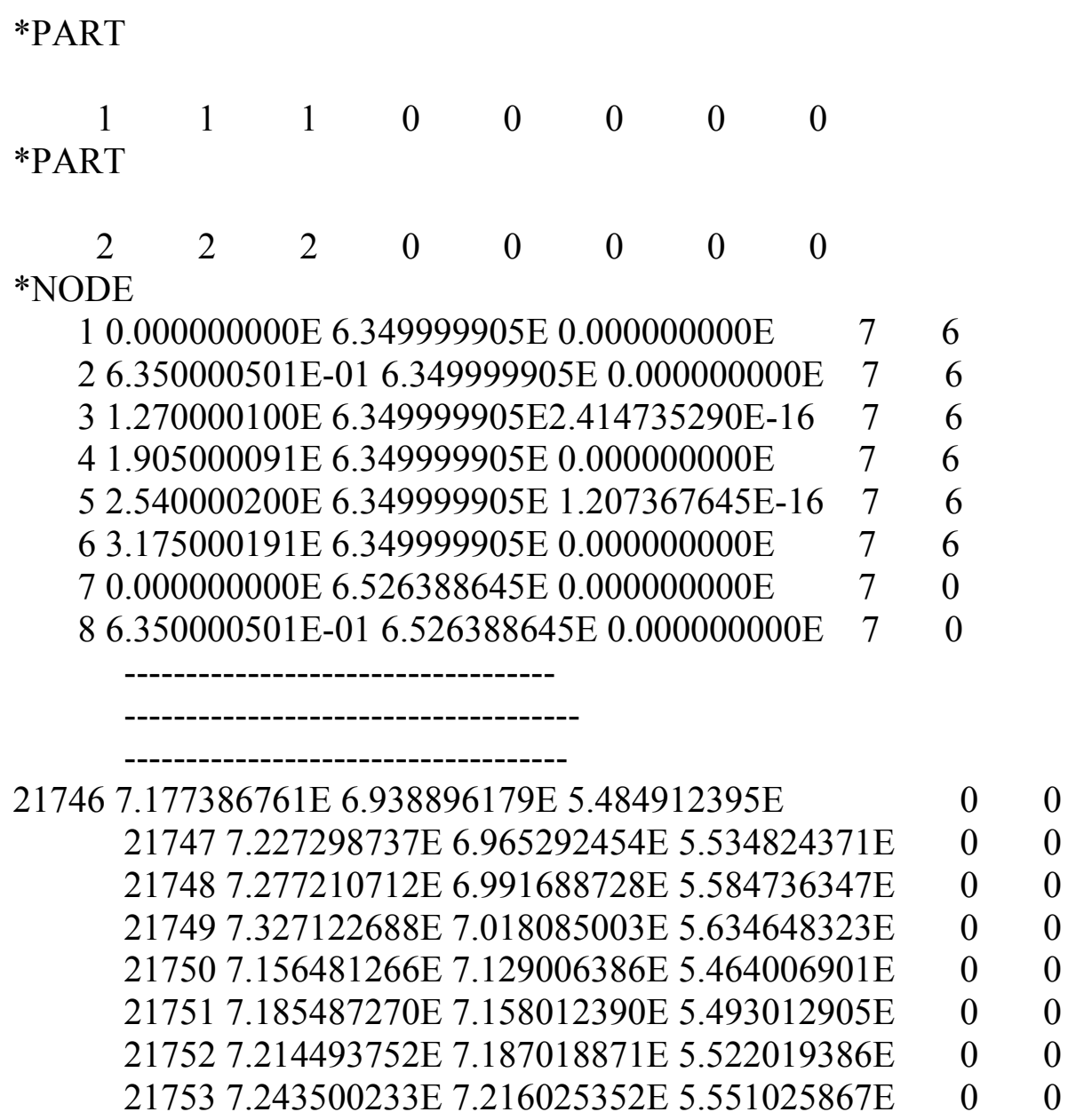

$\begin{array}{cccccccccc}\text { *ELEMENT_SOLID } \\ 1 & 1 & 1 & 2 & 8 & 7 & 115 & 116 & 122 & 121 \\ 2 & 1 & 2 & 3 & 9 & 8 & 116 & 117 & 123 & 122 \\ 3 & 1 & 3 & 4 & 10 & 9 & 117 & 118 & 124 & 123 \\ 4 & 1 & 4 & 5 & 11 & 10 & 118 & 119 & 125 & 124 \\ 5 & 1 & 5 & 6 & 12 & 11 & 119 & 120 & 126 & 125 \\ 6 & 1 & 7 & 8 & 14 & 13 & 121 & 122 & 128 & 127 \\ 7 & 1 & 8 & 9 & 15 & 14 & 122 & 123 & 129 & 128 \\ 8 & 1 & 9 & 10 & 16 & 15 & 123 & 124 & 130 & 129\end{array}$

$\begin{array}{llllllllll}19002 & 2 & 21720 & 21721 & 21725 & 21724 & 21740 & 21741 & 21745 & 21744\end{array}$ $\begin{array}{lllllllllll}19003 & 2 & 21321 & 21722 & 21726 & 21325 & 21341 & 21742 & 21746 & 21345\end{array}$ $\begin{array}{llllllllll}19004 & 2 & 21722 & 21723 & 21727 & 21726 & 21742 & 21743 & 21747 & 21746\end{array}$ $\begin{array}{llllllllll}19005 & 2 & 21723 & 21724 & 21728 & 21727 & 21743 & 21744 & 21748 & 21747\end{array}$ $\begin{array}{llllllllll}19006 & 2 & 21724 & 21725 & 21729 & 21728 & 21744 & 21745 & 21749 & 21748\end{array}$ $\begin{array}{llllllllll}19007 & 2 & 21325 & 21726 & 21730 & 21329 & 21345 & 21746 & 21750 & 21349\end{array}$ $\begin{array}{lllllllllll}19008 & 2 & 21726 & 21727 & 21731 & 21730 & 21746 & 21747 & 21751 & 21750\end{array}$ 
$\begin{array}{llllllllll}19009 & 2 & 21727 & 21728 & 21732 & 21731 & 21747 & 21748 & 21752 & 21751\end{array}$

$\begin{array}{llllllllll}19010 & 2 & 21728 & 21729 & 21733 & 21732 & 21748 & 21749 & 21753 & 21752\end{array}$

*INITIAL_VELOCITY_NODE

10.00000000 .00000000 .0000000

20.00000000 .00000000 .0000000

30.00000000 .00000000 .0000000

40.00000000 .00000000 .0000000

50.00000000 .00000000 .0000000

60.00000000 .00000000 .0000000

70.00000000 .00000000 .0000000

80.00000000 .00000000 .0000000

90.00000000 .00000000 .0000000

21744-75.175430 0.0000000-27.361547

21745-75.175430 0.0000000-27.361547

21746-75.175430 0.0000000-27.361547

21747-75.175430 0.0000000-27.361547

21748-75.175430 0.0000000-27.361547

21749-75.175430 0.0000000-27.361547

21750-75.175430 0.0000000-27.361547

21751-75.175430 0.0000000-27.361547

21752-75.175430 0.0000000-27.361547

21753-75.175430 0.0000000-27.361547

\$INTERFACE NAME: $1 \quad \$ \$$

*CONTACT_SURFACE_TO_SURFACE

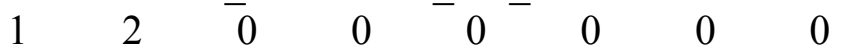

0.00000000 .00000000 .00000000 .00000000 .000000000 .00000000 .0000000

0.00000000 .00000000 .00000000 .00000000 .00000000 .0000000

*SET_SEGMENT

$\$$

\$ Slave segments, surface: 1

$\$$

$\begin{array}{cccc}1 & & & \\ 1944 & 1950 & 8425 & 8407 \\ 1950 & 1956 & 8443 & 8425 \\ 1956 & 1962 & 8461 & 8443 \\ 1962 & 1968 & 8479 & 8461 \\ 1968 & 1974 & 8497 & 8479 \\ 1974 & 1980 & 8515 & 8497 \\ 1980 & 1986 & 8533 & 8515 \\ 1986 & 1992 & 8551 & 8533\end{array}$




\begin{tabular}{|c|c|c|c|}
\hline 1992 & 1998 & 8569 & 8551 \\
\hline \multicolumn{4}{|c|}{--------------- } \\
\hline 16415 & 16433 & 16434 & 16416 \\
\hline 16433 & 16451 & 16452 & 16434 \\
\hline 16451 & 16469 & 16470 & 16452 \\
\hline 16469 & 16487 & 16488 & 16470 \\
\hline 16487 & 16505 & 16506 & 16488 \\
\hline 16505 & 16523 & 16524 & 16506 \\
\hline \multicolumn{4}{|c|}{ *SET_SEGMENT } \\
\hline \multicolumn{4}{|c|}{$\$$} \\
\hline \multicolumn{4}{|c|}{$\begin{array}{l}\text { \$ Master segments, surface: } \\
\$\end{array}$} \\
\hline \multicolumn{4}{|c|}{2} \\
\hline 20530 & 20535 & 20536 & 20531 \\
\hline 20535 & 20540 & 20541 & 20536 \\
\hline 20540 & 20545 & 20546 & 20541 \\
\hline 20545 & 20550 & 20551 & 20546 \\
\hline 20531 & 20536 & 20537 & 20532 \\
\hline 20536 & 20541 & 20542 & 20537 \\
\hline 20541 & 20546 & 20547 & 20542 \\
\hline 20546 & 20551 & 20552 & 20547 \\
\hline 20532 & 20537 & 20538 & 20533 \\
\hline \multicolumn{4}{|c|}{----------------- } \\
\hline 21587 & 21591 & 21592 & 21588 \\
\hline 21576 & 21580 & 21581 & 21577 \\
\hline 21580 & 21584 & 21585 & 21581 \\
\hline 21584 & 21588 & 21589 & 21585 \\
\hline 21588 & 21592 & 21593 & 21589 \\
\hline *END & & & \\
\hline
\end{tabular}




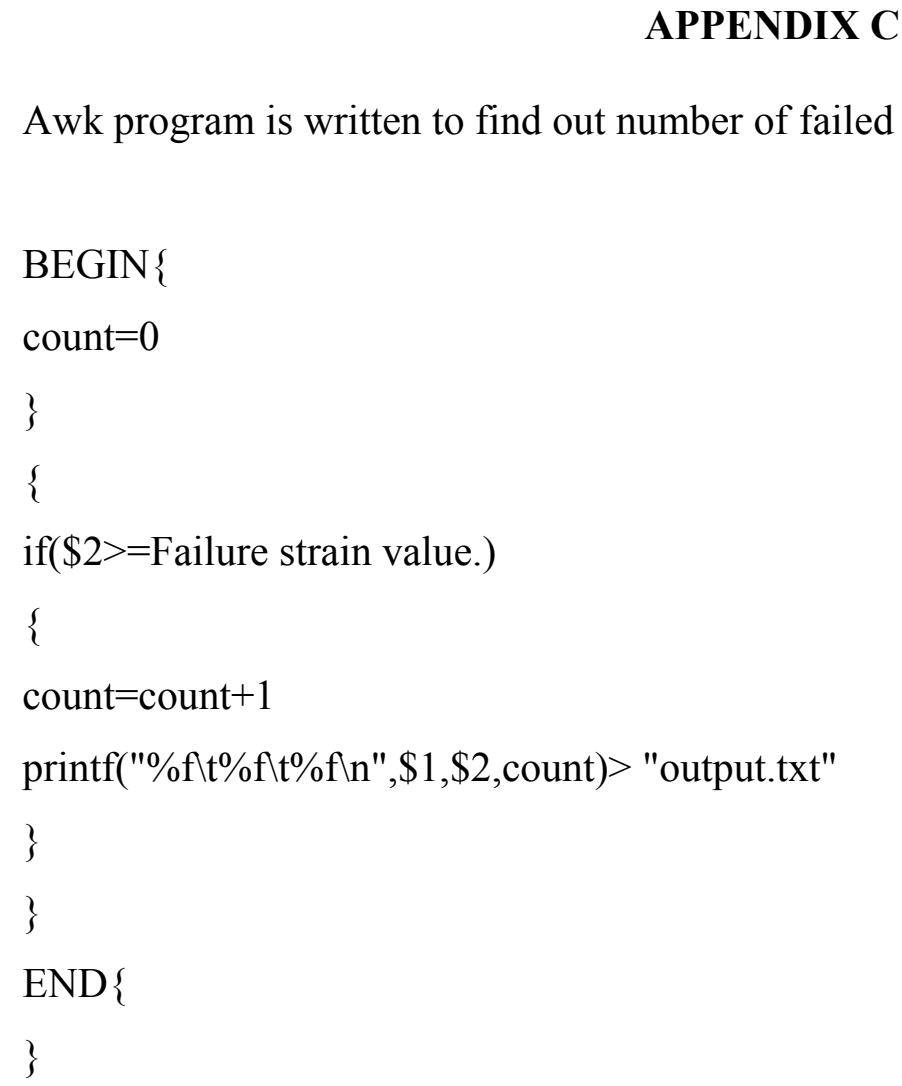




\section{APPENDIX D \\ THEORY IN LS-DYNA3D}

\section{D.1 INTRODUCTION}

LS-DYNA3D is a nonlinear explicit, 3-D finite element program for analyzing the transient dynamic response of three-dimensional solids and structures. It is used in many applications include crash worthiness analyses, elastic-plastic deformation, high-velocity impact, sheet metal forming, machining operations, transient thermal analysis, biomechanics, casting and forging, vehicle dynamics etc explicit time integration method is used in the solution The main method used for solution is based on explicit time integration.

Dyna3D has solids, shell, beam, and truss elements to allow maximum flexibility in modeling physical problems. Many material models are available to represent a wide range of material behavior, including elasticity, plasticity, composites, thermal effects, and rate dependence. It has a sophisticated contact interface capability that includes friction sliding and single surface contact.

\section{D.2 FEM PRILIMINARIES}

The governing equations of LS-DYNA are based on the principle of balance of linear momentum. The momentum equation is given by [26]

$$
\sigma_{i j, j}+\rho f_{i}=\rho x
$$

The above equation should satisfy the traction boundary conditions

$$
\sigma_{i j} n_{i}=t_{i}(t)
$$

on boundary $\partial b_{1}$, the displacement boundary conditions is given by

$$
x_{\mathrm{i}}(X \alpha, t)=D_{\mathrm{i}}(\mathrm{t})
$$

and on boundary $\partial b_{2}$, the contact discontinuity

$$
\left(\sigma_{i j}^{+}-\sigma_{i j}^{-}\right) n_{i}=0
$$


along and interior boundary $\partial \mathrm{b}_{3}$ when

$$
\mathrm{x}_{\mathrm{i}}^{+}=\mathrm{x}_{\mathrm{i}}^{-}
$$

Here $\sigma_{\mathrm{ij}}$ represents the couchy stress, $\rho$ is the density, $f$ is the body force density $\ddot{x}$ is the acceleration; comma denotes the covariant differentiation and $n_{j}$ is the unit vector normal to the boundary element of $\partial b$.

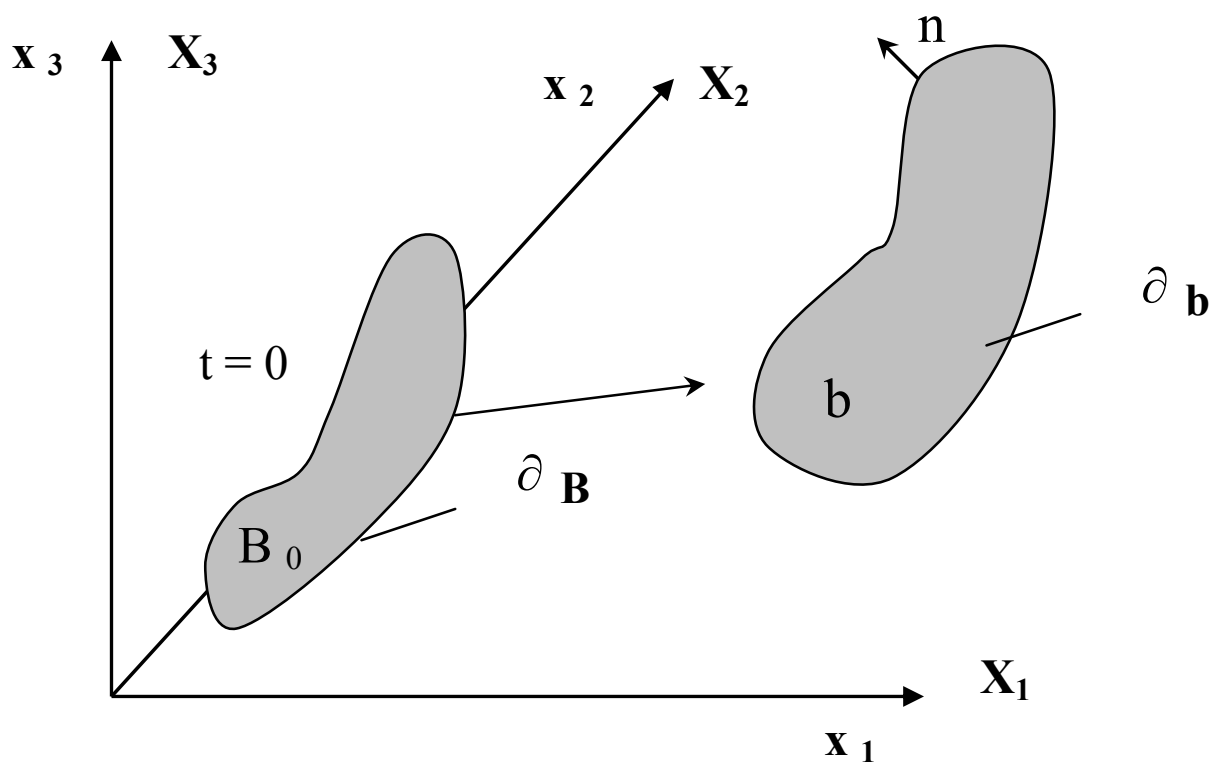

Equations of global energy balance and state evaluations can be obtained by integrating the energy equation in time. The energy equation is as follows

$$
\dot{E}=V_{s_{i j}} \dot{\varepsilon}_{i j}-(p+q) \dot{V}
$$

in equation D.2.5 $s_{i j}$ is the deviatoric stresses and $p$ is the pressure.

Deviatoric stress is given by

$$
s_{i j}=\sigma_{i j}+(p+q) \delta_{i j}
$$

Where $p=-\frac{1}{3} \sigma_{i j} \delta_{i j}-q, \mathrm{q}$ is the bulk viscosity and $\delta_{i j}$ is the Kronecker delta $\left(\delta_{i j}=1\right.$ if $\mathrm{i}=\mathrm{j}$; otherwise $\delta_{i j}=0$ ) and $\varepsilon_{i j}$ is the strain rate tensor. 
When $\delta x_{\text {i }}$ satisfies all boundary conditions on $\delta b_{2}$ the weak form of the equilibrium is given by

$$
\int_{v}\left(\rho \ddot{x}_{i}-\sigma_{i j, j}-\rho f\right) \delta x_{i} d v+\int_{\partial b_{2}}\left(\sigma_{i j} n_{j}-t_{i}\right) \delta x_{i} d s+\int_{\partial b_{3}}\left(\sigma_{i j}^{+}-\sigma_{i j}^{-}\right) n_{j} \delta x_{i} d s=0
$$

Applying the divergence theorem which relates the surface and volume integrals,

$$
\int_{v}\left(\sigma_{i j} \delta x_{i}\right),{ }_{j} d v=\int_{\partial b_{1}} \sigma_{i j} n_{j} \delta x_{i} d s+\int_{\partial b_{3}}\left(\sigma_{i j}^{+}-\sigma_{i j}^{-}\right) n_{j} \delta x_{i} d s
$$

Where

$$
\left(\sigma_{i j} \delta x_{i}\right),{ }_{j} \sigma_{i j, j} \delta x_{i}=\sigma_{i j} \delta x_{i, j}
$$

and a comma denotes a covariant differentiation. Substituting equation D.2.8 back into equation D.2.7 gives a statement of principle of virtual work as follows

$$
\delta \pi=\int_{v} \rho \ddot{x}_{i} \delta x_{i} d v+\int_{v} \sigma_{i j} \delta_{i, j} d v-\int_{v} \rho f_{i} \delta x_{i} d v-\int_{\partial b_{1}} t_{i} \delta x_{i} d s=0
$$

The superimposed mesh of finite elements interconnected at nodal points on a reference configuration and track particles through time is given by

$$
x_{i}\left(X_{\alpha}, t\right)=x_{i}\left(X_{\alpha}(\xi, \eta, \zeta), t\right)=\sum_{j}^{k} \phi_{j}(\xi, \eta, \zeta) x_{i}^{j}(t)
$$

Where $\phi_{j}$ are shape or interpolation functions of the parametric coordinates, $(\xi, \eta, \zeta), \mathrm{k}$ is the number of nodal points defining the element, and $x_{i}^{j}$ is the nodal coordinate of the $\mathrm{j}^{\text {th }}$ node in the $\mathrm{i}^{\text {th }}$ direction.

Summing this function over the n elements yields

$$
\delta \pi=\sum_{m=1}^{n} \delta \pi_{m}=0
$$

From equation (D.2.9), the summation for $n$ elements as in the model is given as

$$
\sum_{m=1}^{n}\left\{\int_{v_{m}} \rho \ddot{x}_{i} \Phi_{i}^{m} d v+\int_{v_{m}} \sigma_{i j}^{m} \Phi_{i, j}^{m} d v-\int_{v_{m}} \rho f_{i} \Phi_{i}^{m} d v-\int_{\partial b_{1}} t_{i} \Phi_{i}^{m} d s\right\}=0
$$

Where

$$
\Phi_{i}^{m}=\left(\phi_{1}, \phi_{2}, \phi_{3}, \ldots \ldots \ldots \phi_{k}\right)_{i}^{m}
$$




\section{D.3 SOLID ELEMENTS}

In the present work a mesh of 8-node hexahedron solid element is used. For a mesh of 8-node hexahedron solid elements, Equation D.2.10 becomes

$$
x_{i}\left(X_{\alpha}, t\right)=x_{i}\left(X_{\alpha}(\xi, \eta, \zeta), t\right)=\sum_{j=1}^{8} \phi_{j}(\xi, \eta, \zeta) x_{i}^{j}(t)
$$

The shape function $\phi_{j}$ is defined for the 8-node hexahedron as

$$
\phi_{j}=\frac{1}{8}\left(1+\xi \xi_{j}\right)\left(1+\eta \eta_{j}\right)\left(1+\zeta \zeta_{j}\right)
$$

Where, $\xi_{j}, \eta_{j}$, and $\zeta_{j}$ take the nodal values of $( \pm 1, \pm 1, \pm 1)$ and $\mathrm{x}_{\mathrm{i}}^{\mathrm{j}}$ is the nodal coordinate of the $\mathrm{j}^{\text {th }}$ node in the $\mathrm{i}^{\text {th }}$ direction as shown in figure D.1

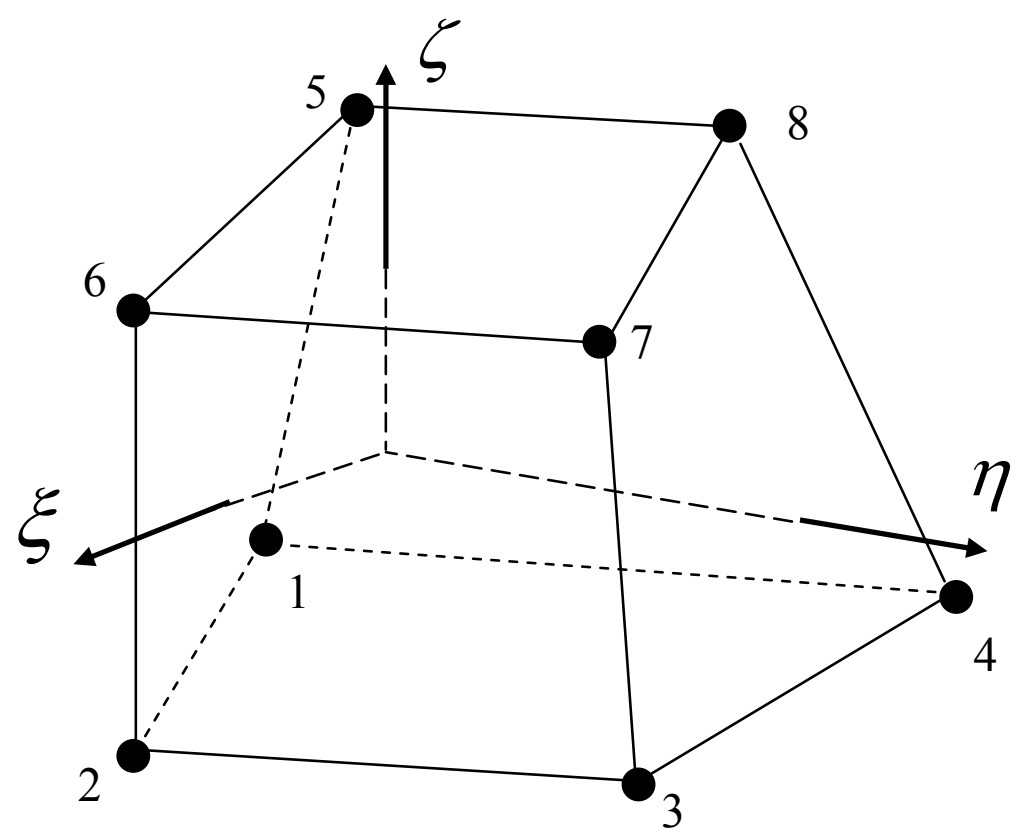

Figure D.1 Eight-node solid hexahedron element

Here the node definition for the eight-node hexahedron element and corresponding values of $\xi, \eta, \zeta$ are as follows 


$\begin{array}{lrrr}\text { Node } & \xi & \eta & \zeta \\ 1 & -1 & -1 & -1 \\ 2 & 1 & -1 & -1 \\ 3 & 1 & 1 & -1 \\ 4 & -1 & 1 & -1 \\ 5 & -1 & -1 & 1 \\ 6 & 1 & -1 & 1 \\ 7 & 1 & 1 & 1 \\ 8 & -1 & 1 & 1\end{array}$

For an 8-node hexahedron solid element B is the $6 \times 24$ strain-displacement matrix and $\mathrm{N}$ is the $3 \times 24$ rectangular interpolation matrix, given by

$$
\mathrm{B}=\left[\begin{array}{ccc}
\frac{\partial}{\partial x} & 0 & 0 \\
0 & \frac{\partial}{\partial y} & 0 \\
0 & 0 & \frac{\partial}{\partial z} \\
\frac{\partial}{\partial y} & \frac{\partial}{\partial x} & 0 \\
0 & \frac{\partial}{\partial z} & \frac{\partial}{\partial y} \\
\frac{\partial}{\partial z} & 0 & \frac{\partial}{\partial x}
\end{array}\right] \mathrm{N} \quad N(\xi, \eta, \zeta)=\left[\begin{array}{cccccccc}
\phi_{1} & 0 & 0 & \phi_{2} & 0 & \ldots \ldots . & 0 & 0 \\
0 & \phi_{1} & 0 & 0 & \phi_{2} & \ldots \ldots & \phi_{8} & 0 \\
0 & 0 & \phi_{1} & 0 & 0 & \ldots \ldots & 0 & \phi_{8}
\end{array}\right]
$$

By summing the rows, we can get a diagonal mass matrix and $k^{\text {th }}$ diagonal term given as

$$
m_{k k}=\int_{v} \rho \phi_{k} \sum_{i=1}^{8} \phi_{i} d v=\int_{v} \rho \phi_{k} d v
$$

Terms in the strain-displacement matrix are calculated as follows 


$$
\begin{aligned}
& \frac{\partial \phi_{i}}{\partial \xi}=\frac{\partial \phi_{i}}{\partial x} \frac{\partial x}{\partial \xi}+\frac{\partial \phi_{i}}{\partial y} \frac{\partial y}{\partial \xi}+\frac{\partial \phi_{i}}{\partial z} \frac{\partial z}{\partial \xi} \\
& \frac{\partial \phi_{i}}{\partial \eta}=\frac{\partial \phi_{i}}{\partial x} \frac{\partial x}{\partial \eta}+\frac{\partial \phi_{i}}{\partial y} \frac{\partial y}{\partial \eta}+\frac{\partial \phi_{i}}{\partial z} \frac{\partial z}{\partial \eta} \\
& \frac{\partial \phi_{i}}{\partial \zeta}=\frac{\partial \phi_{i}}{\partial x} \frac{\partial x}{\partial \zeta}+\frac{\partial \phi_{i}}{\partial y} \frac{\partial y}{\partial \zeta}+\frac{\partial \phi_{i}}{\partial z} \frac{\partial z}{\partial \zeta}
\end{aligned}
$$

Which can be rewritten as

$$
\left[\begin{array}{l}
\frac{\partial \phi_{i}}{\partial \xi} \\
\frac{\partial \phi_{i}}{\partial \eta} \\
\frac{\partial \phi_{i}}{\partial \zeta}
\end{array}\right]=\left[\begin{array}{lll}
\frac{\partial x}{\partial \xi} & \frac{\partial y}{\partial \xi} & \frac{\partial z}{\partial \xi} \\
\frac{\partial x}{\partial \eta} & \frac{\partial y}{\partial \eta} & \frac{\partial z}{\partial \eta} \\
\frac{\partial x}{\partial \zeta} & \frac{\partial y}{\partial \zeta} & \frac{\partial z}{\partial \zeta}
\end{array}\right]\left[\begin{array}{l}
\frac{\partial \phi_{i}}{\partial x} \\
\frac{\partial \phi_{i}}{\partial y} \\
\frac{\partial \phi_{i}}{\partial z}
\end{array}\right]=J\left[\begin{array}{c}
\frac{\partial \phi_{i}}{\partial x} \\
\frac{\partial \phi_{i}}{\partial y} \\
\frac{\partial \phi_{i}}{\partial z}
\end{array}\right]
$$

The desired terms can be obtained by inverting Jacobian Matrix $J$ as given by

$$
\left[\begin{array}{l}
\frac{\partial \phi_{i}}{\partial x} \\
\frac{\partial \phi_{i}}{\partial y} \\
\frac{\partial \phi_{i}}{\partial z}
\end{array}\right]=\mathrm{J}^{-1}\left[\begin{array}{l}
\frac{\partial \phi_{i}}{\partial \xi} \\
\frac{\partial \phi_{i}}{\partial \eta} \\
\frac{\partial \phi_{i}}{\partial \zeta}
\end{array}\right]
$$

\section{D.4 VOLUME INTEGRATION}

Gaussian quadrature is used to carry out the volume integration. If some function $\mathrm{g}$ is defined over the volume with $\mathrm{n}$ number of integration points then

$$
\int_{v} g d v=\int_{-1}^{1} \int_{-1}^{1} \int_{-1}^{1} g|J| d \xi d \eta d \zeta
$$

The above equation (D.4.1) is approximated by

$$
\sum_{j=1}^{n} \sum_{k=1}^{n} \sum_{l=1}^{n} g_{j k l}\left|J_{j k l}\right| w_{j} w_{k} w_{l}
$$


Where $\mathrm{w}_{\mathrm{j}}, \mathrm{w}_{\mathrm{k}}, \mathrm{w}_{\mathrm{l}}$ are the weighing factors, $g_{j k l}=g\left(\xi_{j}, \eta_{k}, \zeta_{l}\right)$ and $|J|$ is the determinant of the jacobian matrix. For one point quadrature $\mathrm{n}=1, \mathrm{w}_{\mathrm{j}}=\mathrm{w}_{\mathrm{k}}=\mathrm{w}_{1}=2$ and $\xi_{1}=\eta_{1}=\zeta_{1}=0$ from which we can write

$$
\int g d v=8 g(0,0,0)|J(0,0,0)|
$$

Here $8|J(0,0,0)|$ approximates the element volume.

The biggest advantage of single point integration is the substantial savings in CPU time. The time spent in determining constitutive relations is reduced by a factor of 8. A disadvantage of 8-point integration is that when it is used in the solution of plasticity problems and other problems where Poisson's ratio approaches 0.5 and these elements tend to lock up in the constant volume bending modes. To avoid locking an average pressure must be used over the elements and hence the zero energy modes are resisted by the deviatoric stresses.

\section{D.5 HOUR GLASS CONTROL}

The biggest disadvantage of single point integration is the need to control the zero energy modes or hourglassing modes. These undesirable hourglass modes arise when they have periods that are much shorter than the periods of the structural response and they are often observed to be oscillatory. The best way of stopping this mode is by giving viscous damping or a small elastic stiffness capable of stopping these modes. The work done by hourglass resistance is neglected because the hourglass modes are orthogonal to the real deformation. LS-DYNA3D provides three types of hourglassing. When compared to Flanagan-Belytschko and Wilkins FDM hourglassing, standard DYNA3D takes the least amount of time and is shown in the following table D.1. It shows the comparison among the different methods for the operation count for constant stress hexahedron, which includes additions, subtractions, multiplications and divisions in major subroutines and is independent of vectorization. 


\begin{tabular}{lccc}
\hline & $\begin{array}{c}\text { STANDARD } \\
\text { DYNA3D }\end{array}$ & $\begin{array}{c}\text { Flanagan- } \\
\text { Belytschko }\end{array}$ & $\begin{array}{c}\text { Wilkins } \\
\text { FDM }\end{array}$ \\
\hline Strain displacement matrix & 94 & 357 & 843 \\
Strain rates & 87 & 156 & --- \\
Force & 117 & 195 & 270 \\
Subtotal & 298 & 708 & 1,113 \\
Hourglass control & 130 & 620 & 680 \\
Total & 428 & 1,328 & 1,793 \\
& & & \\
\hline
\end{tabular}

Table D.1 Operation count for hourglass types.

\section{D.6 TIME STEP CONTROL}

The new time step size is determined by taking the minimum value over all elements given by

$$
\Delta t^{n+1}=a \cdot \min \left\{\Delta t_{1}, \Delta t_{2}, \ldots \ldots \ldots, \Delta t_{N}\right\}
$$

Where $\mathrm{n}$ is the number of elements. For stability reasons the scale factor $\alpha$ is set to a value of 0.9 by default or some smaller value.

For a solid element a critical time step size $\Delta t_{e}$ is computed as follows

$$
\Delta t_{e}=\frac{L_{e}}{\left\{\left[Q+\left(Q^{2}+c^{2}\right)^{1 / 2}\right]\right\}}
$$

Where $\quad L_{e}=\frac{v_{e}}{A_{e \max }}$ for 8 node solid element

$v_{e}$ is the element volume

$A_{\text {emax }}$ is the area of the largest side

$\mathrm{Q}$ is a function of the bulk viscosity coefficients $\mathrm{C}_{0}$ and $\mathrm{C}_{1}$ given by

$$
Q=C_{1} c+C_{0} L_{e}\left|\dot{\varepsilon}_{k k}\right| \quad \text { for } \dot{\varepsilon}_{k k}<0
$$




$$
\mathrm{Q}=0 \quad \text { for } \dot{\varepsilon}_{k k} \geq 0
$$

And $\mathrm{c}$ is the adiabatic sound speed given by

$$
c=\left[\frac{4 G}{3 \rho_{0}}+\frac{\partial p}{\partial \rho}\right]^{1 / 2}
$$

and $\rho$ is the specific mass density.

For an isentrope the incremental energy $E$ is the product of pressure, $p$, and the incremental relative volume, $\mathrm{dV}$, given in pressure units

$$
\mathrm{dE}=-\mathrm{pDV}
$$

and

$$
\left.\left.\left.\left.\frac{\partial p}{\partial \rho}\right)_{s}=\frac{\partial p}{\partial \rho}\right)_{E}+\frac{\partial p}{\partial E}\right)_{\rho} \frac{\partial E}{\partial \rho}\right)_{s}
$$

For an isentropic sound speed is given by

$$
\left.\left.c=\left[\frac{4 G}{3 \rho_{0}}+\frac{\partial p}{\partial \rho}\right)_{E}+\frac{p V^{2}}{\rho_{0}} \frac{\partial p}{\partial E}\right)_{\rho}\right]^{1 / 2}
$$

for elastic materials with a constant bulk modulus the sound speed is given by

$$
c=\sqrt{\frac{E(1-v)}{(1+v)(1-2 v) \rho}}
$$

Where $E$ is Young's modulus and $v$ is Poisson's ratio

\section{D.7 TIME INTEGRATION}

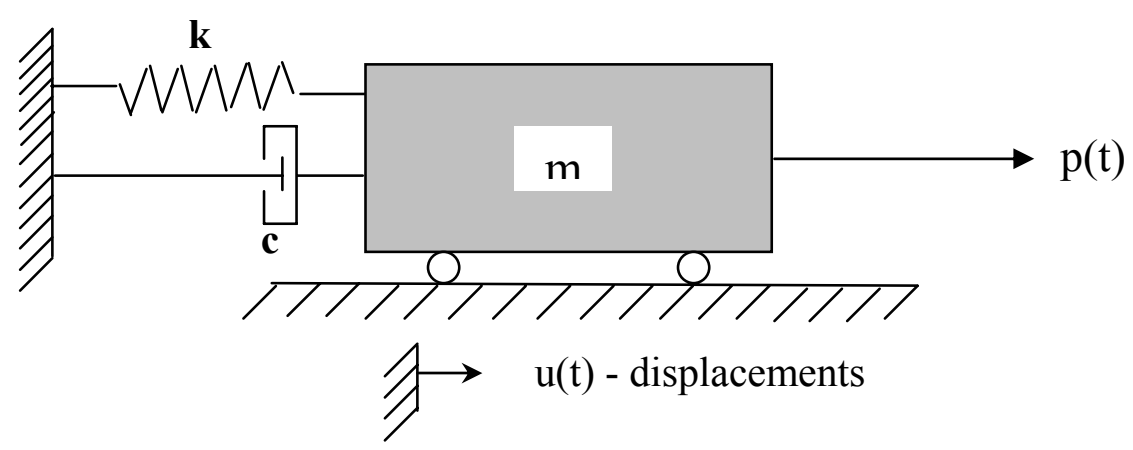

Figure D.2 single degree of freedom damped system 
Forces acting on mass $\mathbf{m}$ are shown below

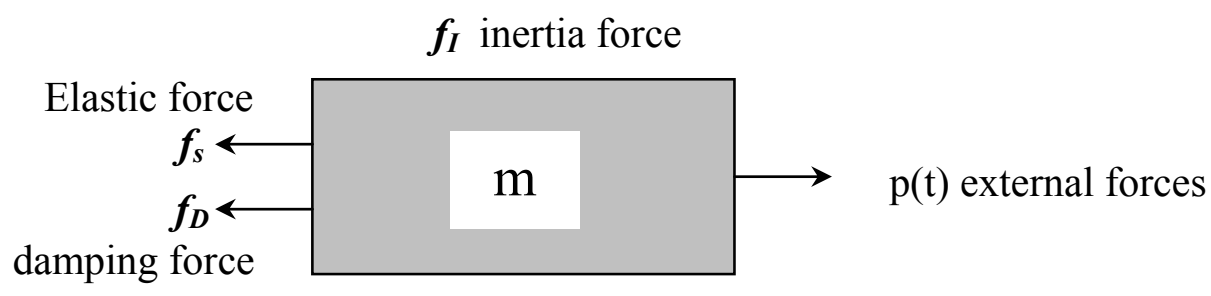

Figure D.3 Forces acting on mass $m$

For the above system the equilibrium equations are obtained from d'Alembert's principle

$$
\begin{aligned}
& f_{I}+f_{D}+f_{\text {int }}=p(t) \\
& f_{I}=m \ddot{u} ; \quad \text { Acceleration } \ddot{u}=\frac{d^{2} u}{d t^{2}} \\
& f_{D}=c \dot{u} \quad ; \quad \text { Velocity } \dot{u}=\frac{d u}{d t} \text { and } \mathrm{c} \text { is the damping coefficient } \\
& f_{\text {int }}=k . u ; \quad \text { Displacement } u \text { and } \mathrm{k} \text { is the linear coefficient }
\end{aligned}
$$

For linear behavior the equations of motion lead to a linear ordinary differential equation given by $m \ddot{u}+c \dot{u}+k u=p(t)$ and for nonlinear case the inertial force varies as a nonlinear function of the displacement leading to a nonlinear ordinary differential equation given by $m \ddot{u}+c \dot{u}+f_{\text {int }}(u)=p(t)$

Here we consider the dynamic response of linear system subjected to a harmonic loading

$$
p(t)=p_{0} \sin \varpi t
$$

The closed form solution with initial conditions $u_{0}=$ initial displacement, $\dot{u}_{0}=$ initial velocity and $\frac{p_{0}}{k}=$ static displacement is given by

$$
u(t)=\underbrace{u_{0} \cos +\frac{u_{0}}{\omega} \sin \omega t}_{\text {homogeneous solution }}+\underbrace{\frac{p_{0}}{k} \frac{1}{1-\beta^{2}}(\sin \bar{\omega} t-\beta \sin \omega t)}_{\text {particular solution }}
$$

only numerical solutions are possible for nonlinear problems. LS-DYNA uses the explicit central difference method to integrate the equations of motion. 
The semi-discrete equations of motion at time $\mathrm{n}$ are:

$$
\mathrm{Ma}^{\mathrm{n}}=\mathrm{P}^{\mathrm{n}}-\mathrm{F}^{\mathrm{n}}+\mathrm{H}^{\mathrm{n}}
$$

Where $\mathrm{M}$ is the diagonal mass matrix, $\mathrm{P}^{\mathrm{n}}$ is the external and body force loads, $\mathrm{F}^{\mathrm{n}}$ is the stress divergence vector, and $\mathrm{H}^{\mathrm{n}}$ is the hourglass resistance. We use central difference time integration to advance to time $\mathrm{t}^{\mathrm{n}+1}$ as follows

$$
\begin{gathered}
\mathrm{a}^{\mathrm{n}}=\mathrm{M}^{-1}\left(\mathrm{P}^{\mathrm{n}}-\mathrm{F}^{\mathrm{n}}+\mathrm{H}^{\mathrm{n}}\right) \\
v^{n+1 / 2}=v^{n-1 / 2}+a^{n} \Delta t^{n} \\
u^{n+1}=u^{n}+v^{n+1 / 2} \Delta t^{n+1 / 2}
\end{gathered}
$$

Where

$$
\Delta t^{n+1 / 2}=\frac{\left(\Delta t^{n}+\Delta t^{n+1}\right)}{2}
$$

and $\mathbf{v}$ and $\mathbf{u}$ are the global nodal velocity and displacement vectors respectively. Initial geometry can be updated by adding the displacement increments

$$
\mathrm{x}^{\mathrm{n}+1}=\mathrm{x}^{0}+\mathrm{u}^{\mathrm{n}+1}
$$

\section{D.8 CONTACT IMPACT ALGORITHM}

LS-DYNA has a powerful capability of handling the sliding and impact along the interfaces. It has three algorithms for contact defined as the kinematic constraint method, the penalty method, and the distributed method. The kinematic constraint method is used only for tying interfaces. In this method constraints are imposed on the global equations by a transformation of the nodal displacement components of the slave nodes along the contact interface. In order to maintain the efficiency of the explicit time integration, only the global degrees of freedom of each master node are coupled. But in this method problems arise when the master surface zone is finer than the slave surface zone. Consistent zoning of the interfaces will minimize such problems.

The penalty method is used in the explicit programs DYNA2D and DYNA3D as well as in the implicit programs NIKE2D and NIKE3D. In this method artificial interface springs are placed normal to all slave and master surfaces and spring stiffness matrix is calculated and assembled into the global stiffness matrix. A unique modulus is computed for the 
element in which it resides. This method seems to be little excited for hourglassing and noise. However for relatively large interface pressures the stiffnesses have to be scaled up and the time step reduced. For such cases the third method "distributed parameter method is more appropriate. This method has a specialization option i.e. sliding only which is used in DYNA3D. In this method the internal stress in each element in contact determines the pressure distribution for the corresponding master surface area. Accelerations are updated after mass and pressure distributions on the master surface are completed. 